\title{
AVALIAÇÃO DO ESTOQUE E COMPOSIÇÃO ISOTÓPICA DO CARBONO DO SOLO NO ACRE
}

\author{
ANTONIO WILLIAN FLORES DE MELO
}

Dissertação apresentada à Escola Superior de Agricultura "Luiz de Queiroz", Universidade de São Paulo, para obtenção do título de Mestre em Ecologia de Agroecossistemas.

PIRACICABA

Estado de São Paulo - Brasil

Novembro - 2003 


\title{
AVALIAÇÃO DO ESTOQUE E COMPOSIÇÃO ISOTÓPICA DO CARBONO DO SOLO NO ACRE
}

\author{
ANTONIO WILLIAN FLORES DE MELO
}

Engenheiro Agrônomo

Orientador: Dr. PLÍNIO BARBOSA DE CAMARGO

Dissertação apresentada à Escola Superior de Agricultura "Luiz de Queiroz", Universidade de São Paulo, para obtenção do título de Mestre em Ecologia de Agroecossistemas.

PIRACICABA

Estado de São Paulo - Brasil

Novembro - 2003 
Dados Internacionais de Catalogação na Publicação (CIP) DIVISÃO DE BIBLIOTECA E DOCUMENTAÇÃO - ESALQ/ USP

Melo, Antonio Willian Flores de

Avaliação do estoque e composição isotópica do carbono do solo no Acre / Antonio Willian Flores de Melo / Piracicaba, 2003

73 p. : il.

Dissertação (mestrado) - - Escola Superior de Agricultura Luiz de Queiroz, 2003.

Bibliografia.

1. Carbono 2. Cobertura do solo 3. Composição isotópica 4. Florestas (Acre)

5. Matéria orgânica do solo 6. Pastagens I. Título

CDD 631.41

"Permitida a cópia total ou parcial deste documento, desde que citada a fonte - $\mathrm{O}$ autor" 


\begin{abstract}
A meus pais Irani e José pela educação e as lições de simplicidade e dedicação que me acompanham e acompanharam por toda minha vida

Dedico
\end{abstract}

A minha esposa Márcia e meu filho Lucas, pela compreensão e força sem as quais este trabalho não seria possível

Ofereço 


\section{AGRADECIMENTOS}

Seria impossível citar, aqui, os nomes de todas as pessoas que me ajudaram a trilhar o caminho que tornou possível este trabalho. Mas devo agradecer a:

- Meus pais, meus orientadores da academia da vida;

- Plínio Camargo, pela amizade, orientação e apoio;

- Reynaldo Victoria, Luiz Martinelli e Marcelo Moreira, por terem me acolhido no grupo e aberto as portas do Laboratório de Ecologia Isotópica;

- Centro de Energia Nuclear na Agricultura - CENA e Escola Superior de Agricultura "Luiz de Queiroz", pela estrutura Educacional;

- Programa de Pós-Graduação Interunidades em Ecologia de Agroecossistemas, pela formação científica e Educacional;

- Projeto LBA, pelo apoio financeiro;

- Coordenação de Aperfeiçoamento de Pessoal de Nível Superior CAPES, pela bolsa de estudo;

- Fundação de Estudo Agrários Luiz de Queiroz, pelo apoio financeiro;

- Laboratório de Fertilidade do Solo da Universidade Federal do Acre, na pessoa do Prof. Manuel Ribeiro, por disponibilizar a estrutura laboratorial e ajuda com as amostras de solos; 
- Parque Zoobotânico da Universidade Federal do Acre, por todo apoio disponibilizado;

- Foster Brown, pelo incentivo, orientação, amizade e por me mostrar os caminhos da ciência, muitas vezes não muito claros;

- Eric Davidson e Susan Trumbore, pelas dicas e orientações;

- Judson Valentim da Embrapa Acre, pela orientação e colaboração;

- Cleber Salimon, pela amizade, orientação e os comentários sempre muito construtivos;

- Maria Victoria Ballester e Daniel Victoria, pelas dicas e ajuda com o ArcGIS;

- Eufran Amaral, pela ajuda com o banco de dados de solos;

- Amigo(a)s de RUCAS, Lais, Nei, Jose Mauro, Cleber, Marisol, Vânia, Rafael, Daniel, Adriana, Catia, Michele e Rafaela, pelo companheirismo;

- Todo(a)s os amigo(a)s, de A a Z, do Laboratório de Ecologia Isotópica, pela convivência, churrascos e festinhas;

- Amada Calil Rodrigues de Moraes, pela fundamental ajuda com o preparo das amostras de solo;

- Tonica, pela grande ajuda com as analises de carbono;

- Sergio Barros e Evandro Figueiredo, por disponibilizarem suas propriedades para realização deste trabalho;

- Márcia e Lucas, sem vocês este trabalho não seria possível. 


\section{SUMÁRIO}

Página

LISTA DE FIGURAS .................................................................................... Viii

LISTA DE TABELAS ...............................................................................

RESUMO ...........................................................................................

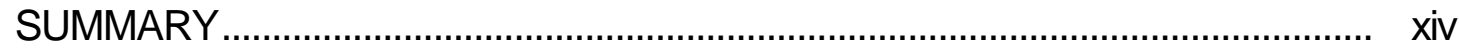

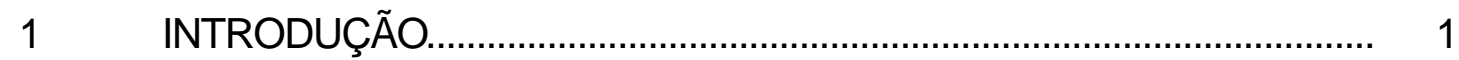

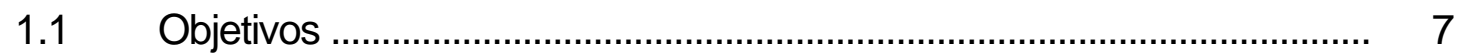

1.2 Ações específicas ................................................................................ 7

2 MATERIAL E MÉTODOS …......................................................... 9

$2.1 \quad$ Área de estudo ....................................................................... 9

2.2 Estimativa do estoque de carbono dos principais solos do estado do Acre ....................................................................................... 12

2.2.1 Mapa de solos................................................................................... 14

2.2.2 Cálculo do estoque de carbono ........................................................... 17

2.2.3 Mapa de carbono do solo ............................................................... 18

2.3 Estoque e composição isotópica do carbono do solo sob pastagem e floresta primária ............................................................................... 19

2.3.1 Amostragem........................................................................... 19

2.3.2 Análises físico-químicas do solo........................................................... 23

2.3.3 Determinação do C, ${ }^{13} \mathrm{C}$.................................................................... 24

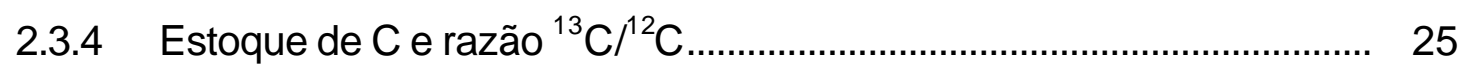

2.3.5 Estimativa das fontes do carbono do solo ............................................ 25 
2.3.6 Analise dos dados e incertezas ............................................................ 26

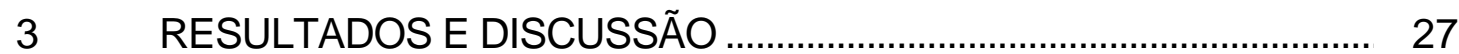

3.1 Estimativa do estoque de carbono dos principais solos do estado do Acre ............................................................................................ 27

3.1.1 Estoque total de carbono dos solos do Acre........................................ 31

3.1.2 Fontes de incertezas das estimativas ................................................... 33

3.2 Estoque e composição isotópica do carbono do solo sob pastagem e floresta primária .................................................................................. 34

3.2.1 Características físicas dos solos ...................................................... 36

3.2.1.1 Composição granulométrica .................................................................. 36

3.2.1.2 Densidade aparente ......................................................................... 39

3.2.2 Características químicas dos solos....................................................... 41

3.2.3 Concentração, estoque, $\delta^{13} \mathrm{C}$ e fontes do carbono do solo................... 45

3.2.3.1 Concentração e estoque de carbono ...................................................... 45

3.2.3.2 Composição isotópica e fontes do carbono do solo .............................. 51

3.2.4 Implicações dos resultados para pecuária do Acre ............................. 57

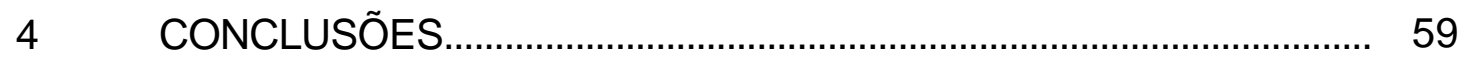

REFERÊNCIAS BIBLIOGRÁFICAS .......................................................... 61 


\section{LISTA DE FIGURAS}

Página

1 Mapa de relevo do Estado do Acre. Fonte: Adaptado de NASA/SRTM/USGS

2 Vista de duas pastagens amostradas.

3 Localização de 182 perfis de solo que foram utilizados para estimar o estoque de carbono dos solos do Estado do Acre.

4 Mapa de solos simplificado do Estado do Acre. Adaptado de Acre (2000), Brasil (1976b, 1977b)...

5 (a) Perfil de Argissolo. (b) Perfil de Luvissolo.

6 Localização geográfica das áreas de estudo. A imagem de satélite Landsat TM 71998 utilizada na figura, faz parte do mosaico do Estado do Acre cedido por Augusto Rocha.

7 Abertura das trincheiras utilizadas para coleta das amostras de solo....

8 Diagrama experimental

9 Processo de coleta de amostra para determinação da densidade aparente do solo.

10 Distribuição relativa dos 6 principais grupos de solos com base no mapa de solos do Estado Acre na escala 1:1.000.000 (Acre, 2000; Brasil, 1976b, 1977b). Para mais detalhes sobre as sub-classes que integram os grupos de solo apresentados nesta Figura ver Tabela 1....

11 Mapa de estoque de carbono dos solos do Estado do Acre (Mg C ha ${ }^{-1}$ para 0-100 cm) 
12 Composição granulométrica dos solos das áreas de estudo. Percentagem de areia, silte e argila nas profundidades de $0-5 \mathrm{~cm}$ gráfico (a), 20-30 cm gráfico (b), 50-60 cm gráfico (c) e 90-100 cm gráfico (d). O gráfico (e) mostra a divisão dos grupos texturais segundo EMBRAPA (1999). Detalhes sobre as áreas de estudo ver Tabela 2.

13 Valores médios e desvios padrões da densidade do solo $\left(\mathrm{g} \mathrm{m}^{-3}\right)$

14 Saturação de bases (a), concentrações de cálcio (b) e concentrações de alumínio mais hidrogênio (c). Os pontos são médias de duas amostras e as barras de erros representam o desvio padrão, com exceção do gráfico (a) onde o erro foi obtido por meio de um cálculo de propagação de erro [eq. (10) e (11)]

15 Valores médios e desvios padrões de concentração de carbono (\%) no solo. Gráfico (a) concentrações de C ate $100 \mathrm{~cm}$. Gráfico (b) concentração de $\mathrm{C}$ ate $40 \mathrm{~cm}$

16 Valores médios e desvios padrões de estoque $\left(\mathrm{kg} \mathrm{m}^{-2}\right)$ de carbono do solo. Gráfico (a) concentrações de C ate $100 \mathrm{~cm}$. Gráfico (b) concentração de $\mathrm{C}$ ate $40 \mathrm{~cm}$.

17 Estoque carbono ( $\mathrm{Mg} \mathrm{ha}^{-1}$ ) nos primeiros $100 \mathrm{~cm}$ de solo das áreas de estudo. Gráficos (a) áreas sobre Argissolo e gráfico (b) áreas sobre Luvissolo.

18 Variação do $\delta^{13} \mathrm{C}(\% \circ)$ do solo com a profundidade nas áreas de estudo. Os valores são médias de seis repetições e as barras de erro indicam o desvio padrão. 
19 Percentagem de $\mathrm{C}$ derivado da pastagem obtido por meio do calculo de diluição isotópica. Valores são médias e o erro foi obtido por meio de cálculo de propagação de erros, conforme descrito no item materiais e métodos...

20 Estoque de carbono $\left(\mathrm{Mg} \mathrm{ha}^{-1}\right)$ correspondente a $\mathrm{C}_{\mathrm{f}}$ (carbono derivado da floresta) e $C_{p}$ (carbono derivado da pastagem) no perfil do solo. $O$ gráfico (a) refere-se a dados da área P20A e o gráfico (b) à área P20B 


\section{LISTA DE TABELAS}

Página

1 Grupos de solo, número de polígonos na base de dados e correlação com a legenda original do mapa de solos (Brasil, 1976b; 1977b; Acre, 2000).

2 Localização e descrição das áreas de estudo. As idades das pastagens referentes a 2002

3 Estoque de carbono $\left(\mathrm{kg} \mathrm{m}^{-2}\right)$ e desvio padrão das classes de solos encontradas no Acre para as profundidades $0-30 \mathrm{~cm}$ e $0-100 \mathrm{~cm}$

4 Estoque de carbono do solo $\left(\mathrm{kg} \mathrm{m}^{-2}\right)$ nos primeiros $100 \mathrm{~cm}$ de profundidade. Comparação entre dados dos solos do Acre e dados da literatura (Bohn, 1976; Moraes et al., 1995; Batjes \& Dijkshoorn, 1999)

5 Código do local de coleta, profundidade de coleta, valores médios e desvios padrões de $\mathrm{C}$ - concentração de carbono (\%), $\mathrm{C}$ - estoque de carbono ( $\left.\mathrm{Mg} \mathrm{ha}^{-1}\right), \boldsymbol{\delta}^{13} \mathrm{C}$ - delta ${ }^{13} \mathrm{C}\left({ }^{\circ}\right)$, Dens. - densidade aparente do solo $\left(\mathrm{g} \mathrm{cm}^{-3}\right)$ e $\mathrm{CP}$ - teor de carbono derivado da pastagem (\%)......

6 Composição granulométrica dos solos das áreas de estudo (FA, FB, P20A, P20B, P20, P15A e P12B). Valores (\%) são médias de duas amostras e o erro representa o desvio padrão.

7 Análise química dos solos das áreas de estudo (FA, FB, P20A, P20B, P20, P15A e P12B). Valores são médias de duas amostras, o erro é representado pelo desvio padrão 


\title{
AVALIAÇÃO DO ESTOQUE E COMPOSIÇÃO ISOTÓPICA DO CARBONO DO SOLO NO ACRE
}

\author{
Autor: ANTONIO WILLIAN FLORES DE MELO \\ Orientador: Dr. PLÍNIO BARBOSA DE CAMARGO
}

\section{RESUMO}

O estado do Acre está localizado no extremo oeste do Brasil, ocupando uma região que teve grande influência geológica da cordilheira dos Andes. Os solos apresentam características pedológicas bem distintas das encontradas no restante da Amazônia brasileira, predominando Cambissolos, Luvissolos e Argissolos, geralmente eutróficos, jovens e pouco intemperizados. Pouco se sabe sobre o impacto do uso da terra sobre a matéria orgânica nestas condições de solo. Os objetivos deste trabalho foram: Estimar o estoque de carbono das principais classes de solos do Estado do Acre e comparar com estudos feitos para região amazônica. Avaliar o efeito da mudança no uso e cobertura da terra sobre o estoque de carbono e composição isotópica da matéria orgânica em duas condições de solo no Acre. Para alcançar os objetivos o trabalho foi executado em duas escalas, regional e local. No primeiro caso, foram estimados os estoques de carbono até um metro de profundidade, utilizando um mapa de solos na escala 1:1.000.000 e dados analíticos de perfis de levantamentos pedológicos realizados na região. No segundo caso foram determinados a concentração de carbono, $\delta^{13} \mathrm{C}$ e densidade do solo de amostras coletadas em pastagens de 12-15 anos, 20 anos e floresta, nas profundidades de 0-5, 5-10, 10-20, 20-30, 30-40, 50-60, 70-80 e 90- 
$100 \mathrm{~cm}$, em Argissolo (bem drenado) e Luvissolo (mal drenado). Os solos do Acre armazenam em torno de $1 \mathrm{Pg}\left(1 \mathrm{Pg}=10^{15} \mathrm{~g}\right)$ de carbono no primeiro metro de profundidade, cerca de $75 \%$ deste valor concentra-se nos primeiros $30 \mathrm{~cm}$. Os solos do Acre apresentam menor concentração de carbono (média $6,5 \mathrm{~kg} \mathrm{~m}^{2}$ ) quando comparados com a média dos solos da Amazônia, embora apresentem melhor fertilidade. A principal razão para este resultado é a maior taxa de decomposição da matéria orgânica nestes solos devido aos constantes ciclos de seca e umedecimento. Estes ciclos estão associados a interação entre o regime pluviométrico e as características físicas (principalmente estrutura) incipientes destes solos, que fazem com que ocorra um lençol freático suspenso que oscila no perfil do solo, podendo chegar até a superfície do mesmo. A mudança no uso da terra alterou de maneira distinta os estoques e a dinâmica da matéria orgânica em Argissolos (bem drenados) e Luvissolos (mal drenados). As pastagens sobre Luvissolos apresentaram maior estoque de carbono (média de $8,4 \mathrm{~kg} \mathrm{~m}^{-2}$ até $1 \mathrm{~m}$ de profundidade), entretanto, os dados isotópicos mostraram que a maior parte deste carbono era remanescente da floresta e uma pequena proporção foi introduzida pela pastagem ( $<40 \%$ na camada $0-5 \mathrm{~cm}$ da pastagem de 20 anos).

$O$ inverso ocorreu com pastagens sobre Argissolos que apresentaram menor estoque (média de $6,4 \mathrm{~kg} \mathrm{~m}^{-2}$ até $1 \mathrm{~m}$ de profundidade) e grande proporção de carbono da pastagem (> $70 \%$ na camada $0-5 \mathrm{~cm}$ da pastagem de 20 anos). Os resultados acima sugerem que: 1) A taxa de decomposição do carbono em Luvissolos é menor que em Argissolos, e o tempo de residência da meteria orgânica maior. Os Argissolos tendem a perder muito mais carbono com a mudança no uso e cobertura da terra. 2) A produtividade da pastagem é baixa sobre Luvissolos, indicando que alem da fertilidade do solo outras características, como estrutura, devem ser consideradas para definição das praticas de manejo que objetivam a obtenção de melhor desempenho da gramínea. 


\title{
EVALUATION OF THE STOCK AND ISOTOPIC COMPOSITION OF CARBON IN THE SOIL OF ACRE
}

\author{
Author: ANTONIO WILLIAN FLORES DE MELO \\ Adviser: PhD. PLÍNIO BARBOSA DE CAMARGO
}

\section{SUMMARY}

The State of Acre is located in the extreme west of Brazil, occupying an area that had great geological influence from the mountain chain of Andes. The soils present pedologic characteristics very different from the ones found in the remaining of Brazilian Amazon, prevailing Inceptisols, Alfisols, and Ultisols, generally eutrophic, young and little weathered. Not much is known about the impact of the use of the earth on the organic matter in these soil conditions. This work had as objectives to estimate the stock of carbon of the main classes of soils of the State of Acre and to compare with studies carried out for the Amazon area. To evaluate the effect of the change in the use and covering of the earth on the stock of carbon and isotopic composition of the organic matter in two soil conditions in Acre. To reach the objectives the work was performed in two scales, local and regional. The first case estimated the stocks of carbon up to one meter deep, using a map of soils in the scale 1:1.000.000 and analytic data of pedologic profiles accomplished in the area. The second case determined the concentration of carbon, $\delta^{13} \mathrm{C}$ and density of the soil of samples collected at 12-15, 20 year-old pasture lands, and forest in the depths $0-5,5-10,10-20,20-30,30-40,50-60,70-80$ e 90-100 cm, in Ultisols (well 
drained) and Alfisols (poorly drained). The soils of Acre store around $1 \mathrm{Pg}$ of carbon in the first meter of depth, around $75 \%$ of this value is concentrated on the first 30 $\mathrm{cm}$. The soils of Acre present smaller concentration of carbon (6.5 kg m${ }^{-2}$, average) when compared with the average of the soils of the Amazon, although they present better fertility. The main reason for this result is the large rate of incident decomposition on these soils due to the constant drought cycles and moistening. These cycles are associated with the physical characteristics (mainly structure) incipient of these soils that impede the percolation of the pluvial waters saturating very quickly and favoring superficial flow off. As the water concentrates on the surface of the soil, it tends to evaporate easily. The effect of the change in the covering and land use on stock and dynamics of the organic matter of the soils happens differently in Ultisols (well drained) and Alfisols (poorly drained). In the two conditions of soils there was a tendency to decrease the total stock of carbon and increase carbon of $\mathrm{C} 4$ origin, however, in Ultisols it was very stressed. Pasture lands on Alfisols presented larger stock of carbon (average of $8.4 \mathrm{~kg} \mathrm{~m}^{-2}$ to $1 \mathrm{~m}$ ), however, the data of $\mathrm{d} 13 \mathrm{C}$ showed that most of carbon was remaining of the forest and a small proportion was introduced by the pasture land $(<40 \%$ to $0-5 \mathrm{~cm}$ in $20 \mathrm{yr}$ old pasture). The inverse fact occurred with pasture lands on Ultisols that presented smaller stock (average of $6.4 \mathrm{~kg} \mathrm{~m}^{-2}$ to $1 \mathrm{~m}$ ) and great proportion of carbon of the pasture land (> $70 \%$ to $0-5 \mathrm{~cm}$ in $20 \mathrm{yr}$ old pasture). This result suggests two conclusions. 1) the rate of carbon decomposition in Alfisols is smaller than in Ultisols, and the time of residence of the organic matter is larger. Ultisols tend to lose carbon more readily with the change in the land use and covering of the land. 2) pasture productivity is low on Alfisols, indicating that besides soil fertility other characteristics, as structure, should be considered in order to establish the management practice to obtain the best output from the grass. 


\section{INTRODUÇÃO}

Nas últimas décadas uma série de eventos climáticos tem despertado a atenção dos cientistas e dirigentes das principais nações do mundo para um possível aumento da concentração dos gases responsáveis pelo efeito estufa, $\mathrm{CO}_{2}, \mathrm{~N}_{2} \mathrm{O}, \mathrm{CH}_{4}, \mathrm{CFC}$ 's, entre outros. Destes, o dióxido de carbono $\left(\mathrm{CO}_{2}\right)$ é o gás com maior destaque, principalmente por ter maior emissão em termos de massa $\left(7,9 \pm 1,2 \mathrm{Pg} \mathrm{ano}^{-1}\right)$ e ser responsável por $60 \%$ da forçante radiativa na atmosfera, desde o início do período industrial (Prentice et al., 2001).

Um dos primeiros cientistas a observar o aumento das concentrações de $\mathrm{CO}_{2}$ na atmosfera terrestre foi Charles David Keeling (Weiner, 1992). Os dados coletados por Keeling mostraram um aumento de $18 \%$ na concentração de $\mathrm{CO}_{2}$ no período de 1959 a 2002, aumentando de 315 para 372 partes por milhão por volume (ppmv) de ar neste período (Keeling \& Whorf, 2003).

A atividade humana é apontada como a principal causa do aumento da concentração de $\mathrm{CO}_{2}$ atmosférico. A queima de combustível fóssil e a mudança no uso da terra, emitiram $6,5 \pm 0,4$ e $2,2 \pm 0,8 \mathrm{Pg}$ de $\mathrm{C}$ por ano, respectivamente, durante a última década (Houghton, 2003).

Em virtude das questões que envolvem as mudanças climáticas globais, uma série de trabalhos científicos tem objetivado quantificar os reservatórios de carbono, bem como determinar os fatores que controlam a dinâmica destes reservatórios. Os principais reservatórios de carbono são os combustíveis fósseis (5.000 Pg C) (Brady \& Weil, 1999b), oceanos (38.000 Pg C), ecossistemas 
terrestres (solo 1.500 Pg C e vegetação 500-600 Pg C) e atmosfera (730-750 Pg C) (Schimel, 1995; Prentice et al., 2001).

Os solos são um importante reservatório de carbono, nos primeiros $100 \mathrm{~cm}$ de profundidade, em termos globais, estão armazenados entre $1.300-2.000 \mathrm{Pg}$ C , correspondendo ao dobro da concentração de carbono atmosférico (Schlesinger, 1977; Post et al., 1982; Eswaran et al., 1993; Sombroek et al., 1993; Batjes, 1996). Os solos tropicais armazenam $506 \mathrm{Pg} \mathrm{C}$ (Eswaran et al., 1993),sendo que destes, $66 \mathrm{Pg} \mathrm{C}$ estão em solos da Amazônia (Batjes \& Dijkshoorn, 1999), e $47 \mathrm{Pg} C$ na Amazônia legal brasileira $\left(5 \times 10^{6} \mathrm{~km}^{-2}\right)$ (Moraes et al., 1995; Batjes \& Dijkshoorn, 1999). Considerando os primeiros $30 \mathrm{~cm}$ de profundidade, os solos do território brasileiro, armazenam em torno de $36,4 \mathrm{Pg} \mathrm{C}$ (Bernoux et al., 2002).

Existem incertezas nestas estimativas devido a variação da densidade de amostras, escala das bases de dados, incompatibilidade de métodos analíticos, variabilidade espacial e temporal dos teores de carbono e de métodos de cálculo (Bernoux, 1998). A precisão de tais estimativas depende do aumento do número de trabalhos em escalas mais detalhadas.

Os solos predominantes na Amazônia brasileira são Latossolos, Argissolos e Alissolos (IBGE, 2003), em geral profundos e com baixa fertilidade, e com a fração argila constituída de minerais caolinita, goetita, gibsita e óxidos de ferro (Kitagawa \& Moller, 1979; Dematte, 2000). Os níveis de $\mathrm{Na}^{+1}, \mathrm{Mg}^{+2}, \mathrm{~K}^{+1}$, $\mathrm{P}, \mathrm{N}$, e $\mathrm{Ca}^{+2}$ são consideravelmente baixos, resultado das altas taxas de intemperismo incidentes sobre esta região durante milhões de anos (Kronberg \& Fyfe, 1983; Jordan, 1986).

Segundo Sombroek (1984), os solos da bacia Amazônica podem ser divididos em quatro grandes regiões segundo o seu material de origem. A porção leste da bacia é composta por sedimentos caoliníticos do terciário da Formação 
Barreiras, originárias principalmente de materiais do complexo cristalino ao norte e sul desta região. Nos extremos norte e sul da região, os solos são mais diversos, apresentando solos como Latossolos, Argissolos, Nitossolos e Litossolos.

A porção oeste da bacia, denominada Amazônia Sul-Ocidental compreendida entre o rio Japurá ao norte, sistema Madeira-Mamoré ao sul, cordilheira do Andes e um limite imaginário a oeste, quase paralelo a longitude $65^{\circ}$ oeste que une a confluência do Japurá - Solimões com a confluência dos rios Abunã - Madeira (Latrubesse, 1992), é a região mais distinta em relação às demais. Esta região apresenta solos menos intemperizados, formados principalmente a partir de sedimentos terciários marinhos, fluviais, lacustres e de deposição de cinzas vulcânicas, originários dos Andes Peruanos, denominado de Formação Solimões (Sombroek, 1984; Gama, 1986; Latrubesse et al., 1997). Nesta região está localizado o estado do Acre, área de estudo do presente trabalho.

O Acre é um estado que se encontra no extremo oeste do Brasil, ocupando uma área de $152.581 \mathrm{~km}^{2}$, cerca de $3 \%$ da Amazônia legal e 1,8\% do território nacional (IBGE, 2002). Devido a sua posição geográfica e condições ambientais, apresenta solos bem distintos dos encontrados na maior parte da Amazônia brasileira.

Em regiões tropicais úmidas a combinação de elevadas temperaturas e precipitações levam ao decréscimo dos teores de $\mathrm{Na}^{+1}, \mathrm{Mg}^{+2}, \mathrm{~K}^{+1}, \mathrm{Ca}^{+2} \mathrm{e}$ acúmulo de óxidos de $\mathrm{Si}^{+4}, \mathrm{Al}^{+3}$ e $\mathrm{Fe}^{+2}$, resultando em uma mineralogia caulinítica e/ou, oxídica, onde a presença de minerais 2:1 está restrita a grupos de solos de várzea com menor taxa de intemperismo (Kronberg \& Nesbitt, 1981; Kronberg \& Fyfe, 1983). Os solos do Acre tendem a ser uma exceção a esse regra, sendo encontrados argilominerais de estrutura 2:1 em Luvissolos (Martins, 1993), Cambissolos e Gleissolos (Silva, 1999). 
A composição granulométrica e química também é diferenciada, sendo encontrados teores altos de silte $(>60 \%)$ e concentrações de $\mathrm{Ca}^{2+}$ e $\mathrm{Mg}^{2+}$ em associação com altos teores de $\mathrm{Al}^{3+}$ (Gama, 1986; Volkoff et al., 1989; Gama et al., 1992; Martins, 1993; Silva, 1999).

Material de origem, clima, biota, topografia e tempo são determinantes das características dos solos durante o processo de formação (Brady \& Weil, 1999a). No caso da região de inserção do Estado do Acre, três fatores podem ser apontados com principais responsáveis pelas características encontradas nos dias atuais: (1) A evidência de aridez desta região durante o último período glacial (Kronberg et al., 1991; Kronberg \& Benchimol, 1993). (2) Material de origem rico em bases (Brasil, 1976a; Gama et al., 1992; Dematte, 2000). (3) Relevo ondulado (Figura 1)

A interação destes fatores afetou diretamente os processos intempéricos de hidrólise e oxidação, principais mecanismos de formação dos solos da região amazônica, resultando em solos com as características anteriormente mencionadas.

De forma geral, existe uma forte relação entre grau de intemperismo e características físicas dos solos. Intensos intemperismos durantes milhões de anos, resultaram em solos de terra firme com baixa concentração de nutrientes, e em geral profundos, bem drenados, e de excelente estrutura, cuja alta estabilidade dos agregados, está relacionada a presença de óxidos amorfos de ferro e alumínio (Jordan, 1986).

O contrário ocorre com solos jovens e pouco intemperizados, que apresentam em geral boa fertilidade, associados a problemas de drenagem, devido a pouca profundidade e estrutura pobremente desenvolvida. Estas condições submetem a vegetação existente sobre essas áreas, principalmente 
após o corte da floresta, a um constante estado de estresse hídrico. Seja por falta ou excesso de água, dependendo da estação do ano.

Isto é particularmente evidenciado em fazendas da região, onde grandes extensões de pastagens de Brachiaria brizatha morrem durante a estação chuvosa. Pelo menos $50 \%$ das pastagens existentes no Acre, estão localizadas em áreas de médio a alto risco de serem atingidas pelo problema morte, devido à baixa permeabilidade do solo, no caso de a gramínea utilizada ser Brachiaria brizantha (Valentim et al., 2000)

No Acre o desmatamento está em torno de $12 \%$ da área total, que é relativamente pequeno se comparado com os outros estados pertencentes ao arco do desmatamento na Amazônia. Entretanto, a atividade antrópica concentrase no leste do estado, onde o índice de desmatamento é de $20 \%, 70 \%$ da população vive nesta região (IBGE, 2001; INPE, 2002; 2003).

A pecuária de corte foi responsável por aproximadamente $75 \%$ das áreas desmatadas até 1998 (em torno de 9\% da área total do Estado), tendo causado as maiores transformações nos ecossistemas naturais do Estado (Valemtim \& Carneiro, 1999). Como conseqüência, esta atividade tem sido o foco de debates com relação aos impactos ambientais e socioeconômicos, decorrentes da conversão de extensas áreas de florestas com alta biodiversidade, em sistemas homogêneos de pastagens de Brachiaria brizantha (Smith et al., 1995; Faminow, 1998; Vosti et al., 2000)

Em ecossistemas naturais a fonte de carbono orgânico tem uma só origem, a vegetação nativa. Nos ecossistemas alterados, como pastagens, há a introdução de uma nova fonte, oriunda da decomposição de resíduos vegetais derivados da gramínea (Cerri et al., 1990; Bernoux et al., 1998a). A quantificação destas fontes pode ser feita com o emprego de técnicas isotópicas baseadas na abundância natural do ${ }^{13} \mathrm{C}$ (Cerri, et al, 1985). O uso de ${ }^{13} \mathrm{C}$ como traçador é 
possível devido a discriminação diferenciada feita pelas plantas, dependendo do ciclo fotossintético a que pertencem (Farquhar et al., 1989). Tecidos de plantas dos ciclos fotossintéticos C3 e C4 apresentam os valores médios - 27 e -12\% de $\delta^{13} \mathrm{C}$, respectivamente (Smith \& Epstein, 1971).

Com a introdução de pastagens, a quantidade de matéria orgânica do solo pode decrescer nos primeiros anos da implantação, aumentando nos anos seguintes, até atingir valores muito próximos ou superiores aos existentes antes da conversão (Cerri, 1986; Choné et al., 1991; Feigl et al., 1995; Moraes, 1995). Entretanto, outros autores têm encontrado uma diminuição com o tempo nos teores de matéria orgânica do solo (Desjardins et al., 1994; García-Oliva et al., 1994; Veldkamp, 1994; Camargo et al., 1999). Esta divergência de resultados está associada às condições ambientais, edáficas e de manejo das áreas de estudo.

Os principais fatores que controlam o comportamento da matéria orgânica em solos tropicais são umidade, clima, estrutura, textura, mineralogia e manejo (Motavalli et al., 1995; Scott et al., 1996; Batjes \& Sombroek, 1997; Feller \& Beare, 1997; Zech et al., 1997; Schjonning et al., 1999; Schoenholtz et al., 2000; Powers \& Schlesinger, 2002; Telles et al., 2003).

Solos como os encontrados na região do Acre, que apresentam: alto conteúdo de argila e silte; drenagem em geral imperfeita; estrutura pouco desenvolvida e presença de minerais 2:1, podem apresentar maior estoque e menor perda de carbono com a mudança no uso e cobertura da terra, quando comparados com outros solos encontrados na Amazônia, devido principalmente aos efeitos de proteção da argila, alta produtividade primária líquida em função da boa fertilidade e menor taxa de decomposição devido a drenagem imperfeita.

Com base neste contexto foram levantadas as seguintes questões: (1) Quanto carbono está armazenado no primeiro metro dos solos do Acre? (2) Os 
solos do Acre apresentam maior estoque de carbono comparativamente com outros solos da Amazônia, já que apresentam melhor fertilidade? (3) A conversão de floresta em pastagem tem o mesmo efeito no estoque de carbono e $\delta^{13} \mathrm{C}$ em Argissolos (mal drenados) e Luvissolos (bem drenados)? (4) Comparando com outros trabalhos feitos na Amazônia, qual o comportamento dos solos da região do Acre, com relação ao estoque e dinâmica da matéria orgânica, após a mudança no uso e cobertura da terra?

\subsection{Objetivos}

Para responder as questões propostas foram estabelecidos os seguintes objetivos:

- Estimar o estoque de carbono das principais classes de solos do Estado do Acre e comparar os resultados com estudos feitos para região amazônica.

- Avaliar o efeito da mudança no uso e cobertura da terra sobre o estoque de carbono e composição isotópica da matéria orgânica em duas condições de solo no Acre.

\subsection{Ações específicas}

a. Estimar o estoque de carbono para os principais tipos de solo existentes no Estado do Acre, para as profundidades 0-30 e 0-100 cm, usando base de dados pré-existente e sistemas de informação geográfica;

b. Estimar a densidade aparente dos horizontes dos perfis de solo contidos na base de dados, usando regressões multilineares (Bernoux et al., 1998b); 
c. Determinar o estoque do carbono e $\delta^{13} \mathrm{C}$ do solo sob pastagens e florestas primárias;

d. Determinar as fontes e seus percentuais de carbono de solos sob pastagens com idades 12-15, 20 anos e tipos de solo diferentes;

e. Comparar os parâmetros coletados em pastagens de idades diferentes (12-15, 20 anos), nas duas condições de solos estudadas. 


\section{MATERIAL E MÉTODOS}

\section{1 Área de estudo}

A área de estudo compreende a região de inserção do estado do Acre. Historicamente, em termos econômicos, este estado dependeu diretamente do extrativismo vegetal, como por exemplo, castanha-do-brasil (Bertholletia excelsa), borracha (Hevea spp.) e exploração madeireira. A partir da década de 70 , com os incentivos do Governo Federal e a exemplo do que ocorreu no restante da Amazônia, a agropecuária tomou impulso na região (Valverde, 1989).

Os solos predominantes são Luvissolos, Cambissolos e Argissolos. O relevo ondulado é predominante em grande parte de do estado (Figura 1). A vegetação é caracterizada como Floresta Ombrófila Aberta, dominada por bambu (Guadua sp.), com manchas de Floresta Ombrófila Densa (Brasil, 1976a; 1977a; Valverde, 1989).

O clima é classificado como Am (Köpen), a temperatura média anual é 26 ${ }^{\circ} \mathrm{C}$ (Brasil, 1976a; 1977a), a pluviosidade oscila entre 1750 e $2000 \mathrm{~mm} / \mathrm{ano}$, média de 1940 \pm 228 mm entre 1970 e 2000, sendo junho o mês mais seco (32 $\mathrm{mm}$ ) e Fevereiro o mês com maior pluviosidade (299 mm) (Duarte et al., 2002). Durante o inverno do hemisfério sul as massas de ar polar provocam a queda da temperatura chegando até $10^{\circ} \mathrm{C}$, a média anual da umidade relativa do ar é de 85\% (Duarte et al., 2002). 


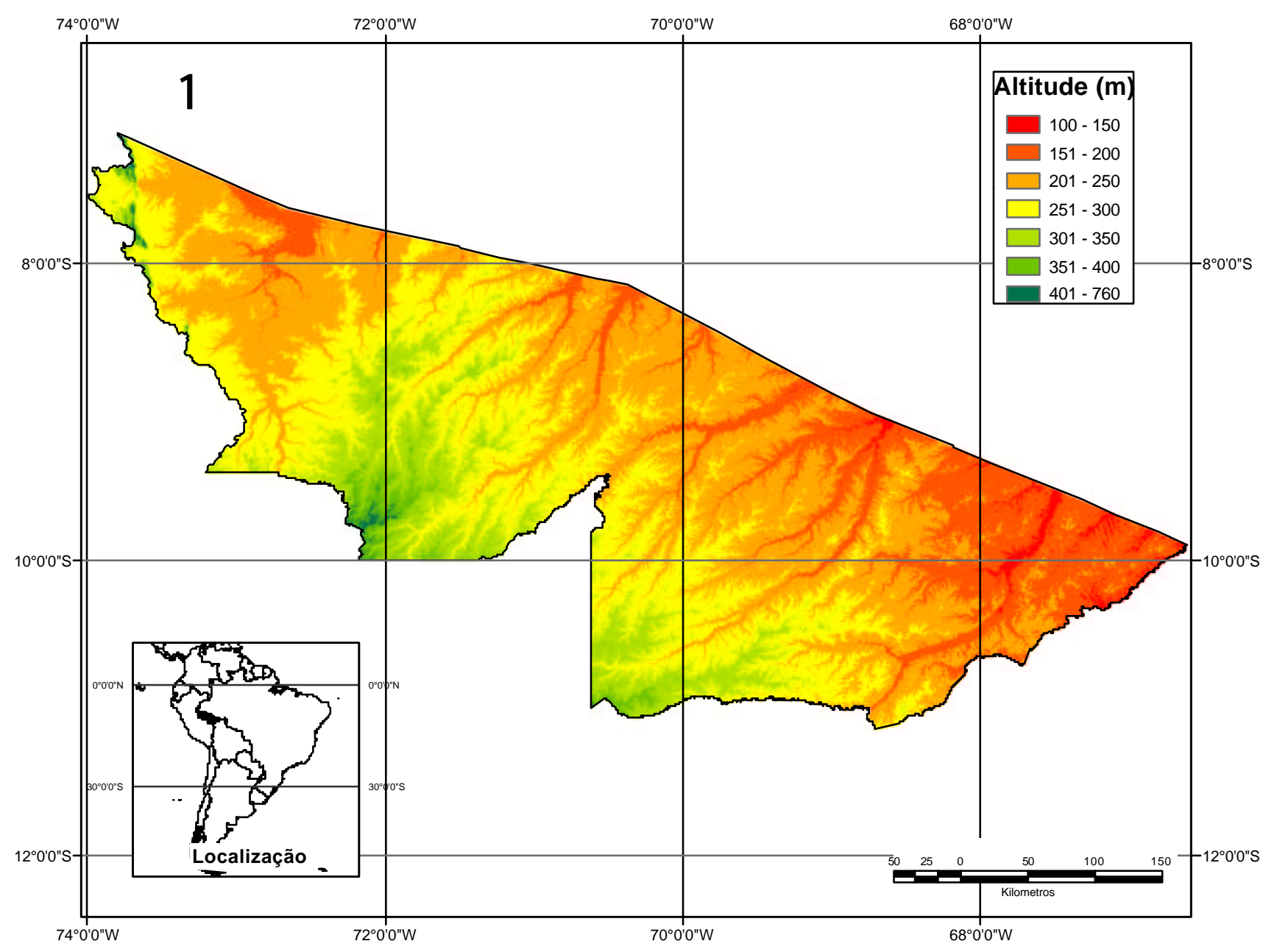

Figura 1 - Mapa de relevo do Estado do Acre. Fonte: Adaptado de NASA/SRTM/USGS 
Este estudo baseourse em levantamentos em escalas local e regional:

Os estoques de carbono dos solos do Acre foram estimados, utilizando uma base cartográfica de solos e dados analíticos de perfis de solos existentes na literatura.

Em escala local, foi avaliado o efeito da mudança do uso da terra no estoque e composição do carbono em duas condições de solos na região leste do estado do Acre. Foram selecionadas pastagens bem manejadas, com uma taxa de lotação média de 1,5 cabeças/há (Figura 2). Em todas as áreas houve a derrubada da floresta, queima e implantação da pastagem.

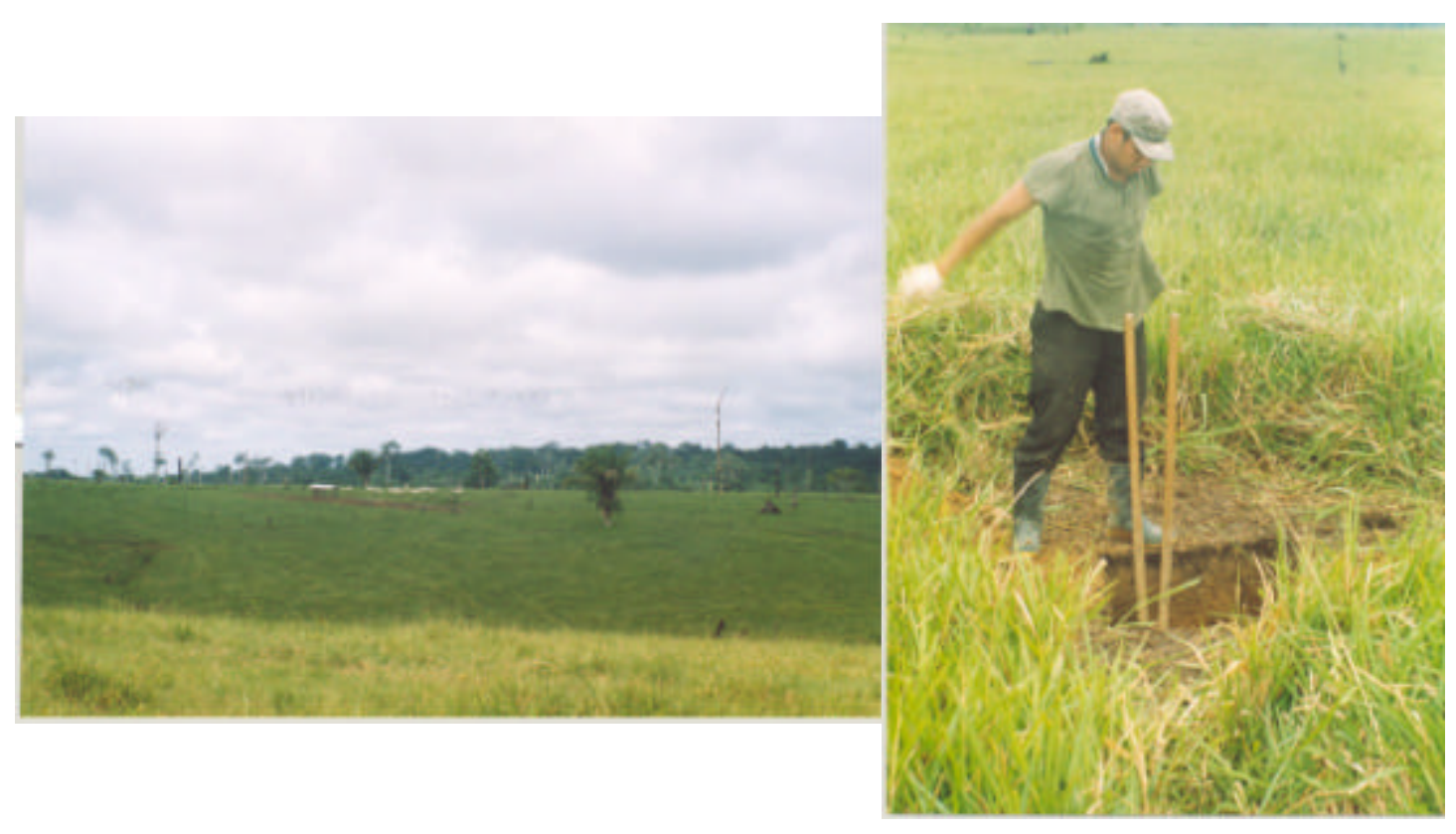

Figura 2 - Vista de duas pastagens amostradas 
2.2 Estimativa do estoque de carbono dos principais solos do estado do Acre

O estoque de carbono dos principais solos do Acre foram estimados utilizando uma base cartográfica de solos na escala 1:1.000.000 (Brasil, 1976b; 1977b; Acre, 2000) e informações analíticas de 227 perfis de solos (Brasil, 1976a; 1977a; Amaral \& Araújo Neto, 1998; Amaral et al., 2000; Araújo, 2000; Melo \& Amaral, 2000; Rodrigues et al., 2001). Os perfis em que constava sua posição geográfica nos trabalhos (182), estão na Figura 3. Todos os dados foram trabalhados no software ArcMap 8.1 para cálculo de área e obtenção dos mapas. 


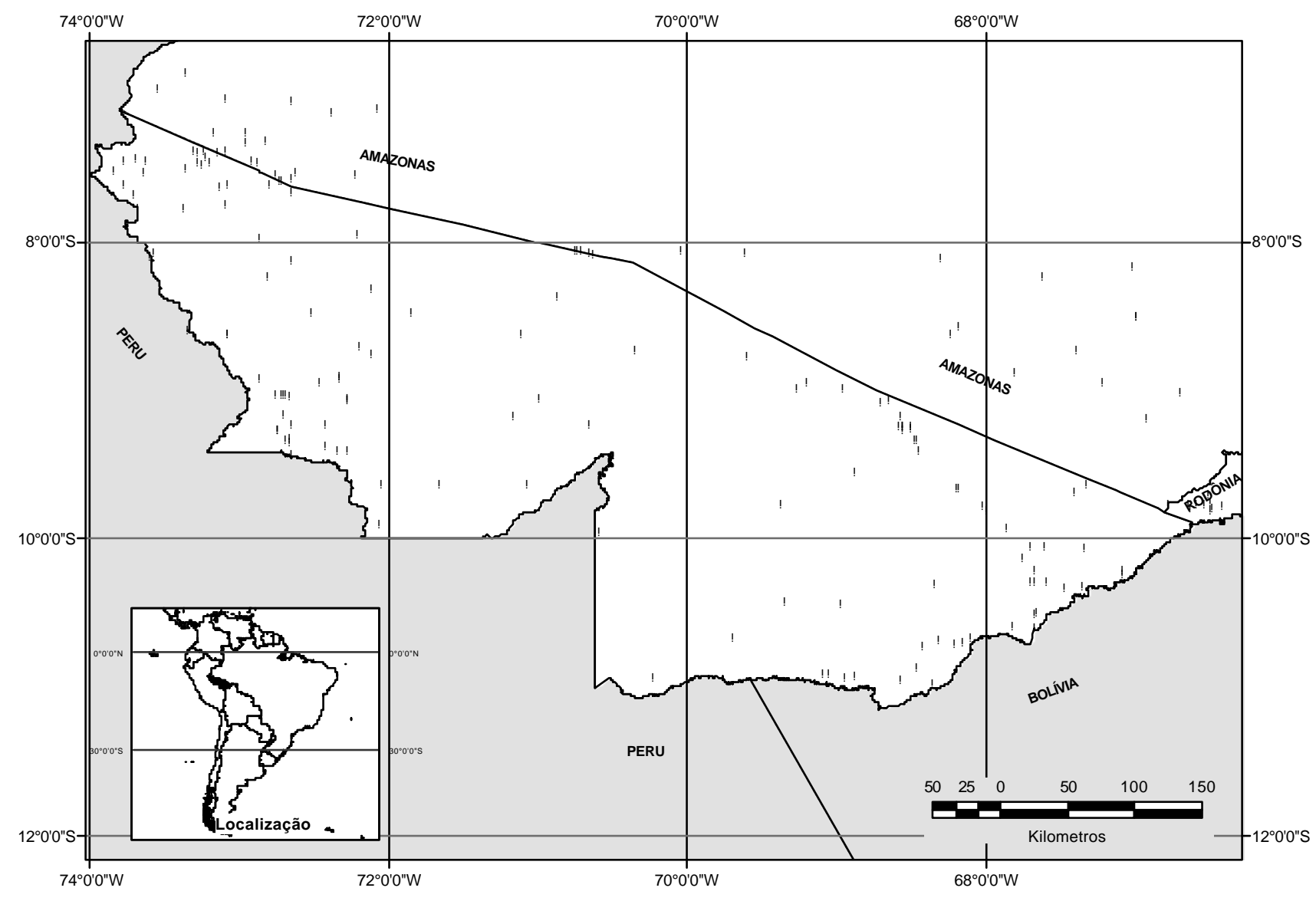

Figura 3 - Localização de 182 perfis de solo que foram utilizados para estimar o estoque de carbono dos solos do Estado do Acre 


\subsubsection{Mapa de solos}

A legenda do mapa original com 283 polígonos divididos em 36 unidades de mapeamentos, foi simplificada (Tabela 1) usando como base os critérios recomendados por Houghton et al. (1997) para inventários de carbono do solo; atividade de argila, saturação por bases e umidade do solo. As 36 unidades de mapeamento de solo foram simplificadas para 6 grupos (Figura 4), que têm as seguintes classes de solo predominantes, G1 - Luvissolos e Argissolos Eutróficos (77 polígonos), G2 - Cambissolos (17 polígonos), G3 - Argissolos Distróficos, Alissolos e Nitossolos (67 polígonos), G4 - Alissolos (31 polígonos), G5 - Gleissolos, Neossolos Flúvicos e Plintossolos (78 polígonos) e G6 Latossolos (14 polígonos). Os solos foram classificados de acordo como o sistema brasileiro de classificação de solos (Embrapa, 1999). 
Tabela 1. Grupos de solo, número de polígonos na base de dados e correlação com a legenda original do mapa de solos (Brasil, 1976b; 1977b; Acre, 2000)

\begin{tabular}{|c|c|c|c|c|}
\hline Grupo & POL* & $\begin{array}{l}\text { Área } \\
\left(\mathrm{Km}^{2}\right)\end{array}$ & $\begin{array}{c}\text { Área }^{\sigma} \\
(\%)\end{array}$ & Classes de solo\# \\
\hline G1 & 77 & 60.796 & 40 & $\begin{array}{l}\text { Luvissolo } \\
\text { Luvissolo Hipocrômico } \\
\text { Argissolo } \\
\text { Argissolo Amarelo eutrófico }\end{array}$ \\
\hline G2 & 17 & 36.850 & 24 & $\begin{array}{l}\text { Cambissolo } \\
\text { Cambissolo Háplico Ta eutrófico } \\
\text { Cambissolo Háplico Tb alumínico }\end{array}$ \\
\hline G3 & 67 & 21.287 & 14 & $\begin{array}{l}\text { Argissolo } \\
\text { Argissolo Vermelho distrófico } \\
\text { Argissolo Vermelho-Amarelo alumínico } \\
\text { Alissolo } \\
\text { Alissolo Crômico argilúvico } \\
\text { Nitossolo } \\
\text { Nitossolo Vermelho eutrófico }\end{array}$ \\
\hline G4 & 31 & 17.104 & 11 & $\begin{array}{l}\text { Alissolo } \\
\text { Alissolo Crômico argilúvico } \\
\text { Argissolo } \\
\text { Argissolo Vermelho distrófico } \\
\text { Argissolo Vermelho-Amarelo alumínico }\end{array}$ \\
\hline G5 & 78 & 13.542 & 9 & $\begin{array}{l}\text { Gleissolo } \\
\text { Gleissolo Háplico Ta eutrófico } \\
\text { Gleissolo Háplico Tb alumínico } \\
\text { Gleissolo Háplico Ta alumínico } \\
\text { Neossolo Flúvico } \\
\text { Neossolo Flúvico Ta eutrófico } \\
\text { Neossolo Flúvico Tb distrófico } \\
\text { Plintossolo } \\
\text { Plintossolo Argilúvico Ta distrófico }\end{array}$ \\
\hline G6 & 14 & 3.018 & 2 & $\begin{array}{l}\text { Latossolo } \\
\text { Latossolo Vermelho distrófico } \\
\text { Latossolo Vermelho Amarelo distrófico } \\
\text { Latossolo Vermelho Amarelo alumínico }\end{array}$ \\
\hline
\end{tabular}

* - Quantidade de polígonos na base cartográfica de solos.

\# - Classes de solo relacionadas na legenda original do mapa de solos.

$\mathrm{Ta}$ - Atividade de argila alta ( $\geq 27 \mathrm{~mol}_{\mathrm{C}} / \mathrm{kg}$ de argila).

$\mathrm{Tb}-$ Atividade de argila baixa $\left(<27 \mathrm{~mol}_{d} / \mathrm{kg}\right.$ de argila).

$\varnothing$ - Distribuição à áreas total do Acre. 


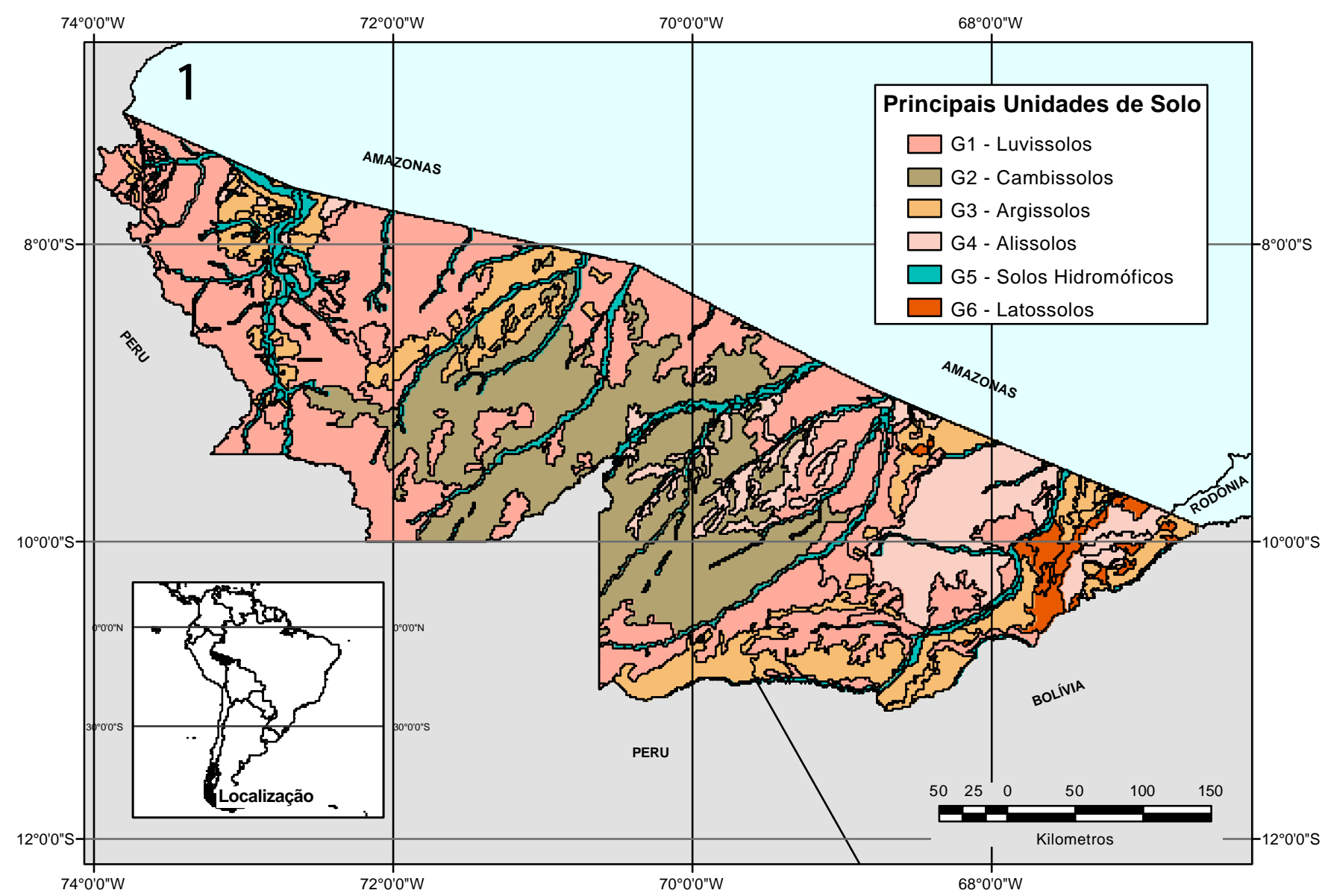

Figura 4 - Mapa de solos simplificado do Estado do Acre. Adaptado de Acre (2000), Brasil (1976b, 1977b) 


\subsubsection{Cálculo do estoque de carbono}

Os estoques de carbono $\left(\mathrm{kg} \mathrm{m}^{-2}\right)$ por horizontes $E C_{h}$ foram obtidos multiplicando a concentração de C (\%), densidade aparente do solo $\left(\mathrm{kg} \mathrm{m}^{-3}\right)$ e espessura $\mathrm{h}(\mathrm{m})$ do horizonte [eq. (1)]. Os estoques de carbono $\left(\mathrm{kg} \mathrm{m}^{-2}\right)$ por perfil de solo $E C_{P}$ foram calculados para duas profundidades, 0-30 e 0-100 cm. $O$ cálculo constituiu da soma dos estoques dos horizontes contidos nas profundidades estabelecidas [eq. (2)].

$$
\begin{aligned}
& E C_{h}=C \times D A \times h \\
& E C_{p}=\sum_{0-100 \mathrm{~cm}}^{0-30 c m} E C_{h}
\end{aligned}
$$

Os valores de densidade do solo não constavam nas publicações utilizadas. Para a sua estimativa foram utilizadas equações multilineares que relacionam teor de argila, carbono e pH com densidade do solo, obtidas a partir de dados de solos representativos da Bacia Amazônica (Bernoux, 1998; Bernoux et al., 1998b). Para horizontes com teor de argila menor $\leq 20 \%$ utilizou-se a seguinte equação:

$$
D S=0,0181 \times(100-T A-5)-0,08 \times C O, r^{2}=0,66
$$

Nos demais casos o cálculo foi efetuado com equações específicas para cada grupo de solo, conforme descrito abaixo.

Grupos G1, G2, G3, G4:

$$
D S=1,394-(0,0051 \times T A)-(0,037 \times C O), r^{2}=0,47
$$

Grupo G5:

$$
D S=1,58-(0,0040 \times T A)-(0,050 \times C O)-(0,047 \times P H), r^{2}=0,51
$$


Grupo G6:

$D S=1,404-(0,0040 \times T A)-(0,048 \times C O), r^{2}=0,71$

Onde:

DS $=$ densidade do solo em peso por volume $\left(\mathrm{g} \mathrm{cm}^{-3}\right)$.

TA = conteúdo de argila (partículas $<2 \mathrm{~mm}$ ), após dispersão com hexametafosfato de sódio (\% [peso/peso] da fração de solo $<2 \mathrm{~mm}$ ).

$\mathrm{CO}=$ carbono orgânico por oxidação dicromática $[\%$ (peso/peso) da fração de solo <2 mm] (Walkley \& Black, 1934).

$\mathrm{PH}=\mathrm{pH}$ em água .

\subsubsection{Mapa de carbono do solo}

No mapa de estoque carbono dos solos do estado do Acre, foram usadas as medianas do conteúdo de carbono da classe de solo predominante em cada polígono da base cartográfica de solos, no ambiente do programa de computador ArcMap 8.1. 
2.3 Estoque e composição isotópica do carbono do solo sob pastagem e floresta primária

\subsubsection{Amostragem}

A coleta de solos foi realizada em duas fazendas na região leste do estado do Acre (Figura 6), Fazenda Iracema e Fazenda Alfenas, onde foram selecionadas pastagens com 12-15, 20 anos e duas áreas de florestas (Tabela 2), em duas condições de solo:

a. Luvissolo: Solo jovem sob o ponto de vista pedológico, B textural, estrutura pouco desenvolvida, textura argilosa a muito argilosa, lençol freático suspenso $(40-70 \mathrm{~cm})$, relevo leve ondulado a ondulado (Figura $5 b)$.

b. Argissolo: Solo bem desenvolvido, B textural, textura média a argilosa, estrutura bem desenvolvida, profundidade do lençol entre 1 e 2 metros, relevo leve ondulado (Figura 5a).

(b)

\section{(a)}

Figura 5 - (a) Perfil de Argissolo. (b) Perfil de Luvissolo 

Em cada pastagem foram abertas duas trincheiras medindo $2 \times 1,5 \times 1,2 \mathrm{~m}$ (comprimento $\mathrm{x}$ largura $\mathrm{x}$ profundidade) (Figura 7). As coletas foram feitas em três paredes de cada trincheira, nas profundidades $0-5,5-10,10-20,20-30,30-40,50-$ $60,70-80$ e $90-100 \mathrm{~cm}$, num total de seis repetições para cada profundidade. A Figura 8 resume o processo de amostragem.

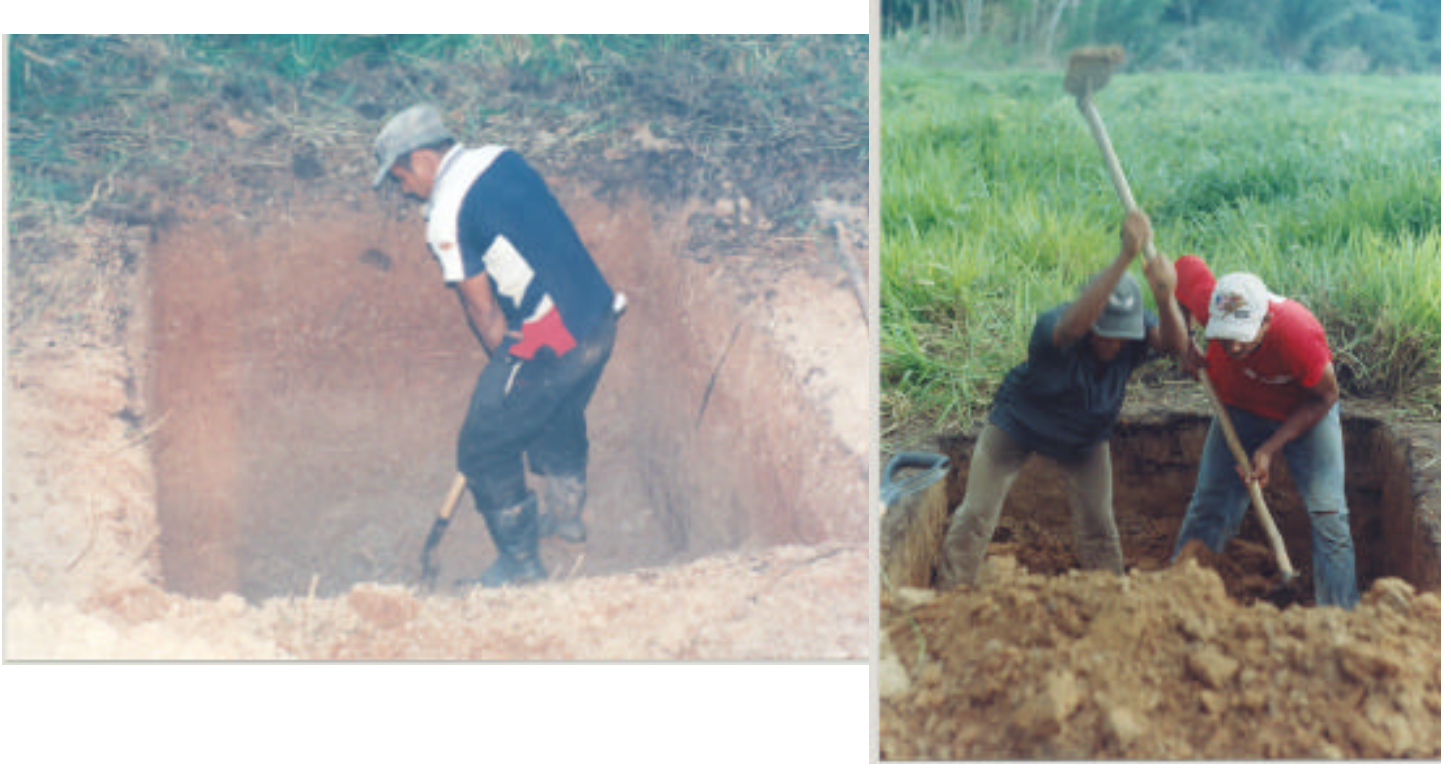

Figura 7 - Abertura das trincheiras utilizadas para coleta das amostras de sob

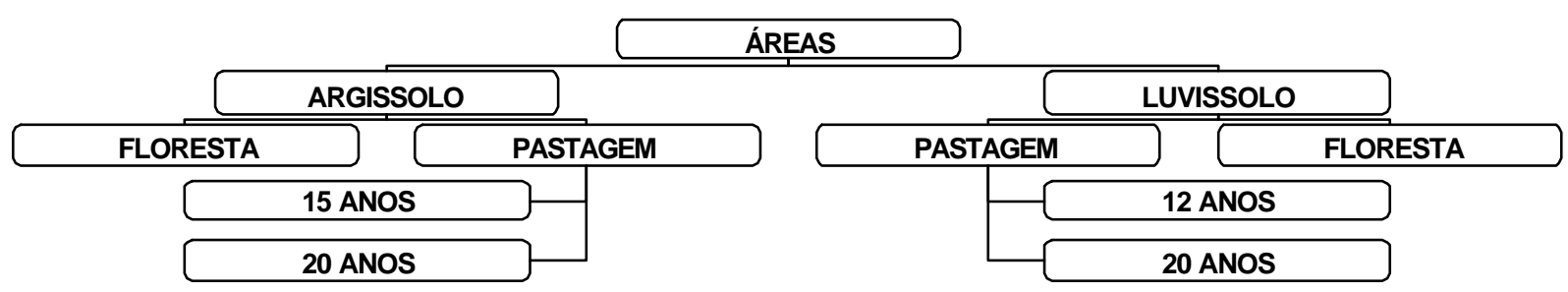

Figura 8 - Diagrama experimental 
Foram analisados os seguintes parâmetros: densidade aparente $\left(\mathrm{g} \mathrm{cm}^{-3}\right)$, concentração (\%) e estoque de carbono $\left(\mathrm{kg} \mathrm{m}^{-2}\right), \quad \delta^{13} \mathrm{C}$ (\%), fertilidade, composição granulométrica (\%) e fontes do carbono (\%).

Tabela 2. Localização e descrição das áreas de estudo. As idades das pastagens referentes a 2002

\begin{tabular}{|c|c|c|c|c|}
\hline \multirow{2}{*}{$\begin{array}{l}\text { Local } \\
\text { de } \\
\text { coleta }\end{array}$} & \multirow[b]{2}{*}{ Código } & \multicolumn{2}{|c|}{ Localização } & \multirow[b]{2}{*}{ Descrição } \\
\hline & & Lat. & Long. & \\
\hline \multirow{5}{*}{ 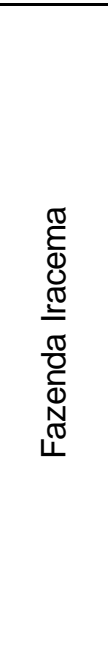 } & FB & $09^{\circ} 40^{\prime} 51 " \mathrm{~S}$ & $67^{\circ} 33^{\prime} 38^{\prime \prime W}$ & $\begin{array}{l}\text { Floresta natural, sobre Luvissolo, pouco } \\
\text { profundo, mal drenado, relevo leve ondulado a } \\
\text { ondulado. }\end{array}$ \\
\hline & P20A & $09 \div 37$ '50"S & $67^{\circ} 36^{\prime} 26^{\prime \prime} \mathrm{W}$ & $\begin{array}{l}\text { Pastagem de Brachiaria brizantha, sobre } \\
\text { Argissolo, profundo, bem drenado, relevo } \\
\text { plano a leve ondulado, } 20 \text { anos. }\end{array}$ \\
\hline & P20 & $09 \div 37$ '50"S & $67^{\circ} 36^{\prime} 04^{\prime \prime} \mathrm{W}$ & $\begin{array}{l}\text { Pastagem de Brachiaria brizantha, sobre } \\
\text { Latossolo, muito profundo, bem drenado, } \\
\text { relevo plano a leve ondulado, } 20 \text { anos. }\end{array}$ \\
\hline & P15A & $09^{\circ} 38^{\prime} 24 " S$ & $67^{\circ} 35^{\prime} 43^{\prime \prime W}$ & $\begin{array}{l}\text { Pastagem de Brachiaria brizantha, sobre } \\
\text { Argissolo, profundo, bem drenado, relevo } \\
\text { plano a leve ondulado, } 15 \text { anos. }\end{array}$ \\
\hline & P12B & 09 이 03 'S & $67^{\circ} 34^{\prime} 57^{\prime \prime W}$ & $\begin{array}{l}\text { Pastagem de Brachiaria brizantha, sobre } \\
\text { Luvissolo, pouco profundo, mal drenado, } \\
\text { relevo leve ondulado a ondulado, } 12 \text { anos. }\end{array}$ \\
\hline \multirow{2}{*}{ 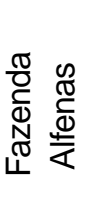 } & FA & $10^{\circ} 01^{\prime} 27 " S$ & $68^{\circ}$ 12' 04"W & $\begin{array}{l}\text { Floresta natural, sobre Argissolo, profundo, } \\
\text { bem drenado, relevo plano a leve ondulado. }\end{array}$ \\
\hline & P20B & 095ㄷㅇ' 04"S & $68^{\circ}$ 10' 52"W & $\begin{array}{l}\text { Pastagem de Brachiaria brizantha, sobre } \\
\text { Luvissolo, pouco profundo, mal drenado, } \\
\text { relevo leve ondulado a ondulado, } 20 \text { anos. }\end{array}$ \\
\hline
\end{tabular}

As referências às classes de drenagem e profundidade contidas na Tabela 2 estão de acordo com EMBRAPA (1999), sendo as mesmas definidas a seguir.

Solo bem drenado é definido como aquele em que a água é removida do solo com facilidade, porém não rapidamente. Os solos com esta classe de drenagem normalmente apresentam textura argilosa ou média, ocorrendo mosqueados profundos, abaixo de $50 \mathrm{~cm}$ da superfície.

Nos solos mal drenados a água é removida tão lentamente que este permanece molhado por uma grande parte do ano. O lençol freático comumente 
está próximo a superfície durante uma considerável parte do ano, e é freqüente a ocorrência de mosqueados e características de gleização no perfil.

Considera-se solo raso aquele com profundidade $\leq 50 \mathrm{~cm}$ de profundidade, pouco profundo $>50 \mathrm{~cm} \mathrm{e} \leq 100 \mathrm{~cm}$, profundo $>100 \mathrm{~cm} \mathrm{e} \leq 200 \mathrm{~cm}$ e muito profundo $>200 \mathrm{~cm}$.

\subsubsection{Análises físico-químicas do solo}

As densidades aparentes dos solos foram determinadas utilizando o método do cilindro de Kopec (Embrapa, 1997) (Figura 9) e realizadas utilizando o Laboratório de Fertilidade do Solo da Universidade Federal do Acre.

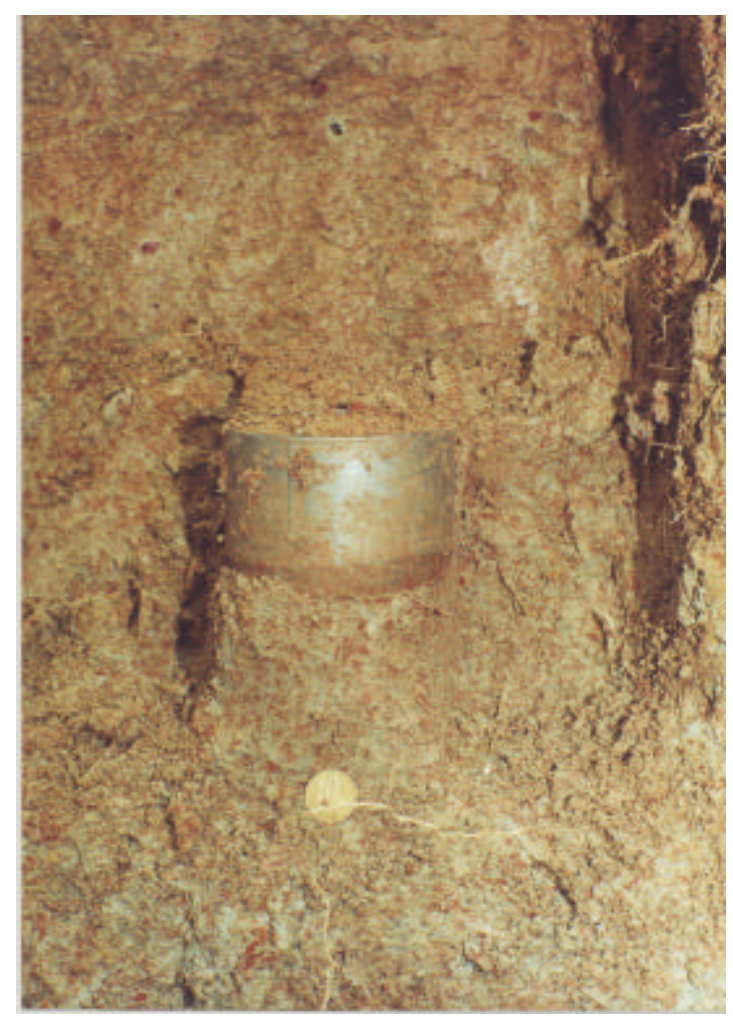

Figura 9 - Processo de coleta de amostra para determinação da densidade aparente do solo 
As análises granulométricas foram realizadas por meio do método do densímetro, utilizando-se como dispersante o hidróxido de sódio e o hexametafosfato de sódio, separando-se areia e argila Camargo et al. (1986) e a fração silte foi obtida por diferença.

Para o complexo sortivo, segundo Raij et al. (1987), foram analisados $\mathrm{pH}$, matéria orgânica, $\mathrm{Ca}^{+2}, \mathrm{Mg}^{+2}, \mathrm{~K}^{+1}, \mathrm{Al}^{+3} \mathrm{e}^{+1}+\mathrm{Al}^{+3}$. A determinação da matéria orgânica foi realizada colorimetricamente; $\circ \mathrm{Ca}^{+2} \mathrm{e} \circ \mathrm{Mg}^{+2}$ foram determinados por espectrofotometria de absorção atômica; o $\mathrm{K}^{+}$por fotometria de chama de emissão e $\circ \mathrm{H}^{+1}+\mathrm{Al}^{+3}$ por titulação. O P solúvel foi extraído pelo método da resina.

As análises granulométricas e complexo sortivo foram realizadas no Laboratório de Fertilidade do Solo do Departamento de Ciência do Solo da Escola Superior de Agricultura "Luiz de Queiroz" - ESALQUSP.

\subsubsection{Determinação do $\mathrm{C},{ }^{13} \mathrm{C}$}

Com o objetivo de obter uma subamostra homogênea e representativa da amostra, estas foram obtidas pelo quarteador de Jones, apontado como um dos melhores métodos de se obter amostras representativas em diferentes análises físicas e químicas (Mullins \& Hutchison, 1982; Smith \& Pratt, 1984; Schumacher et al., 1990). Na subamostra, de cerca de 10 gramas, foram removidos raízes e carvões macroscópicos.

As amostras foram secadas a $60 \stackrel{\circ}{\mathrm{C}}$ até peso constante, moídas e peneiradas a $0,25 \mathrm{~mm}$. Em seguida uma subamostra foi pesada em cápsula de estanho. Estas foram queimadas em meio oxidante, e os gases produzidos separados por cromatografia gasosa, purificados e carreados por um fluxo contínuo de Hélio. A concentração de $\mathrm{C}(\%)$ e a razão isotópica ${ }^{13} \mathrm{C} /{ }^{12} \mathrm{C}(\%)$ foram 
determinados nos equipamentos: analisador elementar Carlo Erba EA 1110 acoplado a um espectrômetro de massa de razão isotópica, Finnigan Delta Plus.

Os erros analíticos foram de $5 \%$ para concentração de C e $0,5 \%$ para a razão isotópica ${ }^{13} \mathrm{C} /{ }^{12} \mathrm{C}$.

\subsubsection{Estoque de $\mathrm{C}$ e razão ${ }^{13} \mathrm{C} /{ }^{12} \mathrm{C}$}

O estoque de carbono foi determinado pela multiplicação da densidade aparente do solo $\left(\mathrm{kg} \mathrm{m}^{-3}\right)$, pela espessura da camada de solo considerada $\mathrm{h}(\mathrm{m}) \mathrm{e}$ sua respectiva concentração de C (\%), a resultante é expressa em $\mathrm{kg} \mathrm{C} \mathrm{m}^{-2}$ [eq. (1)]

A razão ${ }^{13} \mathrm{C} /{ }^{12} \mathrm{C}$ é expressa pela notação $\delta$, na forma por mil (\%), é definida pela equação abaixo:

$$
\delta^{13} C=\left(\frac{R_{\text {amostra }}-R_{\text {padrão }}}{R_{\text {padrão }}}\right) \times 1000
$$

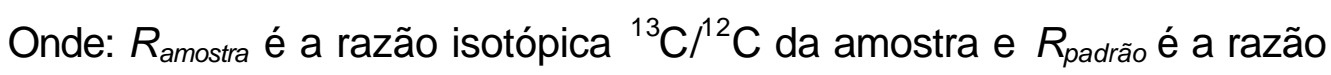
isotópica ${ }^{13} \mathrm{C} /{ }^{12} \mathrm{C}$ do padrão.

O padrão utilizado é a rocha calcária da Formação Pee Dee (PDB - Pee Dee Belemnite). Materiais biológicos geralmente têm uma razão isotópica menor que a razão isotópica do padrão, tornando o valor de $\delta$ negativo.

\subsubsection{Estimativa das fontes do carbono do solo}

A percentagem de carbono derivado da floresta primaria $\left(C_{f}\right)$ e da pastagem $\left(C_{p}\right)$ foram obtidas através do cálculo de diluição isotópica, eq. (8) e (9). 


$$
\begin{aligned}
& C_{p}=\frac{\delta-\delta_{o}}{\delta_{c}-\delta_{o}} \times 100 \\
& C_{f}=100-C p
\end{aligned}
$$

Onde:

$\delta=\delta^{13} \mathrm{C}$ da amostra de solo sob pastagem;

$\delta_{\mathrm{c}}=$ valor de $\delta^{13} \mathrm{C}$ de planta $\mathrm{C}_{4}(-13 \%)$;

$\delta_{0}=$ valor de $\delta^{13} \mathrm{C}$ do solo sob floresta $\mathrm{C}_{3}\left(-28^{\circ}\right)$.

\subsubsection{Analise dos dados e incertezas}

$\mathrm{Na}$ análise estatística dos dados foi utilizado o software STATISTICA for Windows 5.5 (Statsoft, 1999) para aplicar o teste de comparação de médias Kruskal-Wallis ANOVA para dados não paramétricos. Verificando-se a existência de diferença significativa entre os tratamentos, aplicourse o teste Tukey HSD para amostras desiguais.

Os índices de incerteza apresentados nos gráficos e tabelas representam o desvio padrão das amostras. No caso de valores obtidos em função de duas ou mais variáveis como, estoque e fontes do carbono do solo, saturação de bases e atividade de argila, os erros foram obtidos pelas equações de propagação de erros (Caretta, 1997). No caso multiplicação e/ou divisão aplicou-se a equação (10) e soma a equação (11).

$$
\begin{aligned}
& e_{\alpha=(X \times Y) / Z}=\sqrt{\left(e_{X} / X\right)^{2}+\left(e_{Y} / Y\right)^{2}+\left(e_{Z} / Z\right)^{2}} \times \alpha \\
& e_{\alpha=X+Y}=\sqrt{\left(e_{X}{ }^{2}\right)+\left(e_{Y}{ }^{2}\right)}
\end{aligned}
$$




\section{RESULTADOS E DISCUSSÃO}

\subsection{Estimativa do estoque de carbono dos principais solos do estado do}

Acre

Em torno de $78 \%$ da área do estado do Acre é ocupada por três grandes grupos de solos: Luvissolos (40\%), Cambissolos (24\%) e Argissolos (14\%) (Figura 10, Tabela 3). Estes são os grupos com maior participação no estoque total de carbono dos solos, devido não apenas a grande extensão de área que ocupam, como também pelo conteúdo de carbono que apresentam (Tabela 3).

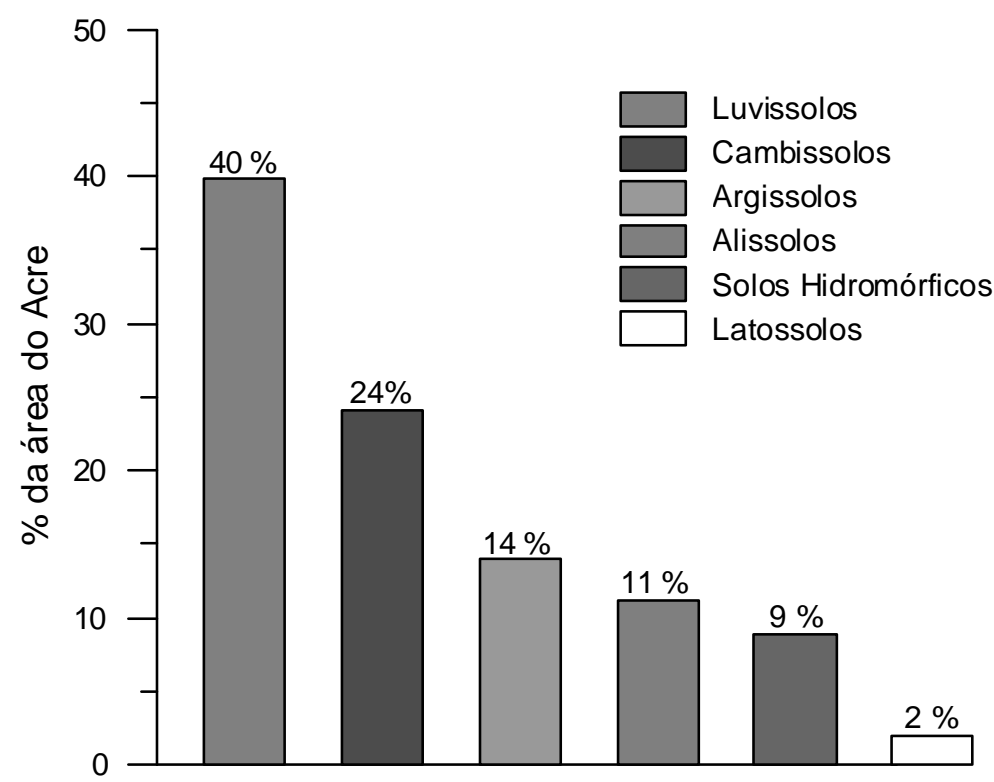

Figura 10 - Distribuição relativa dos 6 principais grupos de solos com base no mapa de solos do Estado Acre na escala 1:1.000.000 (Acre, 2000; Brasil, 1976b, 1977b). Para mais detalhes sobre as sub-classes que integram os grupos de solo apresentados nesta Figura ver Tabela 1

Tabela 3. Estoque de carbono $\left(\mathrm{kg} \mathrm{m}^{2}\right)$ e desvio padrão das classes de solos encontradas no Acre para as profundidades $0-30 \mathrm{~cm}$ e $0-100 \mathrm{~cm}$ 


\begin{tabular}{|c|c|c|c|c|c|}
\hline \multirow[b]{2}{*}{ Classes de solo } & \multicolumn{3}{|c|}{$\mathrm{C}\left(\mathrm{kg} \mathrm{m}^{-2}\right)$} & \multirow{2}{*}{$\begin{array}{c}\text { Grupo } \\
\text { de } \\
\text { Solos }^{£}\end{array}$} & \multirow{2}{*}{$\begin{array}{r}\text { Área }^{*} \\
(\%)\end{array}$} \\
\hline & $N \varnothing$ & $\begin{array}{c}0-30 \\
(\mathrm{~cm})\end{array}$ & $\begin{array}{c}0-100 \\
(\mathrm{~cm})\end{array}$ & & \\
\hline Luvissolos Crômicos & 12 & $4,7 \pm 0,8$ & $7,5 \pm 1,1$ & \multirow{3}{*}{ G1 } & \multirow{4}{*}{40} \\
\hline Luvissolos Hipocrômicos & 12 & $4,4 \pm 1,2$ & $7,1 \pm 1,4$ & & \\
\hline Vertissolos Ebanicos & 1 & $8,6^{\ddagger}$ & $11,3^{*}$ & & \\
\hline Cambissolos Háplicos Ta Eutróficos & 13 & $3,7 \pm 1,0$ & $5,9 \pm 1,6$ & \multirow{4}{*}{ G2 } & \\
\hline Cambissolos Háplicos Ta Distróficos & 6 & $3,4 \pm 0,7$ & $6,9 \pm 1,5$ & & \multirow[t]{3}{*}{24} \\
\hline Cambissolos Háplicos Tb Distróficos & 3 & $4,7 \pm 1,7$ & $6,4 \pm 2,1$ & & \\
\hline Chernossolos Háplicos & 4 & $6,2 \pm 1,6$ & $8,9 \pm 1,4$ & & \\
\hline Argissolos Vermelhos Distróficos & 26 & $3,6 \pm 1,3$ & $6,8 \pm 1,4$ & \multirow{5}{*}{ G3 } & \multirow{5}{*}{14} \\
\hline Argissolos Amarelos Distróficos & 20 & $3,5 \pm 0,6$ & $5,8 \pm 1,3$ & & \\
\hline Argissolos Vermelho-Amarelos Distróficos & 18 & $3,0 \pm 1,2$ & $6,1 \pm 1,9$ & & \\
\hline Nitossolos Háplicos Distróficos & 7 & $4,0 \pm 1,0$ & $5,9 \pm 2.5$ & & \\
\hline Nitossolos Vermelhos Distróficos & 5 & $3,6 \pm 0,7$ & $5,8 \pm 1,0$ & & \\
\hline Alissolos Crômicos & 32 & $3,6 \pm 1,0$ & $6,8 \pm 1,3$ & \multirow{3}{*}{ G4 } & \multirow{3}{*}{11} \\
\hline Alissolos Hipocrômicos & 10 & $3,8 \pm 1,6$ & $7,8 \pm 1,6$ & & \\
\hline Gleissolos Háplicos Ta Eutróficos & 6 & $3,2 \pm 1,4$ & $6,3 \pm 2,1$ & & \\
\hline Gleissolos Háplicos Ta Distróficos & 3 & $5,0 \pm 3,4$ & $7,4 \pm 3,7$ & \multirow{4}{*}{ G5 } & \multirow{4}{*}{9} \\
\hline Neossolos Flúvicos Ta Eutróficos & 8 & $2,8 \pm 0,9$ & $5,2 \pm 1,0$ & & \\
\hline Plintossolos Háplicos Ta Distróficos & 9 & $3,6 \pm 1,0$ & $7,7 \pm 1,4$ & & \\
\hline Plintossolos Argilúvicos Ta Distróficos & 10 & $3,0 \pm 1,0$ & $6,6 \pm 0,8$ & & \\
\hline Latossolos Vermelhos Distróficos & 16 & $3,3 \pm 0,9$ & $5,9 \pm 1,7$ & \multirow{2}{*}{ G6 } & \multirow{2}{*}{2} \\
\hline Latossolos Amarelos Distróficos & 6 & $4,2 \pm 1,2$ & $7,6 \pm 1,3$ & & \\
\hline
\end{tabular}

` N é o número de perfis de solo. ${ }^{\varepsilon}$ Para detalhes sobre os grupos solo ver Tabela 1. ${ }^{¥}$ Distribuição relativa à área total do Estado do Acre. ${ }^{*}$ Valor derivado de um único perfil de solo, sem desvio padrão.

O estoque de carbono de todos os grupos de solos variou entre 2,8 a 8,9 $\mathrm{kg} \mathrm{C} \mathrm{m}{ }^{-2}$ para 0-30 $\mathrm{cm}$ e de 5,2 a $11,3 \mathrm{~kg} \mathrm{C} \mathrm{m}^{-2}$ para 0-100 $\mathrm{cm}$, com média de 4,1 e 6,9 $\mathrm{kg} \mathrm{C} \mathrm{m}^{-2}$ para 0-30 e 0-100 $\mathrm{cm}$, respectivamente (Tabela 3).

Nos três maiores grupos de solo (Luvissolos, Cambissolos e Argissolos) o estoque de carbono variou de 3,0 a $4,7 \mathrm{~kg} \mathrm{C} \mathrm{m}^{-2}$ para 0-30 $\mathrm{cm}$ e 5,8 a $7,5 \mathrm{~kg} \mathrm{C} \mathrm{m}^{-}$ ${ }^{2}$ para 0-100 cm, cuja média foi de 3,8 e 6,6 $\mathrm{kg} \mathrm{C} \mathrm{m}^{-2}$ nas profundidades de 0-30 e 0-100 cm, respectivamente. Estes valores são bem inferiores a outras estimativas feitas para solos da Amazônia, que variaram entre 8 e $11 \mathrm{~kg} \mathrm{C} \mathrm{m}^{-2}$ para 0-100 cm (Tabela 3) (Moraes et al., 1995; Batjes \& Dijkshoorn, 1999).

Com base nas médias dos três maiores grupos de solo, em torno $57 \%$ do estoque de carbono dos solos do Acre concentra-se nos primeiros $30 \mathrm{~cm}$ de profundidade. 
Os Vertissolos apresentaram o maior estoque de carbono $\left(11,3 \mathrm{Kg} \mathrm{C} \mathrm{m}^{-2}\right.$ para 0-100 cm), na base cartográfica de solos na escala 1:1.000.000, esta classe de solos ocupa uma pequena extensão da área do Acre. Entretanto, segundo Amaral (2003), esses solos ocupam uma extensão bem maior do que os encontrados em trabalhos anteriores.

O grupo dos Luvissolos, que ocupa $40 \%$ da área do estado, tem a maior participação no estoque total de carbono $\left(7,3 \mathrm{~kg} \mathrm{C} \mathrm{m}^{-2}\right)$, nos primeiros $100 \mathrm{~cm}$ de profundidade.

De forma geral os solos do Acre apresentam menor estoque de carbono, quando comparado com outras estimativas feitas para solos da região Amazônica (Bohn, 1976; Moraes et al., 1995; Batjes \& Dijkshoorn, 1999) (Tabela 4). Comparando solos eutróficos e distróficos de uma mesma classe pedológica, solos distróficos apresentaram os maiores estoques de carbono. Resultados semelhantes foram observados por Moraes et al. (1995). Esta diferença pode estar associada às características físicas dos solos que podem ser fatores tão importantes quanto a fertilidade para produtividade de plantas, bem como, influenciam na taxa de decomposição da matéria orgânica.

Tabela 4. Estoque de carbono do solo $\left(\mathrm{kg} \mathrm{m}^{-2}\right)$ nos primeiros $100 \mathrm{~cm}$ de profundidade. Comparação entre dados dos solos do Acre e dados da literatura (Bohn, 1976; Moraes et al., 1995; Batjes \& Dijkshoorn, 1999) 


\begin{tabular}{|c|c|c|c|c|}
\hline & Acre $^{\varnothing}$ & $\begin{array}{c}\text { Amazônia } \\
\text { Legal }^{*}\end{array}$ & $\begin{array}{c}\text { Região } \\
\text { Amazônica }^{\#}\end{array}$ & $\begin{array}{l}\text { América } \\
\text { do Sul }{ }^{\varepsilon}\end{array}$ \\
\hline Luvissolos Crômicos & $7,5 \pm 1,1$ & & $8.9+34$ & 4.0 \\
\hline Luvissolos Hipocrômicos & $7,1 \pm 1,4$ & $7,6 \pm 0,4$ & & \\
\hline Vertissolos Ebanicos & 11,3 & 11,3 & & 14,0 \\
\hline Cambissolos Háplicos Ta Eutróficos & $5,9 \pm 1,6$ & $6,8 \pm 1,1$ & & \\
\hline Cambissolos Háplicos Ta Distróficos & $6,9 \pm 1,5$ & $7,7 \pm 0,5$ & $9,5 \pm 46$ & 60,0 \\
\hline Cambissolos Háplicos Tb Distróficos & $6,4 \pm 2,1$ & & & \\
\hline Chernossolos Háplicos & $8,9 \pm 1,4$ & & & 15,0 \\
\hline Argissolos Vermelhos Distróficos & $6,8 \pm 1,4$ & & & \\
\hline Argissolos Amarelos Distróficos & $5,8 \pm 1,3$ & & $8,5 \pm 42$ & 8,0 \\
\hline Argissolos Vermelho-Amarelos Distróficos & $6,1 \pm 1,9$ & $9,5 \pm 0,3$ & & \\
\hline Nitossolos Háplicos Distróficos & $5,9 \pm 2.5$ & & & \\
\hline Nitossolos Vermelhos Distróficos & $5,8 \pm 1,0$ & $15,0 \pm 1,9$ & $11.1 \pm 3$ & \\
\hline Alissolos Crômicos & $6,8 \pm 1,3$ & & & \\
\hline Alissolos Hipocrômicos & $7,8 \pm 1,6$ & & & \\
\hline Gleissolos Háplicos Ta Eutróficos & $6,3 \pm 2,1$ & $7,2 \pm 0,8$ & & \\
\hline Gleissolos Háplicos Ta Distróficos & $7,4 \pm 3,7$ & $12,2 \pm 1,4$ & & \\
\hline Neossolos Flúvicos Ta Eutróficos & $5,2 \pm 1,0$ & $6,8 \pm 0,8$ & $7,5 \pm 46$ & \\
\hline Plintossolos Háplicos Ta Distróficos & $7,7 \pm 1,4$ & & & \\
\hline Plintossolos Argilúvicos Ta Distróficos & $6,6 \pm 0,8$ & $9,4 \pm 0,9$ & $6,1 \pm 4$ & \\
\hline Latossolos Vermelhos Distróficos & $5,9 \pm 1,7$ & $9,3 \pm 0,8$ & $10,2 \pm 40$ & \\
\hline Latossolos Amarelos Distróficos & $6,3 \pm 2,1$ & $8,5 \pm 0,4$ & & 12,0 \\
\hline
\end{tabular}

Solos distróficos apresentam melhores características físicas que solos eutróficos, devido principalmente a maior concentração de óxidos de ferro e alumínio, como produto dos processos intempéricos (Jordan, 1986). Vários trabalhos mencionam a boa fertilidade dos solos encontrados na região do Estado do Acre (Irion, 1984; Sombroek, 1984; Volkoff et al., 1989; Gama et al., 1992; Martins, 1993; Silva, 1999; Dematte, 2000), segundo os mesmos autores em geral estes solos apresentam restrições a drenagem. Estes problemas de drenagem são causados pela estrutura pouco desenvolvida destes solos. Estas características fazem com que haja excesso de água no período chuvoso e falta de água no período seco.

Estes ciclos de seca e umedecimento do solo, comuns na região do Acre, aumentam a mineralização de carbono e nitrogênio (Birch \& Friend, 1961; Sorensen, 1974; Jager \& Bruins, 1975; Seneviratne \& Wild, 1985). Este aumento é atribuído à morte de microorganismos e principalmente ao aumento da 
disponibilidade do carbono orgânico do solo durante o processo de seca e umedecimento (Kieft et al., 1987; Van Gestel et al., 1991). A disponibilidade de carbono orgânico para os microorganismos, resulta do rompimento de microagregados ou poros durante o ciclo de seca e umedecimento (Powlson \& Jenkinson, 1976; Van Gestel et al., 1991), ou da mudança na adsorção de componentes orgânicos (Birch, 1958; 1960).

\subsubsection{Estoque total de carbono dos solos do Acre}

A mediana do estoque de carbono das principais classes de solos encontradas na base cartográfica de solo na escala 1:1.000.000 (Brasil, 1976b; 1977b; Acre, 2000), foi usada para gerar o mapa de estoque de carbono dos primeiros $100 \mathrm{~cm}$ de profundidade dos solos do Estado do Acre (Figura 11). Este mapa apresenta 5 classes de $5 \mathrm{Mg} \mathrm{C}$ ha $^{-1}$ de intervalo, com valor mínimo de 55

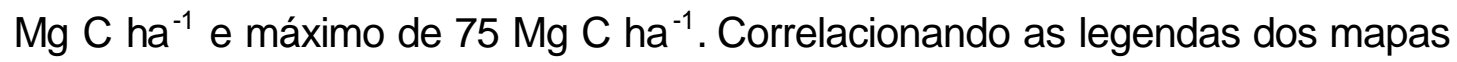
de carbono (Figura 11) e solos (Figura 4) pode se dizer que áreas que têm entre 55-60 Mg C ha ${ }^{-1}$ são cobertas por Cambissolos e Latossolos, $61-65 \mathrm{Mg} \mathrm{C} \mathrm{ha-}^{-1}$ por Solos Heteromórficos, 66-70 Mg C ha ${ }^{-1}$ por Alissolos e Argissolos e $71-75 \mathrm{Mg}$ $\mathrm{C}_{\text {ha }}^{-1}$ por Luvissolos.

O estoque de carbono em todo Estado do Acre foi estimado em $1 \mathrm{Pg} \mathrm{C}$ (0$100 \mathrm{~cm}$ ). Este valor representa 2\% do estimado para a Amazônia legal (47 Pg C) e 1,5\% do estimado para a região amazônica (67 Pg C) (Moraes et al., 1995; Batjes \& Dijkshoorn, 1999). 


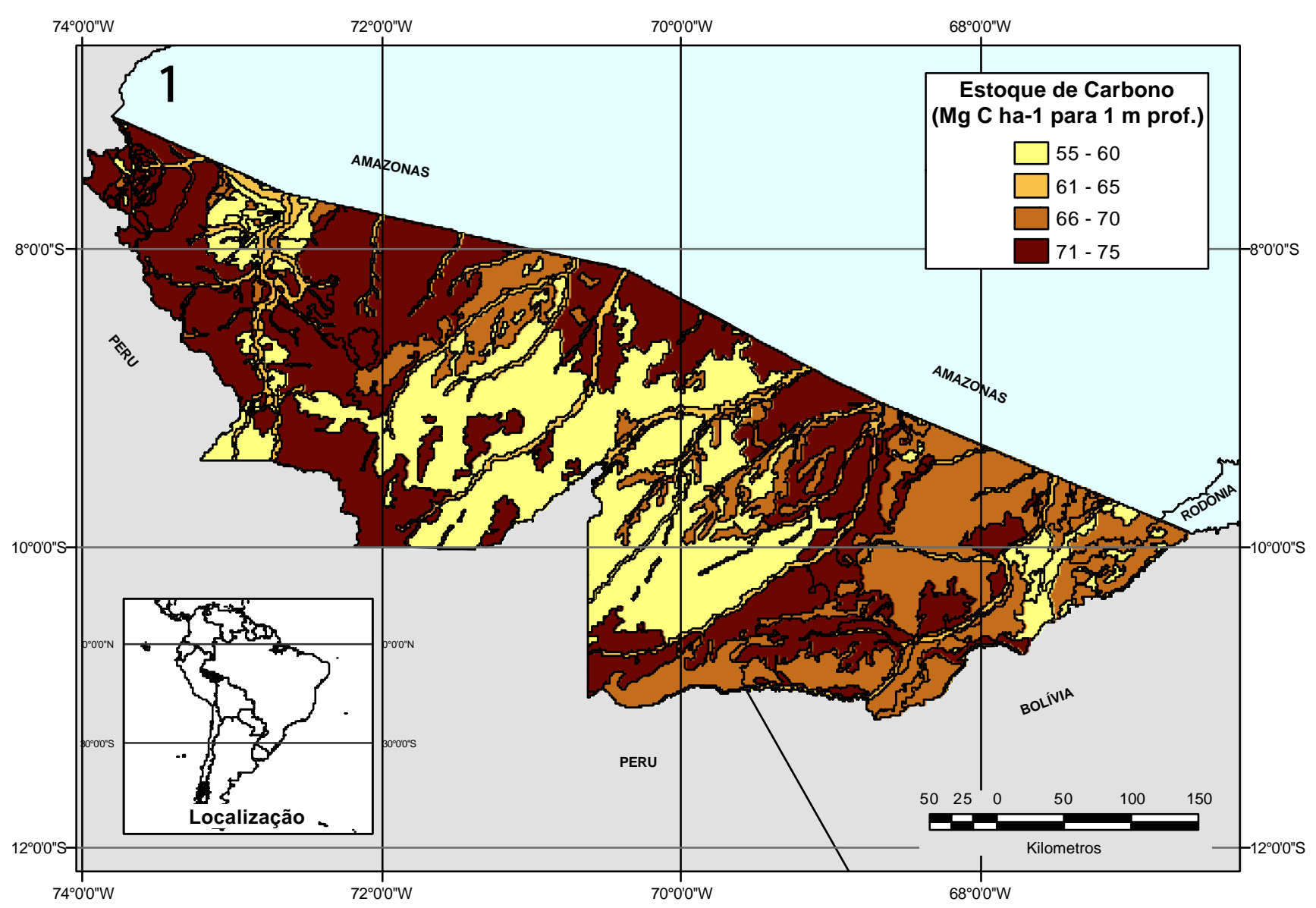

Figura 11 - Mapa de estoque de carbono dos solos do Estado do Acre $\left(\mathrm{Mg} \mathrm{C} \mathrm{ha}^{-1}\right.$ para 0-100 cm) 


\subsubsection{Fontes de incertezas das estimativas}

A primeira fonte de incerteza das estimativas de estoque de carbono é a baixa densidade de amostras para alguns grupos de solos. O Acre, por ser um estado ainda no inicio do estágio de desenvolvimento tem algumas regiões de difícil acesso, contribuindo para uma baixa densidade de dados nestas áreas. A área central do Estado é a região com menor densidade de amostras (Figura 3). Esta é uma área com relevo muito ondulado (Figura 1), onde predomina o grupo dos Cambissolos.

A base de dados analíticos usados neste trabalho não continha informações sobre densidade dos solos, o que obrigou a buscar outras fontes para estimar a densidade. Para estas estimativas foram utilizadas equações multilineares que relacionam teor de argila e carbono com densidade do solo, obtidas a partir de dados de solos representativos da Bacia Amazônica (Bernoux, 1998; Bernoux et al., 1998b). Como já enfatizado, na região do Acre ocorrem solos jovens, pouco intemperizados, muito argilosos e em geral mal drenados. Estas características contribuem para que estes solos apresentem valores mais altos de densidade que os solos predominantes na região amazônica como um todo.

A base cartográfica de solos na escala 1:1.000.000 usada neste trabalho apresenta pouco nível de detalhe. Alguns trabalhos mostram que estimativas de estoque de carbono podem ser sub ou super estimadas dependendo da escala $\mathrm{e}$ legenda do mapa ou base de dados de solos utilizada (Davidson \& Lefebvre, 1993; Batjes, 2000). 
3.2 Estoque e composição isotópica do carbono do solo sob pastagem e floresta primária

Neste item serão apresentados e discutidos os resultados referentes a avaliação do impacto da mudança na cobertura e uso da terra sobre o carbono do solo. Foram avaliadas áreas de floresta e pastagens com duas faixas de idade, $12-15$ e 20 anos. Outra variável considerada foi o tipo de solo, onde foram selecionas florestas e pastagens com Argissolos bem drenados e Luvissolos mal drenados.

A Tabela 5 apresenta médias e desvios padrões para os seguintes parâmetros: $\mathrm{C}$ - teor de carbono (\%), $\mathrm{C}$ - estoque de carbono $\left(\mathrm{Mg} \mathrm{ha}^{-1}\right), \delta^{13} \mathrm{C}-$ delta ${ }^{13} \mathrm{C}$ do solo (\%), Dens. - densidade aparente do solo $\left(\mathrm{mg} \mathrm{cm}^{-3}\right)$ e CP percentagem de carbono do solo proveniente da pastagem (\%).

Estes dados são referentes às áreas: FA, FB, P20A, P20B, P20 P15A e P12A. Para descrição das áreas ver Tabela 2. 
Tabela 5. Código do local de coleta, profundidade de coleta, valores médios e desvios padrões de C - concentração de carbono (\%), C - estoque de carbono $\left(\mathrm{Mg} \mathrm{ha}^{-1}\right), \delta^{13} \mathrm{C}$ - delta ${ }^{13} \mathrm{C}(\%)$, Dens. - densidade aparente do solo $\left(\mathrm{g} \mathrm{cm}^{-3}\right)$ e CP - teor de carbono derivado da pastagem (\%)

\begin{tabular}{|c|c|c|c|c|c|c|}
\hline Local $^{\varnothing}$ & $\begin{array}{l}\text { Prof. } \\
\text { (cm) }\end{array}$ & $\begin{array}{l}C \\
(\%)\end{array}$ & $\begin{array}{c}\mathrm{C} \\
\left(\mathrm{Mg} \mathrm{ha}^{-1}\right)\end{array}$ & $\begin{array}{l}\delta^{13} \mathrm{C} \\
(\%)\end{array}$ & $\begin{array}{l}\text { Dens. } \\
\left(\mathrm{g} \mathrm{cm}^{-3}\right)\end{array}$ & $\begin{array}{l}\mathrm{CP} \\
(\%)\end{array}$ \\
\hline FA & $0-5$ & $3,3 \pm 0,2$ & $18,0 \pm 1,6$ & $-28,0 \pm 0,1$ & $1,1 \pm 0,05$ & - \\
\hline FA & $5-10$ & $0,9 \pm 0,1$ & $5,7 \pm 0,7$ & $-27,2 \pm 0,3$ & $1,2 \pm 0,05$ & - \\
\hline FA & $10-20$ & $0,7 \pm 0,1$ & $8,3 \pm 0,9$ & $-26,4 \pm 0,2$ & $1,2 \pm 0,07$ & - \\
\hline FA & $20-30$ & $0,5 \pm 0,1$ & $7,0 \pm 0,9$ & $-25,7 \pm 0,1$ & $1,3 \pm 0,08$ & - \\
\hline FA & $30-40$ & $0,4 \pm 0,0$ & $6,1 \pm 0,5$ & $-25,6 \pm 0,0$ & $1,4 \pm 0,03$ & - \\
\hline FA & $50-60$ & $0,4 \pm 0,0$ & $6,3 \pm 0,2$ & $-25,4 \pm 0,0$ & $1,5 \pm 0,05$ & - \\
\hline FA & $70-80$ & $0,5 \pm 0,0$ & $6,8 \pm 0,2$ & $-25,2 \pm 0,1$ & $1,4 \pm 0,01$ & - \\
\hline FA & $90-100$ & $0,4 \pm 0,0$ & $5,8 \pm 0,4$ & $-25,3 \pm 0,0$ & $1,4 \pm 0,02$ & - \\
\hline FB & $0-5$ & $3,9 \pm 0,5$ & $21,4 \pm 3,1$ & $-28,6 \pm 0,0$ & $1,1 \pm 0,05$ & - \\
\hline FB & $5-10$ & $0,9 \pm 0,1$ & $6,0 \pm 0,2$ & $-27,4 \pm 0,2$ & $1,4 \pm 0,05$ & - \\
\hline FB & $10-20$ & $0,6 \pm 0,1$ & $8,6 \pm 0,2$ & $-26,6 \pm 0,2$ & $1,4 \pm 0,03$ & - \\
\hline FB & $20-30$ & $0,6 \pm 0,1$ & $8,3 \pm 0,7$ & $-26,3 \pm 0,2$ & $1,5 \pm 0,04$ & - \\
\hline FB & $30-40$ & $0,4 \pm 0,1$ & $6,5 \pm 0,2$ & $-25,8 \pm 0,3$ & $1,5 \pm 0,04$ & - \\
\hline FB & $50-60$ & $0,4 \pm 0,1$ & $6,4 \pm 0,6$ & $-25,6 \pm 0,2$ & $1,6 \pm 0,03$ & - \\
\hline FB & $70-80$ & $0,5 \pm 0,1$ & $7,5 \pm 0,4$ & $-25,4 \pm 0,3$ & $1,5 \pm 0,04$ & - \\
\hline FB & $90-100$ & $0,4 \pm 0,1$ & $5,9 \pm 0,3$ & $-25,2 \pm 0,1$ & $1,4 \pm 0,03$ & - \\
\hline P20A & $0-5$ & $1,3 \pm 0,1$ & $9,8 \pm 0,9$ & $-19,1 \pm 0,3$ & $1,4 \pm 0,03$ & $59,3 \pm 1,9$ \\
\hline P20A & $5-10$ & $0,8 \pm 0,1$ & $6,1 \pm 0,5$ & $-21,1 \pm 0,6$ & $1,5 \pm 0,03$ & $43,1 \pm 4,2$ \\
\hline P20A & $10-20$ & $0,7 \pm 0,1$ & $10,1 \pm 0,9$ & $-22,4 \pm 0,5$ & $1,5 \pm 0,02$ & $29,3 \pm 4,1$ \\
\hline P20A & $20-30$ & $0,6 \pm 0,1$ & $8,8 \pm 0,8$ & $-23,2 \pm 0,7$ & $1,6 \pm 0,02$ & $19,5 \pm 5,3$ \\
\hline P20A & $30-40$ & $0,5 \pm 0,1$ & $7,8 \pm 0,4$ & $-23,3 \pm 0,7$ & $1,5 \pm 0,04$ & $18,0 \pm 5,2$ \\
\hline P20A & $50-60$ & $0,5 \pm 0,1$ & $6,5 \pm 0,3$ & $-24,1 \pm 0,6$ & $1,4 \pm 0,04$ & $10,6 \pm 4,6$ \\
\hline P20A & $70-80$ & $0,4 \pm 0,1$ & $5,3 \pm 0,3$ & $-24,5 \pm 0,4$ & $1,3 \pm 0,03$ & $5,9 \pm 3,1$ \\
\hline P20A & $90-100$ & $0,4 \pm 0,1$ & $4,9 \pm 0,3$ & $-24,5 \pm 0,3$ & $1,3 \pm 0,05$ & $6,8 \pm 2,8$ \\
\hline P20B & $0-5$ & $2,9 \pm 0,3$ & $17,0 \pm 1,9$ & $-22,7 \pm 0,7$ & $1,2 \pm 0,06$ & $37,8 \pm 4,8$ \\
\hline P20B & $5-10$ & $1,4 \pm 0,1$ & $9,1 \pm 1,4$ & $-23,7 \pm 0,5$ & $1,3 \pm 0,06$ & $25,5 \pm 3,3$ \\
\hline P20B & $10-20$ & $0,9 \pm 0,1$ & $13,1 \pm 2,2$ & $-24,2 \pm 0,5$ & $1,4 \pm 0,03$ & $17,5 \pm 4,1$ \\
\hline P20B & $20-30$ & $0,7 \pm 0,2$ & $10,7 \pm 2,7$ & $-24,7 \pm 0,2$ & $1,5 \pm 0,04$ & $12,4 \pm 1,3$ \\
\hline P20B & $30-40$ & $0,7 \pm 0,1$ & $10,6 \pm 1,3$ & $-25,0 \pm 0,2$ & $1,5 \pm 0,05$ & $6,8 \pm 1,7$ \\
\hline P20B & $50-60$ & $0,5 \pm 0,1$ & $7,4 \pm 1,2$ & $-25,6 \pm 0,5$ & $1,4 \pm 0,07$ & $1,5 \pm 0.6$ \\
\hline P20B & $70-80$ & $0,5 \pm 0,1$ & $6,2 \pm 1,8$ & $-26,0 \pm 0,2$ & $1,3 \pm 0,04$ & $0,0 \pm 0,0$ \\
\hline P20B & $90-100$ & $0,5 \pm 0,1$ & $7,1 \pm 2,0$ & $-26,4 \pm 0,1$ & $1,3 \pm 0,04$ & $0,0 \pm 0,0$ \\
\hline P20 & $0-5$ & $1,8 \pm 0,2$ & $12,8 \pm 1,8$ & $-16,0 \pm 0,3$ & $1,4 \pm 0,02$ & $80,3 \pm 1,8$ \\
\hline P20 & $5-10$ & $0,9 \pm 0,3$ & $7,2 \pm 2,4$ & $-18,2 \pm 0,6$ & $1,5 \pm 0,03$ & $63,1 \pm 4,0$ \\
\hline P20 & $10-20$ & $0,6 \pm 0,1$ & $9,4 \pm 2,1$ & $-20,7 \pm 0,8$ & $1,5 \pm 0,03$ & $42,3 \pm 6,0$ \\
\hline P20 & $20-30$ & $0,4 \pm 0,1$ & $6,4 \pm 0,9$ & $-22,3 \pm 0,5$ & $1,5 \pm 0,03$ & $26,4 \pm 3,7$ \\
\hline P20 & $30-40$ & $0,4 \pm 0,0$ & $5,6 \pm 0,6$ & $-23,0 \pm 0,4$ & $1,5 \pm 0,01$ & $20,9 \pm 3,2$ \\
\hline P20 & $50-60$ & $0,4 \pm 0,0$ & $5,0 \pm 0,3$ & $-23,4 \pm 0,3$ & $1,3 \pm 0,03$ & $15,9 \pm 2,1$ \\
\hline P20 & $70-80$ & $0,4 \pm 0,0$ & $4,9 \pm 0,5$ & $-23,8 \pm 0,2$ & $1,3 \pm 0,06$ & $11,5 \pm 1,7$ \\
\hline P20 & $90-100$ & $0,3 \pm 0,0$ & $3,6 \pm 0,4$ & $-24,2 \pm 0,5$ & $1,3 \pm 0,05$ & $9,1 \pm 4,3$ \\
\hline P15A & $0-5$ & $1,7 \pm 0,1$ & $11,0 \pm 0,7$ & $-19,0 \pm 0,2$ & $1,3 \pm 0,03$ & $60,3 \pm 1,4$ \\
\hline P15A & $5-10$ & $1,2 \pm 0,1$ & $8,9 \pm 0,6$ & $-20,2 \pm 0,5$ & $1,5 \pm 0,04$ & $49,4 \pm 3,8$ \\
\hline P15A & $10-20$ & $0,9 \pm 0,2$ & $14,7 \pm 2,9$ & $-21,5 \pm 0,5$ & $1,6 \pm 0,04$ & $36,1 \pm 3,7$ \\
\hline P15A & $20-30$ & $0,6 \pm 0,0$ & $9,5 \pm 0,6$ & $-23,2 \pm 0,3$ & $1,6 \pm 0,04$ & $19,9 \pm 2,5$ \\
\hline
\end{tabular}


Tabela 5. Código do local de coleta, profundidade de coleta, valores médios e desvios padrões de $\mathrm{C}$ - concentração de carbono (\%), C - estoque de carbono $\left(\mathrm{Mg} \mathrm{ha}{ }^{-1}\right), \delta^{13} \mathrm{C}$ - delta ${ }^{13} \mathrm{C}(\% \circ)$, Dens. - densidade aparente do solo $\left(\mathrm{g} \mathrm{cm}^{-3}\right)$ e CP - teor de carbono derivado da pastagem (\%)

\begin{tabular}{lcccccc}
\hline P15A & $30-40$ & $0,5 \pm 0,0$ & $7,9 \pm 0,3$ & $-23,8 \pm 0,2$ & $1,7 \pm 0,05$ & $14,4 \pm 1,8$ \\
$\mathrm{P} 15 \mathrm{~A}$ & $50-60$ & $0,4 \pm 0,0$ & $6,8 \pm 0,4$ & $-23,9 \pm 0,2$ & $1,7 \pm 0,03$ & $12,2 \pm 1,3$ \\
$\mathrm{P} 15 \mathrm{~A}$ & $70-80$ & $0,4 \pm 0,0$ & $6,1 \pm 0,6$ & $-23,9 \pm 0,3$ & $1,7 \pm 0,03$ & $10,8 \pm 2,2$ \\
$\mathrm{P} 15 \mathrm{~A}$ & $90-100$ & $0,3 \pm 0,0$ & $4,6 \pm 0,2$ & $-24,0 \pm 0,4$ & $1,5 \pm 0,01$ & $10,6 \pm 3,2$ \\
$\mathrm{P} 12 \mathrm{~B}$ & $0-5$ & $4,7 \pm 0,3$ & $26,3 \pm 1,6$ & $-17,5 \pm 0,3$ & $1,1 \pm 0,02$ & $71,3 \pm 1,9$ \\
$\mathrm{P} 12 \mathrm{~B}$ & $5-10$ & $1,6 \pm 0,2$ & $10,2 \pm 1,0$ & $-23,3 \pm 0,9$ & $1,3 \pm 0,02$ & $28,5 \pm 6,1$ \\
$\mathrm{P} 12 \mathrm{~B}$ & $10-20$ & $1,0 \pm 0,1$ & $13,2 \pm 1,0$ & $-24,0 \pm 0,4$ & $1,3 \pm 0,02$ & $19,1 \pm 2,7$ \\
$\mathrm{P} 12 \mathrm{~B}$ & $20-30$ & $0,9 \pm 0,2$ & $12,0 \pm 2,2$ & $-24,9 \pm 0,4$ & $1,3 \pm 0,04$ & $10,9 \pm 2,7$ \\
$\mathrm{P} 12 \mathrm{~B}$ & $30-40$ & $0,8 \pm 0,1$ & $11,1 \pm 0,7$ & $-25,5 \pm 0,6$ & $1,3 \pm 0,02$ & $2,7 \pm 4,3$ \\
$\mathrm{P} 12 \mathrm{~B}$ & $50-60$ & $0,6 \pm 0,1$ & $7,3 \pm 1,5$ & $-25,8 \pm 0,6$ & $1,3 \pm 0,01$ & $0,0 \pm 0,0$ \\
$\mathrm{P} 12 \mathrm{~B}$ & $70-80$ & $0,3 \pm 0,1$ & $4,3 \pm 0,8$ & $-26,1 \pm 0,5$ & $1,2 \pm 0,04$ & $0,0 \pm 0,0$ \\
$\mathrm{P} 12 \mathrm{~B}$ & $90-100$ & $0,2 \pm 0,0$ & $2,8 \pm 0,5$ & $-27,3 \pm 0,5$ & $1,3 \pm 0,05$ & $0,0 \pm 0,0$ \\
No código que identifica as áreas de estudo "F" representa floresta, "P" \\
pastagem, "A" área sobre Argissolo (bem drenado), "B" área sobre Luvissolo (mal \\
drenado), o número indica a idade da pastagem. A área P20 é uma pastagem sobre \\
Latossolo.
\end{tabular}

\subsubsection{Características físicas dos solos}

\subsubsection{Composição granulométrica}

De forma geral, os solos das áreas de estudo apresentaram textura argilosa ou muito argilosa (Tabela 6, Figura 12).

Comparando as duas condições de solos estudadas, observa-se que as áreas de Luvissolos (mal drenados), apresentaram textura argilosa em superfície $(0-30 \mathrm{~cm})$ e muito argilosa em profundidade $(50-100 \mathrm{~cm})$ (Figura 12). Os teores de silte são bastante elevados, semelhante aos encontrados por Silva (1999) e Salimon (2003).

Já as áreas de Argissolos (bem drenados), apresentaram textura média a argilosa na porção superior $(0-5 \mathrm{~cm})$ e argilosa em profundidade $(50-60 \mathrm{~cm})$ (Figura 12). 
Tabela 6. Composição granulométrica dos solos das áreas de estudo (FA, FB, P20A, P20B, P20, P15A e P12B). Valores (\%) são médias de duas amostras e o erro representa o desvio padrão

\begin{tabular}{|c|c|c|c|c|}
\hline Local $^{\#}$ & Profundidade & $\begin{array}{c}\text { Areia Total } \\
(\%)\end{array}$ & $\begin{array}{l}\text { Silte } \\
(\%)\end{array}$ & $\begin{array}{l}\text { Argila } \\
(\%)\end{array}$ \\
\hline FA & $0-5$ & $49,5 \pm 0,7$ & $20,5 \pm 3,5$ & $30,0 \pm 2,8$ \\
\hline FA & $5-10$ & $49,5 \pm 2,1$ & $24,5 \pm 4,9$ & $26,0 \pm 2,8$ \\
\hline $\mathrm{FA}$ & $10-20$ & $50,0 \pm 0,4$ & $20,5 \pm 0,7$ & $29,5 \pm 0,7$ \\
\hline $\mathrm{FA}$ & $20-30$ & $45,5 \pm 0,7$ & $17,5 \pm 3,5$ & $37,0 \pm 4,2$ \\
\hline $\mathrm{FA}$ & $50-60$ & $33,5 \pm 2,1$ & $20,5 \pm 0,7$ & $46,0 \pm 1,4$ \\
\hline FA & $90-100$ & $27,0 \pm 2,8$ & $19,0 \pm 1,4$ & $54,0 \pm 1,4$ \\
\hline FB & $0-5$ & $26,5 \pm 0,7$ & $43,5 \pm 0,7$ & $30,0 \pm 1,4$ \\
\hline FB & $5-10$ & $26,0 \pm 1,4$ & $40,5 \pm 0,7$ & $33,5 \pm 0,7$ \\
\hline FB & $10-20$ & $21,0 \pm 1,4$ & $39,0 \pm 0,0$ & $40,0 \pm 1,4$ \\
\hline FB & $20-30$ & $24,0 \pm 5,7$ & $33,0 \pm 2,8$ & $43.0 \pm 2,8$ \\
\hline $\mathrm{FB}$ & $50-60$ & $19,5 \pm 0,7$ & $32,5 \pm 0,7$ & $48,0 \pm 1,4$ \\
\hline FB & $90-100$ & $9,5 \pm 4,9$ & $21,0 \pm 5,7$ & $69.5 \pm 10,6$ \\
\hline P20A & $0-5$ & $71,0 \pm 1,4$ & $13,0 \pm 1,4$ & $16,0 \pm 0,0$ \\
\hline P20A & $5-10$ & $69,0 \pm 4,2$ & $14,0 \pm 2,8$ & $17,0 \pm 1,4$ \\
\hline P2OA & $10-20$ & $63,0 \pm 1,4$ & $16,0 \pm 0,0$ & $21,0 \pm 1,4$ \\
\hline P20A & $20-30$ & $59,0 \pm 1,4$ & $17,0 \pm 1,4$ & $24,0 \pm 0,0$ \\
\hline P20A & $50-60$ & $50,0 \pm 5,7$ & $15,0 \pm 1,4$ & $35,0 \pm 4,2$ \\
\hline P20A & $90-100$ & $39,0 \pm 7,1$ & $13,0 \pm 1,4$ & $48,0 \pm 5,7$ \\
\hline P20B & $0-5$ & $13,5 \pm 3,5$ & $42,0 \pm 4,2$ & $44,5 \pm 0,7$ \\
\hline P20B & $5-10$ & $12,5 \pm 0,7$ & $37,0 \pm 0,0$ & $50,5 \pm 0,7$ \\
\hline P20B & $10-20$ & $8,5 \pm 0,7$ & $38,0 \pm 1,4$ & $53,5 \pm 2,1$ \\
\hline P20B & $20-30$ & $8,0 \pm 0,0$ & $32,0 \pm 1,4$ & $60,0 \pm 1,4$ \\
\hline P20B & $50-60$ & $7,5 \pm 3,5$ & $21,5 \pm 3,5$ & $71,0 \pm 0,0$ \\
\hline P20B & $90-100$ & $3,5 \pm 0,7$ & $17,0 \pm 0,0$ & $79,5 \pm 0,7$ \\
\hline P20 & $0-5$ & $55,0 \pm 1,4$ & $14,0 \pm 2,8$ & $28,0 \pm 0,0$ \\
\hline P20 & $5-10$ & $51,0 \pm 1,4$ & $16,0 \pm 0,0$ & $33,0 \pm 1,4$ \\
\hline P20 & $10-20$ & $49,5 \pm 3,5$ & $15,0 \pm 1,4$ & $35,5 \pm 2,1$ \\
\hline P20 & $20-30$ & $39,5 \pm 0,7$ & $14,5 \pm 0,7$ & $45,0 \pm 1,4$ \\
\hline P20 & $50-60$ & $40,5 \pm 0,7$ & $12,5 \pm 0,7$ & $46,0 \pm 0,0$ \\
\hline P20 & $90-100$ & $36,0 \pm 2,8$ & $15,0 \pm 4,2$ & $52,0 \pm 2,8$ \\
\hline P15A & $0-5$ & $50,5 \pm 0,7$ & $17,0 \pm 1,4$ & $32,5 \pm 0,7$ \\
\hline P15A & $5-10$ & $47,0 \pm 1,4$ & $15,0 \pm 1,4$ & $38,0 \pm 0,0$ \\
\hline P15A & $10-20$ & $40,5 \pm 2,1$ & $15,5 \pm 0,7$ & $44,0 \pm 2,8$ \\
\hline P15A & $20-30$ & $38,0 \pm 1,4$ & $16,0 \pm 1,4$ & $46,0 \pm 2,8$ \\
\hline P15A & $50-60$ & $38,0 \pm 4,2$ & $12,0 \pm 2,8$ & $50,0 \pm 7,1$ \\
\hline P15A & $90-100$ & $34,0 \pm 9,9$ & $9,0 \pm 4,2$ & $57,0 \pm 14,1$ \\
\hline P12B & $0-5$ & $11,5 \pm 0,7$ & $41,5 \pm 0,7$ & $46,5 \pm 0,7$ \\
\hline P12B & $5-10$ & $7,0 \pm 1,4$ & $40,0 \pm 0,0$ & $53,0 \pm 1,4$ \\
\hline P12B & $10-20$ & $4,0 \pm 0,0$ & $28,0 \pm 1,4$ & $68,0 \pm 1,4$ \\
\hline P12B & $20-30$ & $3,3 \pm 0,4$ & $12,0 \pm 1,4$ & $85,0 \pm 1,4$ \\
\hline P12B & $50-60$ & $2,0 \pm 0,0$ & $18,5 \pm 4,9$ & $79,5 \pm 4,9$ \\
\hline P12B & $90-100$ & $7,0 \pm 0,0$ & $21,0 \pm 5,7$ & $72,0 \pm 5,7$ \\
\hline
\end{tabular}

\# No código que identifica as áreas de estudo "F" representa floresta, "P" pastagem, "A" área sobre Argissolo (bem drenado), "B" área sobre Luvissolo (mal drenado), o número indica a idade da pastagem. A área P20 é uma pastagem sobre Latossolo. 

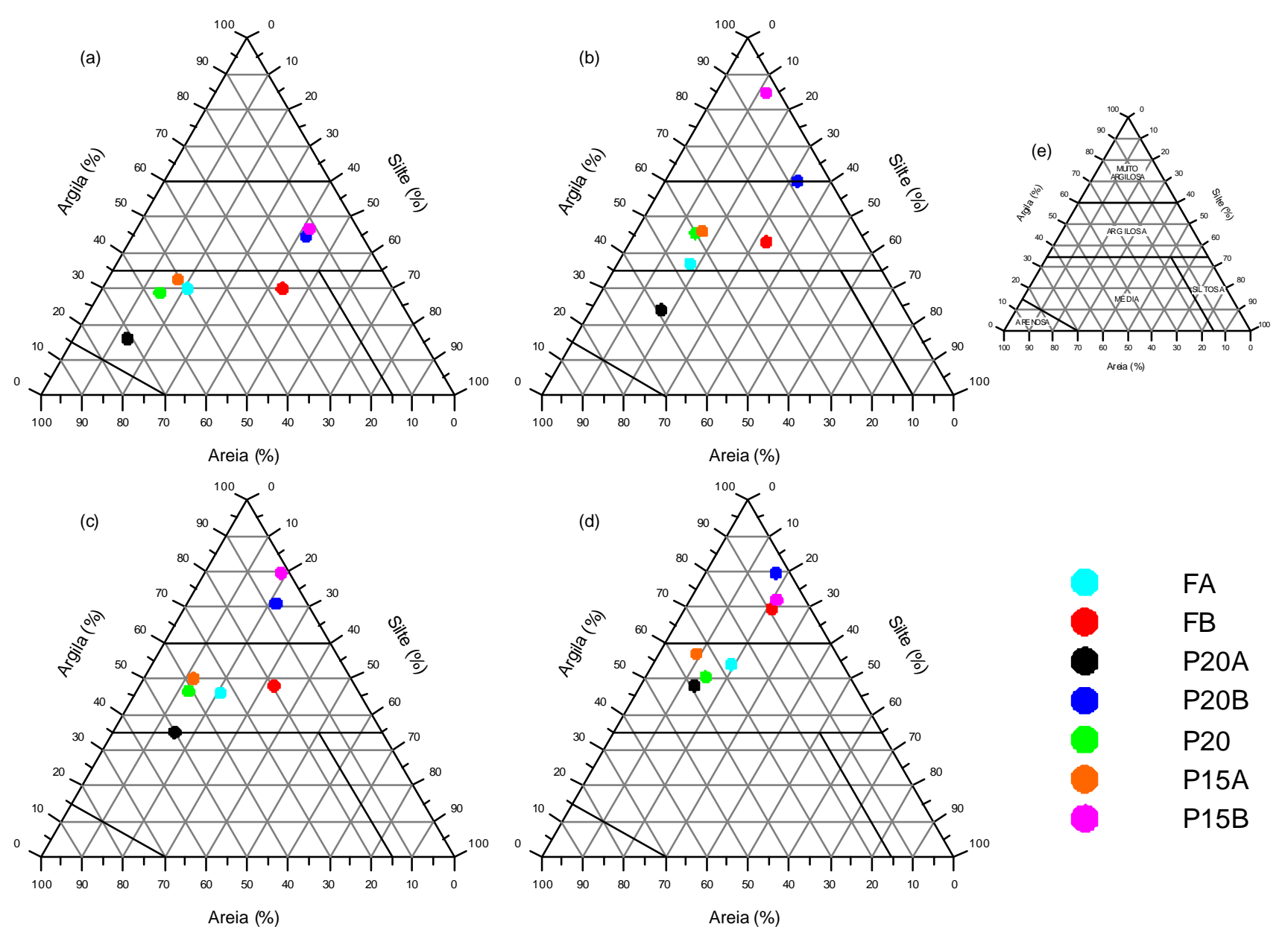

Figura 12 - Composição granulométrica dos solos das áreas de estudo. Percentagem de areia, silte e argila nas profundidades de $0-5 \mathrm{~cm}$ gráfico (a), $20-30 \mathrm{~cm}$ gráfico (b), $50-60 \mathrm{~cm}$ gráfico (c) e $90-100 \mathrm{~cm}$ gráfico (d). 0 gráfico (e) mostra a divisão dos grupos texturais segundo EMBRAPA (1999). Detalhes sobre as áreas de estudo ver Tabela 2 


\subsubsection{Densidade aparente}

A densidade do solo tende a valores mais elevados em profundidade em todas as áreas de estudo. Os valores mais altos concentraram-se entre 10 e 60 $\mathrm{cm}$ de profundidade, com uma tendência decrescente de 60 a $100 \mathrm{~cm}$.

Nas áreas de floresta a densidade variou de entre 1,1 na superfície do solo e $1,5 \mathrm{~g} \mathrm{~cm}^{-3}$ em profundidade. Nas pastagens mais velhas, sobre tudo naquelas sobre solo bem drenado (P20A, P20), fica evidente o efeito de retirada da floresta sobre os valores de densidade. Estas áreas apresentam média de $1,3 \mathrm{~g} \mathrm{~cm}^{-3}$ na superfície solo (Tabela 6, Figura 13). Outros autores encontraram valores semelhantes (Moraes, 1991; Cerri et al., 1992; Neill et al., 1996; Camargo, 1997).

Este efeito pode ser atribuído principalmente ao pastejo intensivo de gado e também exposição mais intensa do solo à ação das chuvas, devido à baixa proteção da cobertura vegetal. Outro fator que contribui é a erosão superficial que ocorre com a retirada da floresta, ocasionando a perda dos primeiros centímetros do perfil do solo, geralmente mais estruturados e com maior porosidade.

Algumas áreas apresentaram valores altos de densidade, semelhantes aos encontrados por Cerri et al. (1992) e Salimon (2003), e maiores do que os valores de (Moraes (1991), Moraes et al. (1996) e Camargo (1997).

Dois podem ser os principais fatores responsáveis por estes resultados. primeiro, é a ocorrência de concreções de ferro que apresentam densidade média de 2,4 $\mathrm{g} \mathrm{cm}^{-3}$ (Singh \& Gilkes, 1996), principalmente entre 20 e $60 \mathrm{~cm}$ de profundidade. A área P15A apresentou grande densidade destas concreções tendo influência direta sobre os valores de densidade aparente do solo, que variaram entre $1,3 \mathrm{em}$ superfície e $1,7 \mathrm{~g} \mathrm{~cm}^{-3}$ aos $60 \mathrm{~cm}$ de profundidade. As áreas que não apresentaram concreções tiveram valores menores, como é caso 
da área $\mathrm{P} 12 \mathrm{~A}$, que teve valor mínimo de 1,1 e máximo de $1,3 \mathrm{~g} \mathrm{~cm}^{-3}$ ao logo do perfil do solo (Tabela 5, Figura 13).

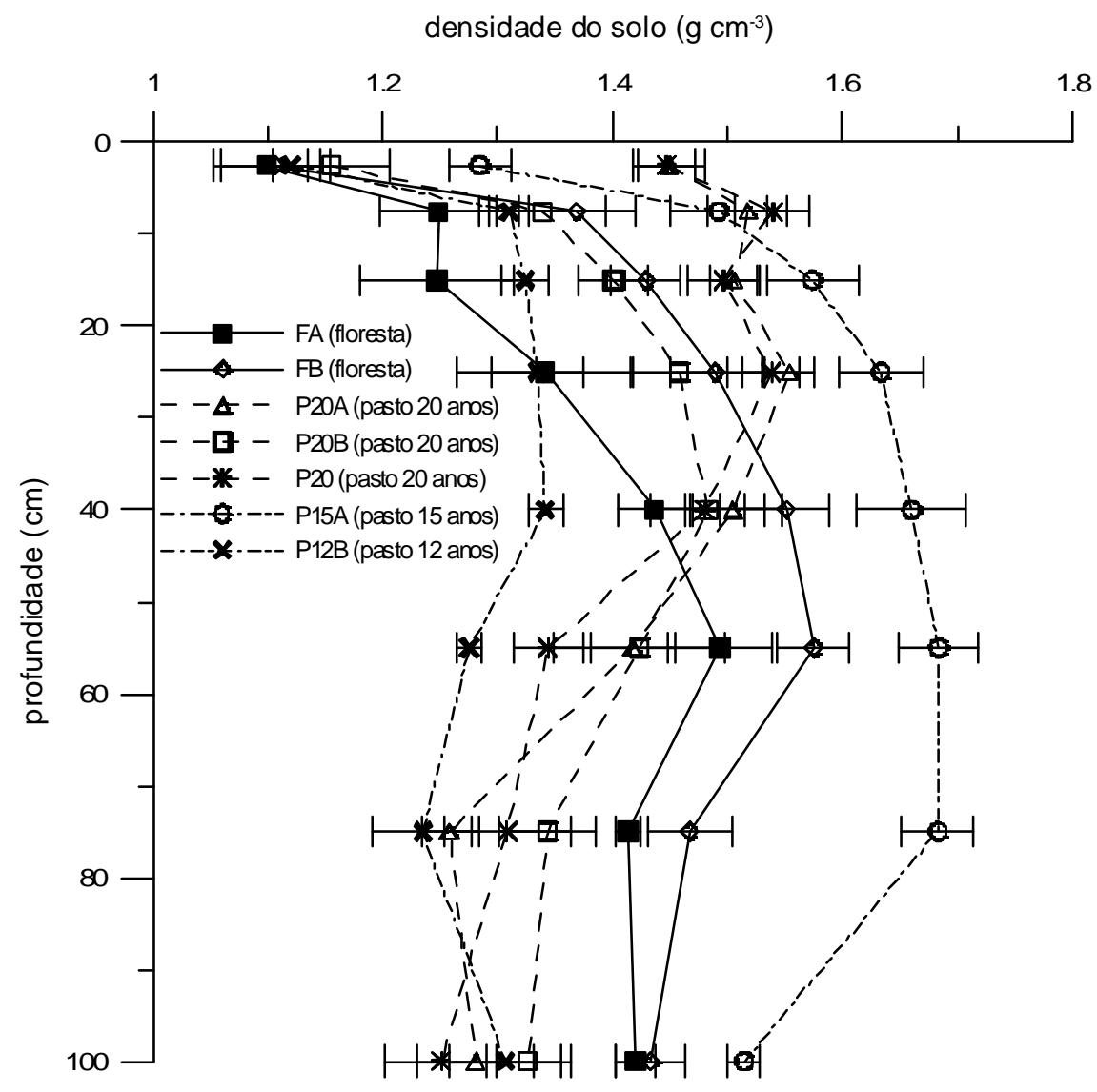

Figura 13 - Valores médios e desvios padrões da densidade do solo $\left(\mathrm{g} \mathrm{m}^{-3}\right)$

O segundo é o fato dos solos da região serem jovens, em termos pedológicos. Neste caso a estrutura é pouco desenvolvida e a densidade naturalmente elevada. Outro agravante é a alta susceptibilidade a erosão devido à baixa permeabilidade e tendência de escorrimento superficial das águas pluviais. Estas características tornam estes solos muito sensíveis à mudança no uso e cobertura da terra. 


\subsubsection{Características químicas dos solos}

Todos os valores dos elementos químicos avaliados encontram-se na Tabela 7.

Os valores médios de $\mathrm{pH}\left(\mathrm{CaCl}_{2}\right)$ variaram entre 3,5 e 6,0. Na superfícies do solo $(0-10 \mathrm{~cm})$ variou entre 4,0 e 6,0. Estes valores são superiores aos de Salimon (2003), que foram de 3,2 a 5,5 (0-10cm) em áreas de floresta, capoeira e pastagem do leste do Estado do Acre. As áreas sobre Argissolos apresentaram um $\mathrm{pH}$ mais ácido que as sobre Luvissolos, principalmente entre 0 e $10 \mathrm{~cm}$ de profundidade.

Analisando a saturação de bases trocáveis das áreas é possível dividi-las em dois grupos diferentes ( $p<0,05$; Figura 14a), que coincide com os tipos de solos estudados. Este fato é mais evidente na superfície do solo.

Nos valores de cálcio esta diferença é significativa ( $p<0,05$; Figura 14b), mostrando ser este o elemento que mais contribui para a saturação de bases trocáveis, seguido por magnésio. Estes valores altos de cálcio nas áreas de Luvissolos comprovam o caráter jovem destes solos, mostrando alta relação com os sedimentos sobre os quais se desenvolveram, em geral ricos em minerais de gipsita (sulfato de cálcio) (Kronberg et al., 1991; Kronberg \& Benchimol, 1993).

Outro índice que evidencia o baixo grau de intemperismo do Luvissolos é a atividade de argila (Tabela 7). Este índice refere-se a capacidade de troca de cátions correspondente à fração argila. Atividade alta $(\mathrm{Ta})$, designa valor igual ou superior a $27 \mathrm{cmol}_{\mathrm{c}} \mathrm{Kg}^{-1}$ de argila e atividade baixa (Tb), valor inferior a esse, sem correção para carbono (Embrapa, 1999). Com exceção da floresta $F A$, as áreas sobre Luvissolos apresentaram valores superiores a $27 \mathrm{cmol}_{\mathrm{C}} \mathrm{Kg}^{-1}$ entre 20 e 60 $\mathrm{cm}$ de profundidade. 
Tabela 7. Análise química dos solos das áreas de estudo (FA, FB, P20A, P20B, P20, P15A e P12B). Valores são médias de duas amostras, o erro é representado pelo desvio padrão

\begin{tabular}{|c|c|c|c|c|c|c|c|c|c|c|c|c|}
\hline \multirow{2}{*}{ Local" } & \multirow{2}{*}{$\begin{array}{l}\text { Prof. } \\
\text { (cm) }\end{array}$} & \multirow{2}{*}{$\begin{array}{c}\mathrm{pH} \\
\left(\mathrm{CaCl}_{2}\right)\end{array}$} & \multirow{2}{*}{$\begin{array}{c}\mathrm{MO} \\
\left(\mathrm{g} \mathrm{dm}^{-3}\right)\end{array}$} & $\mathrm{Ca}^{++}$ & $\mathrm{Mg}^{++}$ & $\mathrm{K}^{+}$ & $\mathrm{Al}^{+++}+\mathrm{H}^{+}$ & SB & $\mathrm{T}$ & $\mathrm{V}$ & \multirow{2}{*}{$\begin{array}{c}P \\
\left(\mathrm{mg} \mathrm{dm}^{-3}\right)\end{array}$} & \multirow{2}{*}{ At. Arg. } \\
\hline & & & & \multicolumn{6}{|c|}{$\mu \mathrm{mol}_{\mathrm{c}} \mathrm{dm}^{-3}$} & $(\%)$ & & \\
\hline FA & $0-5$ & 5,1 & 61,0 & 69,0 & 20,5 & 2,9 & 22,5 & 92,4 & 114,9 & 80,4 & 21,5 & 38,7 \\
\hline FA & $5-10$ & 4,0 & 18,5 & 11,0 & 7,0 & 2,3 & 30,5 & 20,3 & 50,8 & 39,9 & 5,5 & 19,6 \\
\hline FA & $10-20$ & 3,6 & 14,0 & 3,5 & 5,5 & 2,1 & 46,5 & 11,1 & 57,6 & 19,2 & 2,0 & 19,5 \\
\hline FA & $20-30$ & 3,7 & 13,3 & 2,0 & 3,3 & 1,7 & 68,5 & 6,9 & 75,4 & 9,1 & 2,0 & 20,4 \\
\hline $\mathrm{FA}$ & $50-60$ & 3,7 & 8,0 & 2,0 & 1,8 & 1,6 & 77,0 & 5,3 & 82,3 & 6,4 & 1,0 & 17,9 \\
\hline FB & $0-5$ & 5,1 & 67,0 & 129,5 & 22,5 & 2,4 & 20,5 & 154,4 & 174,9 & 88,3 & 20,0 & 58,3 \\
\hline FB & $5-10$ & 4,0 & 19,0 & 92,0 & 19,5 & 1,7 & 34,0 & 113,2 & 147,2 & 76,9 & 5,0 & 43,9 \\
\hline FB & $10-20$ & 3,6 & 14,5 & 49,0 & 16,0 & 1,4 & 42,5 & 66,4 & 108,9 & 61,0 & 2,0 & 27,2 \\
\hline FB & $20-30$ & 3,7 & 13,5 & 23,5 & 10,5 & 2,3 & 67,5 & 36,3 & 103,8 & 34,9 & 2,5 & 24,1 \\
\hline FB & $50-60$ & 3,7 & 9,0 & 8,5 & 5,5 & 1,6 & 73,5 & 15,6 & 89,1 & 17,5 & 1,5 & 18,6 \\
\hline P20A & $0-5$ & 4,5 & 36,0 & 12,0 & 5,5 & 2,0 & 31,0 & 19,5 & 50,5 & 38,6 & 7,5 & 31,6 \\
\hline P20A & $5-10$ & 4,6 & 26,0 & 9,5 & 2,5 & 1,5 & 25,0 & 13,5 & 38,5 & 35,0 & 5,0 & 22,6 \\
\hline P20A & $10-20$ & 4,6 & 19,5 & 8,0 & 2,5 & 1,2 & 22,5 & 11,7 & 34,2 & 34,1 & 2,0 & 16,3 \\
\hline P20A & $20-30$ & 4,4 & 15,0 & 4,0 & 3,5 & 0,7 & 21,0 & 8,2 & 29,2 & 28,1 & 1,0 & 12,2 \\
\hline P20A & $50-60$ & 3,9 & 9,5 & 1,0 & 1,5 & 0,1 & 43,0 & 2,6 & 45,6 & 5,7 & 1,0 & 13,0 \\
\hline P20B & $0-5$ & 6,0 & 52,0 & 88,5 & 20,5 & 2,0 & 41,0 & 111,0 & 152,0 & 73,0 & 73,0 & 34,1 \\
\hline P20B & $5-10$ & 5,7 & 27,0 & 77,5 & 22,0 & 2,2 & 28,0 & 101,7 & 129,7 & 78,4 & 21,5 & 25,7 \\
\hline P20B & $10-20$ & 5,6 & 17,0 & 45,5 & 21,5 & 3,1 & 54,0 & 70,1 & 124,1 & 56,5 & 8,0 & 23,2 \\
\hline P20B & $20-30$ & 5,1 & 16,0 & 30,0 & 22,5 & 3,4 & 118,0 & 55,9 & 173,9 & 32,1 & 4,5 & 29,0 \\
\hline P20B & $50-60$ & 4,1 & 11,5 & 21,5 & 18,5 & 5,2 & 313,5 & 45,2 & 358,7 & 12,6 & 3,0 & 50,5 \\
\hline P20 & $0-5$ & 4,5 & 33,0 & 29,0 & 7,5 & 1,6 & 25,0 & 38,1 & 63,1 & 60,4 & 1,5 & 22,5 \\
\hline P20 & $5-10$ & 4,7 & 27,5 & 26,0 & 6,5 & 0,7 & 34,5 & 33,2 & 67,7 & 49,0 & 2,5 & 20,5 \\
\hline P20 & $10-20$ & 4,2 & 18,0 & 16,0 & 3,5 & 0,2 & 32,0 & 19,7 & 51,7 & 38,0 & 1,5 & 14,5 \\
\hline P20 & $20-30$ & 3,8 & 14,0 & 2,0 & 2,0 & 0,7 & 46,0 & 4,7 & 50,7 & 9,2 & 1,0 & 11,3 \\
\hline P20 & $50-60$ & 3,7 & 11,0 & 1,5 & 1,5 & 0,1 & 53,5 & 3,1 & 56,6 & 5,5 & 1,0 & 12,3 \\
\hline P15A & $0-5$ & 3,9 & 29,5 & 11,0 & 7,0 & 3,6 & 52,5 & 21,6 & 74,1 & 29,1 & 4,0 & 22,8 \\
\hline P15A & $5-10$ & 3,7 & 19,0 & 4,5 & 1,0 & 1,9 & 44,5 & 7,4 & 51,9 & 14,3 & 2,5 & 13,7 \\
\hline P15A & $10-20$ & 3,7 & 16,5 & 1,5 & 1,0 & 1,0 & 58,0 & 3,5 & 61,5 & 5,6 & 1,5 & 14,0 \\
\hline P15A & $20-30$ & 3,6 & 16,0 & 1,0 & 1,0 & 0,7 & 61,0 & 2,7 & 63,7 & 4,2 & 2,0 & 13,8 \\
\hline P15A & $50-60$ & 3,7 & 11,0 & 1,0 & 1,0 & 0,3 & 68,0 & 2,3 & 70,3 & 3,2 & 1,0 & 14,1 \\
\hline
\end{tabular}


Tabela 7. Análise química dos solos das áreas de estudo (FA, FB, P20A, P20B, P20, P15A e P12B). Valores são médias de duas amostras, o erro é representado pelo desvio padrão

\begin{tabular}{|c|c|c|c|c|c|c|c|c|c|c|c|c|}
\hline \multirow{2}{*}{ Local $^{\#}$} & \multirow{2}{*}{$\begin{array}{l}\text { Prof. } \\
(\mathrm{cm})\end{array}$} & \multirow{2}{*}{$\begin{array}{c}\mathrm{pH} \\
\left(\mathrm{CaCl}_{2}\right)\end{array}$} & \multirow{2}{*}{$\begin{array}{c}\mathrm{MO} \\
\left(\mathrm{g} \mathrm{dm}^{-3}\right)\end{array}$} & $\mathrm{Ca}^{++}$ & $\mathrm{Mg}^{++}$ & $\mathrm{K}^{+}$ & $\mathrm{Al}^{+++}+\mathrm{H}^{+}$ & SB & $\mathrm{T}$ & $\mathrm{V}$ & \multirow{2}{*}{$\begin{array}{c}\mathrm{P} \\
\left(\mathrm{mg} \mathrm{dm}^{-3}\right)\end{array}$} & \multirow{2}{*}{ At. Arg. } \\
\hline & & & & \multicolumn{6}{|c|}{$\mu \mathrm{mol}_{\mathrm{c}} \mathrm{dm}^{-3}$} & $(\%)$ & & \\
\hline P12B & $0-5$ & 5,3 & 90,5 & 137,5 & 27,5 & 2,4 & 28,0 & 167,4 & 195,4 & 85,7 & 46,0 & 42,0 \\
\hline P12B & $5-10$ & 5,5 & 34,0 & 104,5 & 21,5 & 2,4 & 23,5 & 128,4 & 151,9 & 84,5 & 12,5 & 28,7 \\
\hline P12B & $10-20$ & 4,8 & 19,0 & 62,5 & 19,5 & 2,6 & 52,5 & 84,6 & 137,1 & 73,8 & 4,5 & 16,9 \\
\hline P12B & $20-30$ & 4,0 & 21,0 & 30,5 & 12,5 & 3,7 & 267,0 & 46,7 & 313,7 & 14,9 & 4,0 & 36,9 \\
\hline $\mathrm{P} 12 \mathrm{~B}$ & $50-60$ & 3,9 & 12,5 & 12,5 & 8,0 & 4,0 & 330,0 & 24,5 & 354,5 & 6,9 & 1,0 & 44,6 \\
\hline
\end{tabular}

\# Para descrição dos locais ver Tabela 2.

$\mathrm{SB}=$ Soma de bases

$\mathrm{T}$ = Capacidade de troca de cátions

$\mathrm{V}=$ Saturação de bases

At. Arg. = Atividade de argila 

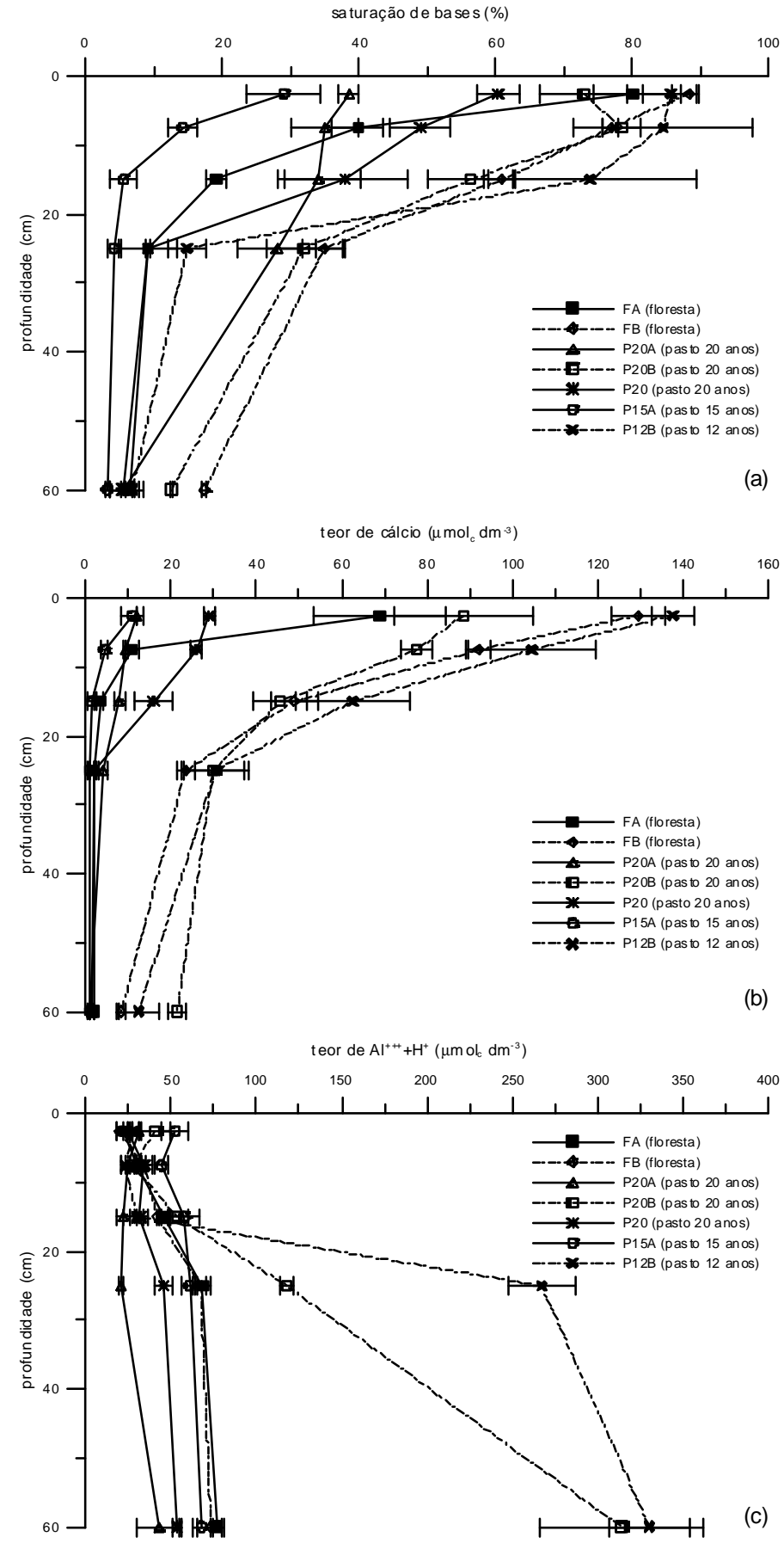

Figura 14 - Saturação de bases (a), concentrações de cálcio (b) e concentrações de alumínio mais hidrogênio (c). Os pontos são médias de duas amostras e as barras de erros representam o desvio padrão, com exceção do gráfico (a) onde o erro foi obtido por meio de um cálculo de propagação de erro [eq. (10) e (11)] 
O fósforo, considerado o elemento mais limitante a produção vegetal em ecossistemas amazônicos, teve valores variando entre 1 e $73 \mathrm{mg} \mathrm{dm}^{-3}$ (Tabela 7). Os maiores valores $\left(20\right.$ a $\left.73 \mathrm{mg} \mathrm{dm}^{-3}\right)$ foram observados na superfície $(0-5 \mathrm{~cm})$ das áreas sobre Luvissolos, decrescendo em profundidade, não havendo diferença $(p>0,05)$ entres os locais.

Nas áreas P20B e P12B observa-se altos teores de alumínio mais hidrogênio, associados com altos teores cálcio e magnésio nas profundidades 20-30 e 50-60 cm (Figura 14c; Tabela 7). Outros trabalhos já apontaram ocorrência semelhantes (Volkoff et al., 1989; Gama et al., 1992). Uma possível explicação para este fato, pode ser a transformação de minerais interestratificados (ilita/esmectira) no solo e/ou devido a determinação utilizando $\mathrm{KCl} 1 \mathrm{~mol} \mathrm{~L}^{-1}$ extrair não apenas Al trocável, mas também outras formas de alumínio, como os hidróxidos $\mathrm{Al}(\mathrm{OH})_{2}{ }^{1+}$ e $\mathrm{Al}(\mathrm{OH})^{2+}($ Silva, 1999).

\subsubsection{Concentração, estoque, $\delta^{13} \mathrm{C}$ e fontes do carbono do solo}

\subsubsection{Concentração e estoque de carbono}

As concentrações de carbono variaram entre 0,2 e 4,7\%. Valores acima de $1 \%$ são observados apenas nas camadas superficiais do solo, na maioria das áreas apenas em 0-5 cm (Figura 15; Tabela 5). Os locais sobre Luvissolos apresentaram valores superiores aos sobre Argissolos até $40 \mathrm{~cm}$ de profundidade, sendo que entre $0-5 \mathrm{~cm}$ a diferença é significativa $(p<0,05)$.

$\mathrm{O}$ estoque de $\mathrm{C}\left(\mathrm{Mg} \mathrm{C} \mathrm{ha}^{-1}\right)$ tem perfil semelhante ao teor (\%), apresentando as maiores concentrações na superfície do solo, variando entre 3,6 e 26,3 $\mathrm{Mg} \mathrm{ha}^{-1}$ (Figura 16; Tabela 5). As maiores variações ocorreram entre $0 \mathrm{e}$ $40 \mathrm{~cm}$ do solo. 


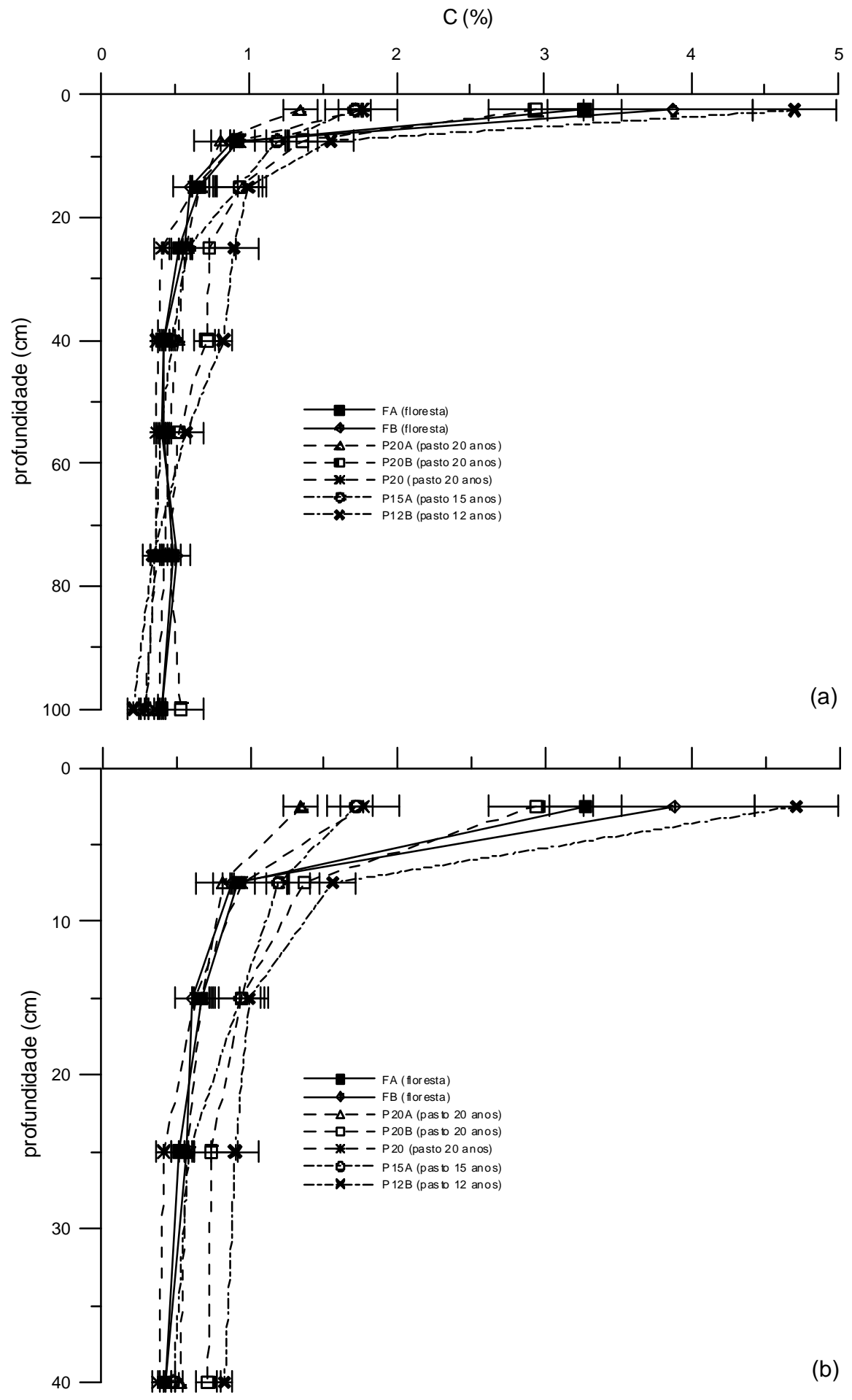

Figura 15 - Valores médios e desvios padrões de concentração de carbono (\%) no solo. Gráfico (a) concentrações de C ate $100 \mathrm{~cm}$. Gráfico (b) concentração de $\mathrm{C}$ ate $40 \mathrm{~cm}$ 
Entre 50 a $60 \%$ do carbono do solo, concentrou-se nos primeiros $30 \mathrm{~cm}$ de profundidade nas áreas estudadas, resultado da alta atividade biológica na superfície do solo (Figuras 15 e 16; Tabela 5). Outros autores chegaram a resultados semelhantes trabalhando com outros solos da região amazônica (Veldkamp, 1994; Moraes et al., 1995; Moraes et al., 1996; Batjes \& Dijkshoorn, 1999). Esta alta densidade de carbono na porção mais ativa do solo, pode ser potencialmente sensível àmudança na cobertura e uso da terra (Moraes et al., 1995; Batjes \& Dijkshoorn, 1999).

Os locais sob floresta apresentaram valores de estoque de $\mathrm{C}$ semelhantes, não diferindo entre si $(p<0,5)$. Analisando as pastagens com diferentes idades e florestas sobre os dois tipos de solos estudados, observa-se que existem efeitos consideráveis de tipo de uso, tempo e solo, sobre tudo nas camadas mais superficiais (Figura 16; Tabela 5).

Nas áreas sobre Argissolos, houve um decréscimo no estoque de $\mathrm{C}$ devido à conversão de floresta em pastagem na camada $0-5 \mathrm{~cm}$, em todos os locais esta foi a camada do solo com maiores concentrações. O estoque decresceu de 18,0 \pm 1,6 Mg C ha- em floresta para 11,0 $\pm 0,7 \mathrm{Mg} \mathrm{C}^{-1}$ ha $^{-1}$ no pasto de 15 anos (P15A) e 9,8 $\pm 0,9 \mathrm{Mg} \mathrm{C}^{-1}$ no pasto de 20 anos (P20A). Já nas áreas sobre Luvissolos, houve aumento no estoque de $C$ de floresta $(21,4 \pm 3,1$ $\mathrm{Mg} \mathrm{C}$ ha $\left.^{-1}\right)$ para o pasto de 12 anos $\left(26,3 \pm 1,6 \mathrm{Mg} \mathrm{C}^{-1}\right)$, decrescendo no pasto de 20 anos $\left(17,0 \pm 1,9 \mathrm{Mg} \mathrm{C}^{-1} \mathrm{ha}^{-1}\right)$. 


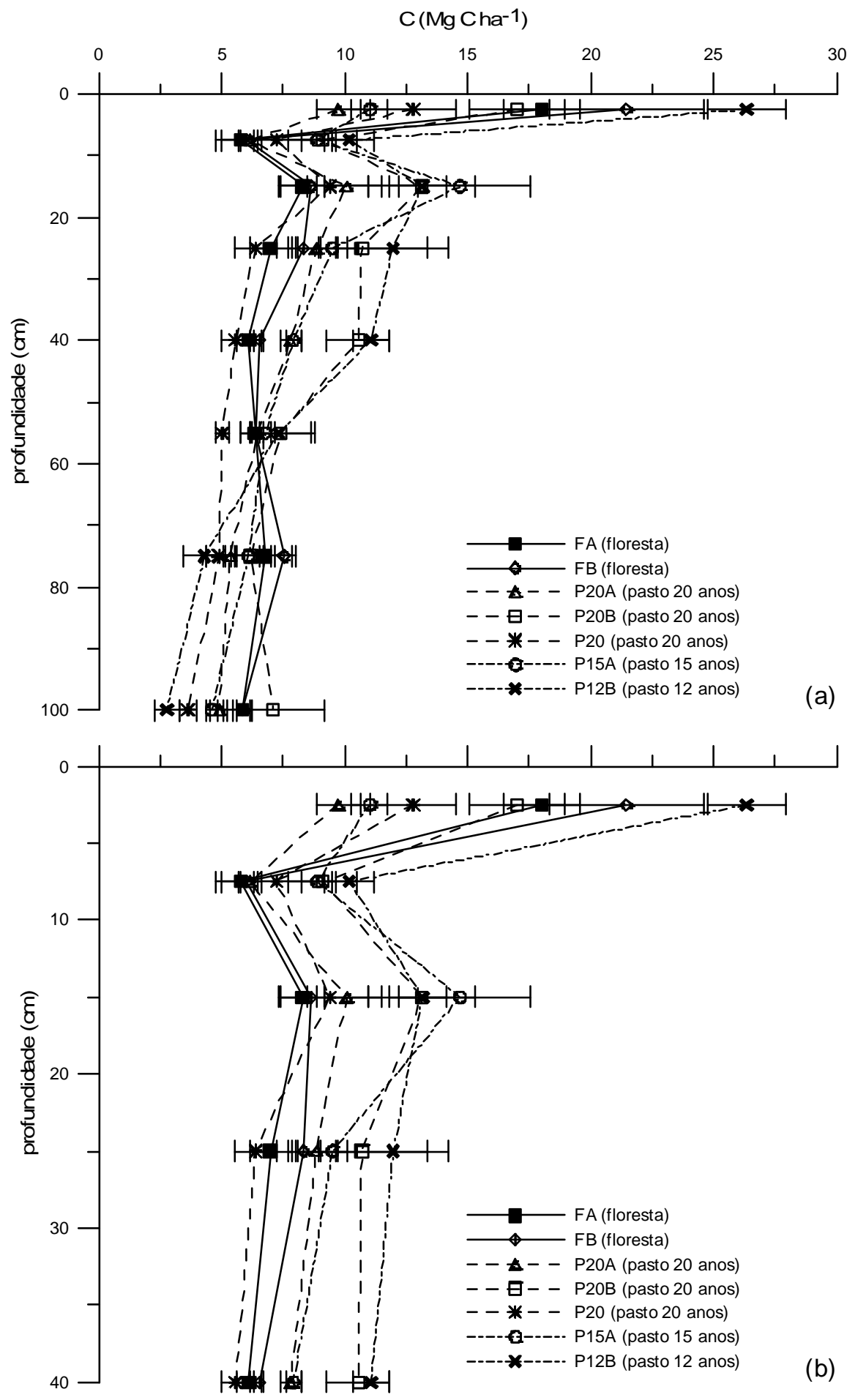

Figura 16 - Valores médios e desvios padrões de estoque $\left(\mathrm{Mg} \mathrm{ha}^{-15}\right)$ de carbono do solo. Gráfico (a) concentrações de C ate $100 \mathrm{~cm}$. Gráfico (b) concentração de $\mathrm{C}$ ate $40 \mathrm{~cm}$ 
Analisando o estoque de $\mathrm{C}$ no primeiro metro de solo e considerando as áreas sob floresta como precursoras do carbono dos solos sob pastagem, observa-se que existe uma tendência de aumento do estoque de carbono nos primeiros anos após a conversão, decrescendo nas pastagens mais antigas (Figura 17).

Nas áreas sobre Argissolo essa perda com o tempo (floresta $64 \pm 2 \mathrm{Mg}$ $\mathrm{C}$ ha $^{-1}$; pasto 15 anos $69 \pm 3 \mathrm{Mg} \mathrm{C}$ ha $^{-1}$; pasto 20 anos $59 \pm 2 \mathrm{Mg} \mathrm{C}$ ha $^{-1}$ ); é bem mais acentuada que nas áreas sobre Luvissolo (floresta $71 \pm 3 \mathrm{Mg} \mathrm{C}^{-1}$; pasto 12 anos $87 \pm 4 \mathrm{Mg} \mathrm{C}^{-1}$, pasto 20 anos $81 \pm 5 \mathrm{MgC} \mathrm{ha}^{-1}$ ). No primeiro caso o estoque de $C$ na pastagem mais velha (20 anos) é menor que na floresta. No segundo caso existe uma tendência decrescente, entretanto, o estoque de $C$ na pastagem de 20 anos ainda é maior que nas áreas sob floresta.

Isto indica que a velocidade de perda de carbono, com o tempo, nas duas condições de solos é diferente, sendo menor nas áreas sobre Luvissolos, que apresentam lençol freático suspenso e textura muito argilosa. Segundo a literatura, essas duas características têm efeitos contrários, no que se refere à proteção do carbono orgânico à ação dos processos de decomposição.

Ciclos de seca e umedecimento, comuns nos solos do Acre, aumentam a mineralização de carbono e nitrogênio (Birch \& Friend, 1961; Sorensen, 1974; Jager \& Bruins, 1975; Seneviratne \& Wild, 1985). Outros autores apontam a fração argila como um importante fator de proteção do carbono orgânico, aumentando o tempo de residência deste no solo (Desjardins et al., 1994; Koutika et al., 1999; Telles et al., 2003). Em geral existe uma correlação positiva entre teor de argila e estoque de carbono do solo.

Os dados deste trabalho estão mostrando que a combinação destes dois fatores, resultou em maior estoque de carbono e diminuição da taxa de perda ao logo do tempo, em função da mudança no uso da terra nos Luvissolos. 

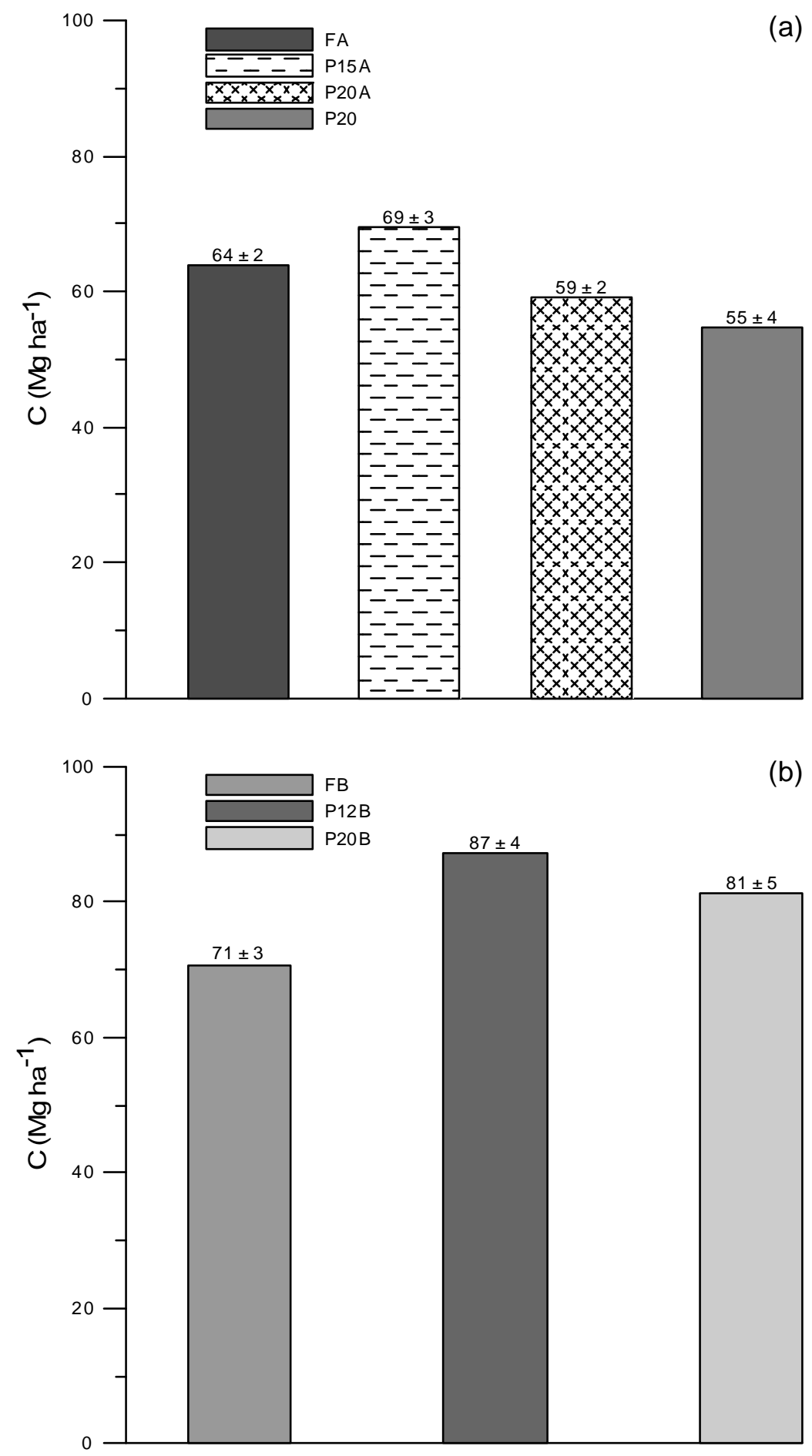

Figura 17 - Estoque carbono (Mg ha $\left.{ }^{-1}\right)$ nos primeiros $100 \mathrm{~cm}$ de solo das áreas de estudo. Gráficos (a) áreas sobre Argissolo e gráfico (b) áreas sobre Luvissolo. Os valores que indicam incerteza foram obtidos por meio da eq. (11) 
Alguns autores têm encontrado valores de estoque de carbono em pastagens, superiores aos originalmente existente no solo sob floresta (Cerri, 1986; Feigl et al., 1995; Moraes, 1995; Salimon, 2003), já outros trabalhos mostram um decréscimo com o tempo de introdução da pastagem (Desjardins et al., 1994; García-Oliva et al., 1994; Veldkamp, 1994; Camargo et al., 1999). Estes resultados contrários podem estar relacionados às diferenças climáticas, edáficas e de manejo das pastagens das áreas estudadas.

Este trabalho apresenta resultados que se enquadram nas duas tendências. Sob pastagem de 20 anos os Argissolos apresentam valores de C menores sob floresta e os Luvissolos valores maiores, entretanto, há uma tendência decrescente neste segundo caso, indicando haver a necessidade outros ensaios para que se possa chegar a resultados mais conclusivos.

\subsubsection{Composição isotópica e fontes do carbono do solo}

Os valores de $\delta^{13} \mathrm{C}$ dos solos sob floresta variaram entre $-28,6$ \% na superfície do solo e $-25,2 \%$ em profundidade $(90-100 \mathrm{~cm}$ ) (Tabela 5; Figura 18). Este enriquecimento em ${ }^{13} \mathrm{C}$ com a profundidade solo foi observado outros trabalhos encontrados na literatura (Cerri, 1986; Veldkamp, 1994; Feigl et al., 1995; Moraes, 1995; Neill et al., 1996; Camargo et al., 1999; Salimon, 2003; Telles et al., 2003), e pode ser apontado como efeito do fraciona mento durante a decomposição da matéria orgânica ao longo do perfil do solo (Martinelli et al., 1996).

Comparando áreas de floresta e pastagem observou-se claramente a influência da mudança na cobertura vegetal predominante $C_{3}$ para gramínea $C_{4}$ (Brachiaria brizantha), sendo os valores de $\delta^{13} \mathrm{C}$ do solo sob pastagem significativamente $(P<0,05)$ maiores que o solo sob floresta. Entretanto, essa diferença foi mais acentuada nas áreas sobre Argissolos, que diferiram 
significativamente das áreas sob floresta e sobre Luvissolos ao longo de todo perfil do solo (Tabela 5; Figura 18).

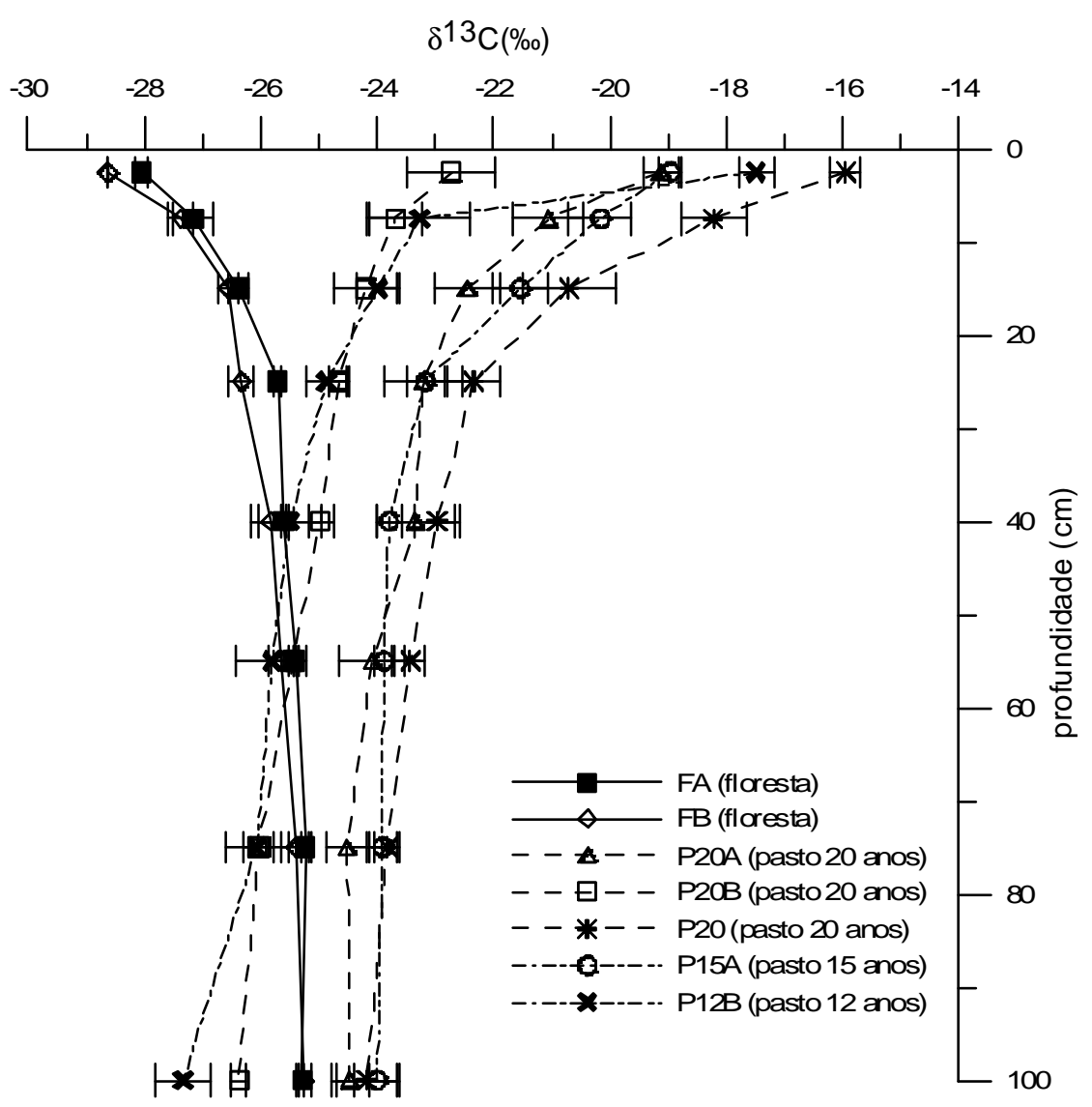

Figura 18 - Variação do $\delta^{13} \mathrm{C}(\%)$ do solo com a profundidade nas áreas de estudo. Os valores são médias de seis repetições e as barras de erro indicam o desvio padrão

Utilizando o cálculo de diluição isotópica [eq. (8) e (9)], foi calculada a percentagem de carbono derivado da pastagem (Figura 19). As pastagens sobre Argissolos apresentaram os maiores incrementos de carbono derivado da pastagem, variando entre 55 e $85 \%$ na superfície do solo e 5 e $12 \%$ a $1 \mathrm{~m}$ de profundidade. A pastagem de 20 anos sobre Latossolo (P20) apresentou valores semelhantes aos encontrados por Moraes et al. (1996) para uma pastagem de 81 anos, em torno de $80 \%$ na superfície do solo. 
Com exceção de um valor, na profundidade $0-5 \mathrm{~cm}$ para a pastagem de 12 anos (P12B), as áreas de pastagem sobre Luvissolos apresentaram valores significativamente menores $(P<0,05)$ de carbono de origem $C_{4}$, variando entre 38 $\%$ na superfície e $1,5 \%$ a $60 \mathrm{~cm}$ de profundidade.

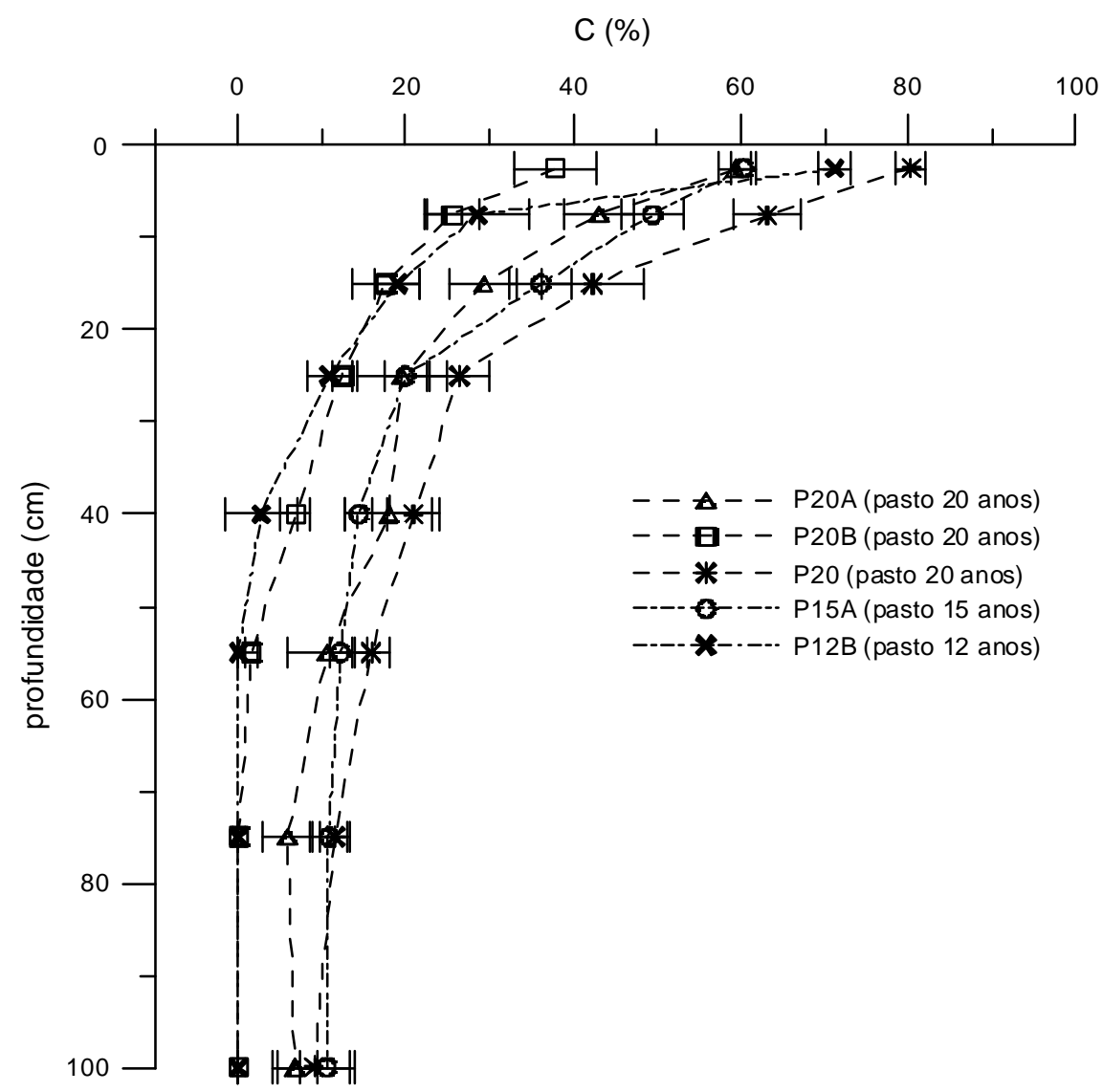

Figura 19 - Percentagem de $\mathrm{C}$ derivado da pastagem obtido por meio do calculo de diluição isotópica. Valores são médias e o erro foi obtido por meio de cálculo de propagação de erros, conforme descrito no item materiais e métodos

A Figura 20 mostra uma comparação dos valores de carbono derivado da floresta, carbono derivado da pastagem e carbono total, entre as pastagens de 20 anos sobre Argissolo (P20A) e sobre Luvissolo (P20B). Os dados desta figura mostram que sobre Argissolo, a pastagem apresenta pouco carbono remanescente da floresta e um grande incremento de carbono $\mathrm{C}_{4}$, resultando em 
um baixo estoque de carbono total. O inverso ocorre sobre Luvissolo, onde a pastagem grande quantidade de carbono remanescente da floresta, pouco carbono $\mathrm{C}_{4}$ e maior estoque total.

Isto sugere que a o tempo de residência da matéria orgânica e menor em Argissolos que Luvissolos e que o menor estoque total de carbono em Argissolos pode ser devido a maior taxa de perda de carbono remanescente da floresta, ocorrendo o inverso em Luvissolos.

Este resultados podem ser efeito das características físicas do solo (textura e estrutura). A pastagem P20B (Luvissolos) está sobre solo pouco desenvolvido, cujas características físicas condicionam excesso de água no período chuvoso e baixa umidade no período seco, em função da pequena profundidade e pouca porosidade do solo.

Estas características podem fazer com que a matéria orgânica proveniente da pastagem se concentre nas primeiras camadas do solo, sendo decomposta mais rapidamente, ou ainda, as gramíneas sob estas condições podem ser menos produtivas comparativamente. Outro efeito pode ser uma diminuição na taxa de decomposição da matéria orgânica remanescente da floresta em profundidade, resultando em maiores teores de carbono total e remanescente da floresta, comparativamente com a pastagem de 20 anos (P20A), sobre solo bem intemperizado.

Este trabalho mostra uma tendência de decréscimo do estoque de carbono e a aumento da fração de carbono derivada da pastagem ao logo do tempo, com a mudança no uso e cobertura da terra. Esta tendência é bem mais acentuada nos Argissolos. Outros autores têm encontrado tendências contrárias ao decréscimos de carbono ao longo do tempo de uso (Cerri, 1986; Feigl et al., 1995; Moraes, 1995; Trumbore et al., 1995; Salimon, 2003), a maioria destes 
autores enfatizam que a manutenção destas concentrações de carbono no solo, ao longo tempo, depende do manejo das pastagens em questão.

Em torno de $64 \%$ da área do estado do Acre é coberta por Luvissolos e Cambissolos, a grande maioria destes solos apresentam boa fertilidade natural, entretanto, são solos que demandam práticas rígidas de manejo para um uso adequado, em função de apresentarem alta susceptibilidade àerosão, devido æ̀ características físicas pobres e relevo movimentado. 

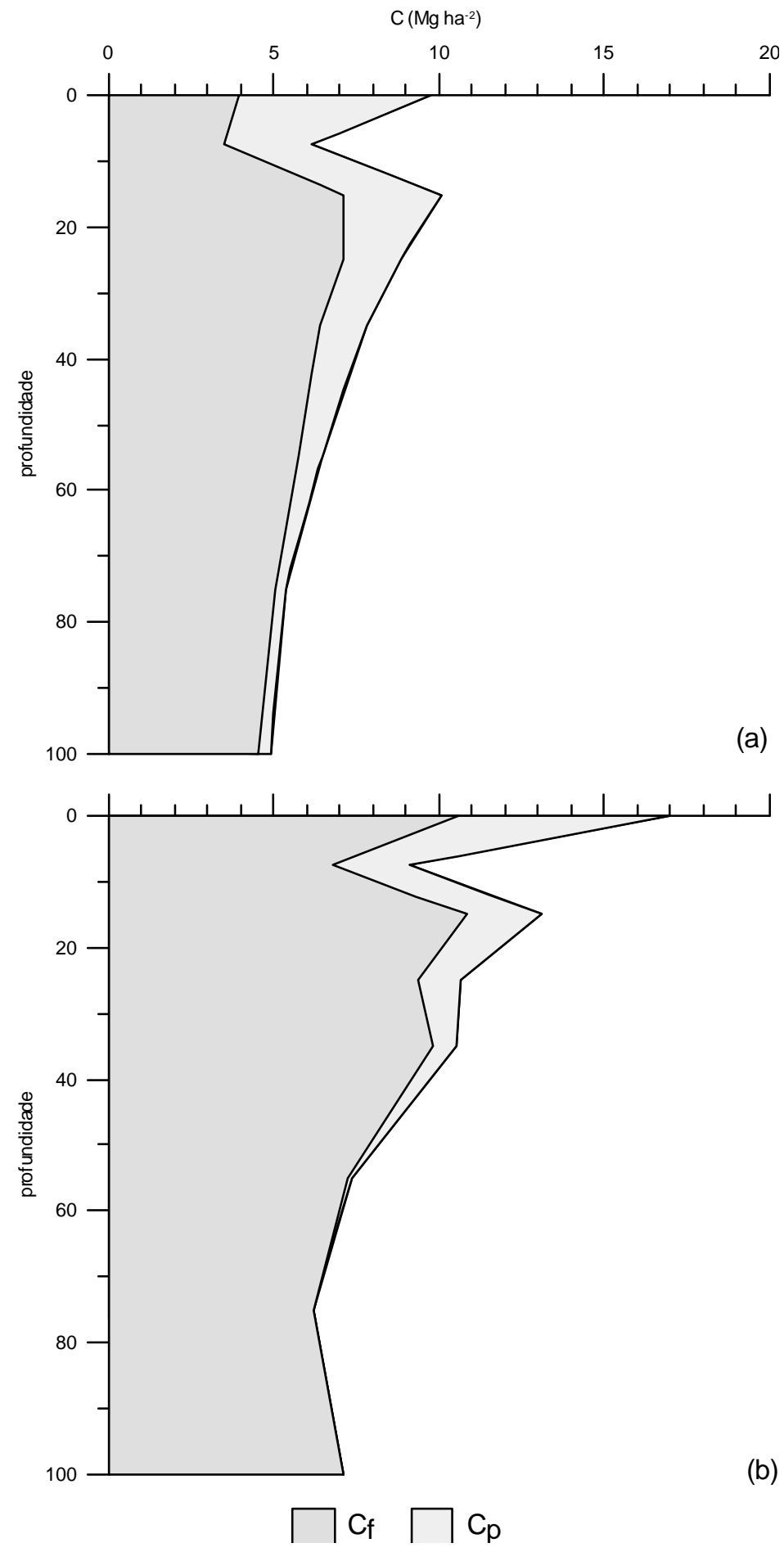

Figura 20 - Estoque de carbono $\left(\mathrm{Mg} \mathrm{ha}^{-1}\right)$ correspondente $a \mathrm{C}_{\mathrm{f}}$ (carbono derivado da floresta) e $C_{p}$ (carbono derivado da pastagem) no perfil do solo. O gráfico (a) refere-se a dados da área P20A e o gráfico (b) à área P20B 
O sistema de pecuária extensiva, com níveis tecnológicos médios a baixos, que predominam em grande parte das pequenas, médias e grandes propriedades do Acre (Valentim et al., 2002a), associado com solos sensíveis a mudanças no uso e cobertura da terra, podem levar a ocorrência de grandes áreas de pastagens degradadas, e consideráveis perdas de carbono do solo.

\subsubsection{Implicações dos resultados para pecuária do Acre}

Segundo Valentim et al. (2002b), o Acre possui cerca de 375.000 ha de áreas de pastagens degradadas e capoeiras abandonadas. Além disto, outros 525.000 ha estão em processo de degradação, onde o Zoneamento Ecológico Econômico constatou a ocorrência da morte de pastagens de Brachiaria. brizantha cv. Marandu (Valentim et al., 2000).

A recuperação das áreas degradadas tem custo maior do que a conversão de novas áreas de florestas em pastagens (Valentim et al., 2000). Este fato tem feito com que a maioria dos produtores, sem acesso a assistência técnica e linhas de crédito adequadas optem por um processo contínuo de desmatamento de áreas de florestas para a formação de pastagens, muitas vezes avançando sobre as áreas de reserva legal de suas propriedades

Apesar do Acre possuir cerca de 900.000 ha de pastagens improdutivas ou de baixa produtividade, muito pouco tem sido feito para viabilizar as tecnologias e os meios necessários para que os produtores possam optar por recuperar áreas degradadas e aumentar a produtividade das áreas ainda produtivas em vez de avançarem sobre a floresta (Valentim et al., 2002a).

Mantida a taxa anual de crescimento de $12 \%$ ao ano, o rebanho bovino do Acre deve passar de 2.000 .000 de cabeças em 2003 para 4.000 .000 de cabeças em 2008 (Valentim, 2003). Mantido o padrão tecnológico atual nas propriedades do Estado, isto implicará no desmatamento de aproximadamente 
1,5 milhão de hectares de florestas para a formação de pastagens visando alimentar este rebanho bovino.

O aumento do nível tecnológico da pecuária bovina no Acre é fundamental para manutenção da sustentabilidade econômica e ecológica desta atividade. Coincidentemente, a maior parte das áreas de pastagem existentes no Acre estão sobre os solos com as melhores características agronômicas (principalmente físicas). Esta realidade começa a mudar com o avanço da fronteira de exploração para o oeste do estado, onde acorrem os solos que demandam práticas de manejo mais refinadas.

Diante desta realidade, torna-se cada vez mais urgente a intervenção dos órgãos competentes, que ditam os rumos da ciência, tecnologia e políticas públicas, com o objetivo de gerar de tecnologias adequadas de manejo e conservação das áreas de pastagens já existentes e buscar alternativas econômicas, sociais e ecológicas para o uso dos recursos naturais existentes.

Segundo (Andrade, 2002; Valentim, 2002; Valentim et al., 2002b; Valentim, 2003) existem diversas alternativas visando a recuperação de áreas de pastagens degradadas ou $\mathrm{o}$ aumento da produtividade das áreas em degradação.

Os resultados deste estudo mostram que é essencial priorizar o avanço no conhecimento sobre: 1) a dinâmica da matéria orgânica nos diferentes tipos de solos sob pastagens; 2) o efeito de sistemas de pastejo com locação continua e rotacionada sobre as condições físicas e químicas dos solos, particularmente dos Argissolos e Luvissolos do Acre. Estes estudos são importantes para permitir orientar os produtores sobre as práticas de manejo das pastagens que contribuam para conciliar o aumento da produtividade e a rentabilidade de seus empreendimentos com a conservação dos recursos naturais. 


\section{CONCLUSÕES}

Os solos do Acre armazenam em torno de $1 \mathrm{Pg}$ de carbono no primeiro metro de profundidade, cerca de $75 \%$ deste valor concentra-se nos primeiros 30 $\mathrm{cm}$.

Os solos do Acre apresentam menor concentração de carbono (média 6,5 $\mathrm{kg} \mathrm{m}^{-2}$ ) quando comparados com a média dos solos da Amazônia, embora apresentem melhor fertilidade. A principal razão para este resultado é a maior taxa de decomposição da matéria orgânica nestes solos devido aos constantes ciclos de seca e umedecimento. Estes ciclos estão associados a interação entre o regime pluviométrico e as características físicas (principalmente estrutura) incipientes destes solos, que fazem com que ocorra um lençol freático suspenso que oscila no perfil do solo, podendo chegar até a superfície do mesmo.

A mudança mo uso da terra alterou de maneira distinta os estoques e a dinâmica da matéria orgânica em Argissolos (bem drenados) e Luvissolos (mal drenados). Nas duas condições de solos houve uma tendência de decréscimo do estoque total de carbono e aumento de carbono de origem $\mathrm{C}_{4}$, entretanto, nos Argissolos esta tendência foi muito mais acentuada.

As pastagens sobre Luvissolos apresentaram maior estoque de carbono (média de $8,4 \mathrm{~kg} \mathrm{~m}^{-2}$ até $1 \mathrm{~m}$ de profundidade), entretanto, os dados isotópicos mostraram que a maior parte deste carbono era remanescente da floresta e uma pequena proporção foi introduzida pela pastagem ( $<40 \%$ na camada $0-5 \mathrm{~cm}$ da pastagem de 20 anos). $O$ inverso ocorreu com pastagens sobre Argissolos que apresentaram menor estoque (média de $6,4 \mathrm{~kg} \mathrm{~m}^{-2}$ até $1 \mathrm{~m}$ de profundidade) e 
grande proporção de carbono da pastagem ( $>70 \%$ na camada $0.5 \mathrm{~cm}$ da pastagem de 20 anos).

Os resultados acima sugerem que: 1) A taxa de decomposição do carbono em Luvissolos é menor que em Argissolos, e o tempo de residência da meteria orgânica maior. Os Argissolos tendem a perder muito mais carbono com a mudança no uso e cobertura da terra. 2) A produtividade da pastagem é baixa sobre Luvissolos, indicando que alem da fertilidade do solo, outras características, como estrutura, devem ser consideradas para definição das praticas de manejo que objetivam a obtenção de melhor desempenho da gramínea. 


\section{REFERÊNCIAS BIBLIOGRÁFICAS}

ACRE. Secretaria Executiva de Ciência, Tecnologia e Meio Ambiente. Zoneamento ecológico-econômico: recursos naturais e meio ambiente. Rio Branco: Secretaria Executiva de Ciência, Tecnologia e Meio Ambiente, 2000. v.1, $116 \mathrm{p}$.

AMARAL, E. F. Ambientes, com ênfase nos solos e indicadores ao uso agroflorestal das bacias dos rios Acre e laco, Acre, Brasil. Viçosa, 2003. 178

p. Dissertação (Mestrado) - Universidade Federal de Viçosa.

AMARAL, E. F.; ARAÚJO NETO, S. E. Levantamento de reconhecimento dos solos e avaliação da aptidão agrícola das terras do projeto de assentamento Favo de Mel, Sena Madureira-AC. Rio Branco: Embrapa Acre, 1998. 75 p. (Documentos, 36).

AMARAL, E. F.; MELO, A. W. F.; OLIVEIRA, T. K. Levantamento de reconhecimento de baixa intensidade dos solos da região de inserção do projeto RECA, Estados de Rondônia, Acre e Amazonas. Rio Branco: Embrapa Acre, 2000. 39 p. (Boletim de Pesquisa, 27).

ANDRADE, C. M. S. Recomendação de calagem e adubação para pastagens no Acre. Rio Branco: Embrapa Acre, 2002. 6 p. (Circular Técnica, 46).

ARAÚJO, E. A. Caracterização de solos e modificação provocadas pelo uso agrícola no assentamento Favo de Mel, na região do Purus - Acre. Viçosa, 2000. 122 p. Dissertação (Mestrado) - Universidade Federal de Viçosa. 
BATJES, N. H. Total carbon and nitrogen in the soils of the world. European Journal of Soil Science, v.47, n.2, p.151-163, June. 1996.

BATJES, N. H. Effects of mapped variation in soil conditions on estimates of soil carbon and nitrogen stocks for South America. Geoderma, v.97, n.1/2, p.135144, Aug. 2000.

BATJES, N. H.; DIJKSHOORN, J. A. Carbon and nitrogen stocks in the soils of the Amazon region. Geoderma, v.89, n.3/4, p.273-286, May. 1999.

BATJES, N. H.; SOMBROEK, W. G. Possibilities for carbon sequestration in tropical and subtropical soils. Global Change Biology, v.3, n.2, p.161-173, Apr. 1997.

BERNOUX, M. Conteúdo de carbono dos solos da Amazônia ocidental e mudanças decorrentes da conversão da floresta em pastagens. Piracicaba, 1998. 98 p. Tese (Doutorado) - Centro de Energia Nuclear na Agricultura, Universidade de São Paulo.

BERNOUX, M.; CARVALHO, M. D. S.; VOLKOFF, B.; CERRI, C. C. Brazil's soil carbon stocks. Soil Science Society of America Journal, v.66, n.3, p.888896, May./June. 2002.

BERNOUX, M.; CERRI, C. C.; NEILL, C.; de MORAES, J. F. L. The use of stable carbon isotopes for estimating soil organic matter turnover rates. Geoderma, v.82, n.1/3, p.43-58, Feb. 1998a.

BERNOUX, M.; ARROUAYS, D.; CERRI, C.; VOLKOFF, B.; JOLIVET, C. Bulk densities of brazilian Amazon soils related to other soil properties. Soil Science Society of America Journal, v.62, n.3, p.743-749, May./June. 1998b.

$\mathrm{BIRCH}, \mathrm{H}$. F. The effect of soil drying on humus decomposition and nitrogen availability. Plant and Soil, v.10, n.1, p.9-31, Sept. 1958.

$\mathrm{BIRCH}, \mathrm{H}$. F. Nitrification in soils after different periods of dryness. Plant and Soil, v.12, n.1, p.81-96, 1960. 
BIRCH, H. F.; FRIEND, M. T. Resistance of humus to decomposition. Nature, v.191, n.4789, p.731-732, 1961.

BOHN, H. L. Estimate of organic carbon in world soils. Soil Science Society of America Journal, v.40, n.3, p.468-470, 1976.

BRADY, N. C.; WEIL, R. R. Formation of soils from parent materials. In: BRADY, N.

C.; WEIL, R. R. (Ed.). The nature and properties of soils. New Jersey: Prentice-Hall, 1999a. cap. 2, p. 29-70.

BRADY, N. C.; WEIL, R. R. The nature and properties of soils. 12.ed. New Jersey: Prentice-Hall, 1999b. 881 p.

BRASIL. Folhas SC. 19 Rio Branco; geologia, geomorfologia, pedologia, vegetação e uso potencial da terra. Rio de Janeiro: Ministério das Minas e Energia, 1976a. 464 p. (Levantamento de Recursos Naturais, 12).

BRASIL. Mapa exploratório de solos, folha SC. 19 Rio Branco. Rio de Janeiro: Ministério das Minas e Energia, 1976b. 1 mapa: color.; 85 x $60 \mathrm{~cm}$. Escala 1:1.000.000.

BRASIL. Folhas SB/SC. 18 Javari/Contamana; geologia, geomorfologia, pedologia, vegetação e uso potencial da terra. Rio de Janeiro: Ministério das Minas e Energia, 1977a. 420 p. (Levantamento de Recursos Naturais, 13). BRASIL. Mapa exploratório de solos, folhas SB/SC. 18 Javari/Contamana. Rio de Janeiro: Ministério das Minas e Energia, 1977b. 1 mapa: color.; 55 × 85 cm. Escala 1:1.000.000.

CAMARGO, O. A.; MONIZ, A. C.; JORGE, J. A.; VALDARES, J. M. A. S. Métodos de análise química, mineralógica e física de solos do Instituto Agronômico de Campinas. Campinas: Instituto Agronômico de Campinas, 1986. 94 p. (Boletim Técnico, 106). 
CAMARGO, P. B. Dinâmica da matéria orgânica do solo decorrente das mudanças do uso da terra utilizando isótopos de carbono, estudo de caso: Paragominas, PA. Piracicaba, 1997. 98 p. Tese (Doutorado) - Centro de Energia Nuclear na Agricultura, Universidade de São Paulo.

CAMARGO, P. B.; TRUMBORE, S. E.; MARTINELLI, L. A.; DAVIDSON, E. A.; NEPSTAD, D. C.; VICTORIA, R. L. Soil carbon dynamics in regrowing forest of eastern Amazonia. Global Change Biology, v.5, n.6, p.693-702, Aug. 1999.

CARETTA, R. A. Experimental errors and propagation of errors. Minnesota: University of Minnesota, 1997. http://www3.cems.umn.edu/courses/chen4402/ERROR.HTML\#ADD (23 Set. 2003).

CERRI, C. C. Dinâmica da matéria orgânica do solo no agrossistema cana-deaçúcar. Piracicaba, 1986. 197 p. Tese (Livre Docência) - Escola Superior de Agricultura "Luiz de Queiroz", Universidade de São Paulo.

CERRI, C. C.; EDUARDO, B. P.; PICCOLO, M. C. Use of stable isotopes in soil organic matter studies. In: INTERNATIONAL SYMPOSIUM ON THE USE OF STABLE ISOTOPES IN PLANT NUTRITION, SOIL FERTILITY AND ENVIRONMENTAL STUDIES, Vienna, 1990. Proceedings. Vienna: International Atomic Energy Agency, 1991. p.247-259.

CERRI, C. C.; MORAES, J. F. L.; VOLKOFF, B. Dinâmica do carbono orgânico em solos vinculados a pastagem da Amazônia brasileira. Revista INIA de Investigaciones Agronómicas, v.1, p.96-102, 1992.

CHONÉ, T.; ANDREUX, F.; CORREA, J. C.; VOLKOFF, B.; CERRI, C. C. Changes in organic matter in an oxisol from the central Amazonian forest during eight years as pasture, determined by ${ }^{13} \mathrm{C}$ isotopic composition. In: BERGHEIM, J. (Ed.). Diversity of environmental biogeochemistry. Amsterdam: Elsevier, 1991. p. 397-405. 
DAVIDSON, E. A.; LEFEBVRE, P. A. Estimating regional carbon stocks and spatially co varying seraphic factors using soil maps at 3 scales. Biogeochemistry, v.22, n.2, p.107-131, 1993.

DEMATTE, J. L. I. Solos. In: SALATI, E.; ABSY, M. L.; VICTORIA, R. L. (Ed.). Amazônia: um ecossistema em transformação. Manaus: INPA, 2000. cap. 6 , p. 119-162.

DESJARDINS, T.; ANDREUX, F.; VOLKOFF, B.; CERRI, C. C. Organic carbon and ${ }^{13} \mathrm{C}$ contents in soils and soil size- fractions, and their changes due to deforestation and pasture installation in eastern Amazonia. Geoderma, v.61, n.1/2, p.103-118, Feb. 1994.

DUARTE, A. F.; ARTAXO NETO, P.; BROWN, I. F.; QUINTELA, T. S.; CHAIM, A. C. O clima em Rio Branco - Acre, Brasil entre os anos 1970 e 2000. Rio Branco: CNPq, 2002. 25 p. (Relatório Técnico).

EMPRESA BRASILEIRA DE PESQUISA AGROPECUÁRIA. Manual de métodos de analise de solo. 2.ed. Rio de Janeiro: EMBRAPA/CNPS, 1997. $212 p$.

EMBRAPA. Sistema brasileiro de classificação de solos. Rio de Janeiro: Embrapa Solos, 1999. 412 p.

ESWARAN, H.; VANDENBERG, E.; REICH, P. Organic carbon in soils of the world. Soil Science Society of America Journal, v.57, n.1, p.192-194, Jan.Feb. 1993.

FAMINOW, M. D. Cattle, deforestation and development in the Amazon: an economic, agronomic and environmental perspective. New York: CAB International, 1998. $253 \mathrm{p}$.

FARQUHAR, G. D.; EHLERINGER, J. R.; HUBICK, K. T. Carbon isotope discrimination and photosynthesis. Annual Review of Plant Physiology and Plant Molecular Biology, v.40, p.503-537, 1989. 
FEIGL, B. J.; MELLLO, J.; CERRI, C. C. Changes in the origin and quality of soil organic matter after pasture introduction in Rondônia (Brazil). Plant and Soil, v.175, n.1, p.21-29, Aug. 1995.

FELLER, C.; BEARE, M. H. Physical control of soil organic matter dynamics in the tropics. Geoderma, v.79, n.1/4, p.69-116, Sept. 1997.

GAMA, J. R. N. F. Caracterização e formação de solos com argila de atividade alta do Estado do Acre. Itaguaí, 1986. 150 p. Dissertação (Mestrado) Universidade Federal Rural do Rio de Janeiro.

GAMA, J. R. N. F.; KUSABA, T.; OTA, T.; AMANO, Y. Influência de material vulcânico em alguns solos do Estado do Acre. Revista Brasileira de Ciência do Solo, v.16, n.1, p.13-106, 1992.

GARCÍA-OLIVA, F.; CASAR, I.; MORALES, P.; MAASS, J. M. Forest-to-pasture conversion influences on soil organic carbon dynamics in a tropical deciduous forest. Oecologia, v.99, n.3-4, p.392-396, Oct. 1994.

HOUGHTON, J. T.; MEIRA FILHO, L. G.; LIM, B.; TREANTON, K.; MAMATY, I.; BONDUKI, Y.; GRIGGS, D. J.; CALLENDER, B. A. Revised 1996 IPCC guidelines for national greenhouse gas inventories: Reference manual. London: $\quad$ IPCC/OECD/IEA, $1997 . \quad$ http://www.ipccnggip.iges.or.jp/public/gl/invs6.htm (20 jul. 2003).

HOUGHTON, R. A. Revised estimates of the annual net flux of carbon to the atmosphere from changes in land use and land management 1850-2000. Tellus Series B-Chemical and Physical Meteorology, v.55, n.2, p.378-390, Apr. 2003.

INSTITUTO BRASILEIRO DE GEOGRAFIA E ESTATístICA. Censo demográfico 2000. Rio de Janeiro: IBGE, 2001. http://www.ibge.gov.br/home/estatistica/populacao/censo2000/default.shtm (08 jul. 2003). 
INSTITUTO BRASILEIRO DE GEOGRAFIA E ESTATÍSTICA. Área territorial de estados e municípios brasileiros. Rio de Janeiro: IBGE, 2002. http://www.ibge.gov.br/home/geografia/areaterritorial/t_area.shtm $\quad(07 \quad$ jul. 2003).

INSTITUTO BRASILEIRO DE GEOGRAFIA E ESTATÍSTICA. Mapa de solos do

Brasil, 2003. http://map.ibge.gov.br/website/solos/ (16 set. 2003).

INSTITUO NACIONAL DE PESQUISAS ESPACIAIS. Monitoramento da

floresta amazônica brasileira por satélite, 2000-2001. São Jose dos

Campos: INPE, 2002.

http://www.obt.inpe.br/prodes/prodes 20002001 arquivos/sheet001.htm (07 jul. 2003).

INSTITUO NACIONAL DE PESQUISAS ESPACIAIS. Área desmatada por município do Estado do Acre, 2000. São José dos Campos: INPE, 2003. http://www.obt.inpe.br/prodesdigital/municipios.php?\&MUNICIPIO=\&ESTADO= AC\&ORDEM=DESMATAMENTO2000\%20DESC (09 jul. 2003).

IRION, G. Clay minerals of amazonian soils. In: SIOLI, H. (Ed.). The Amazon: limnology and landscape ecology of a mighty tropical river and its basin. Dordrecht: W. Junk, 1984. cap. 21, v.56, p. 537-579.

JAGER, G.; BRUINS, E. H. Effect of repeated drying at different temperatures on soil organic-matter decomposition and characteristics, and on soil microflora. Soil Biology \& Biochemistry, v.7, n.2, p.153-159, 1975.

JORDAN, C. F. Soils of the Amazon rainforest. In: PRANCE, G. T.; LOVEJOY, T. E. (Ed.). Amazonia. Oxford: Pegamon Press, 1986. p. 83-94.

KEELING, C. D.; WHORF, T. P. Atmospheric $\mathrm{CO}_{2}$ records from sites in the SIO air sampling network. Oak Ridge: U. S. Department of Energy, 2003. http://cdiac.ornl.gov/trends/co2/sio-mlo.htm (13 set. 2003). 
KIEFT, T. L.; SOROKER, E.; FIRESTONE, M. K. Microbial biomass response to a rapid increase in water potential when dry soil is wetted. Soil Biology \& Biochemistry, v.19, n.2, p.119-126, 1987.

KITAGAWA, Y.; MOLLER, M. R. F. Clay mineralogy of some typical soils in the brasilian Amazon region. Pesquisa Agropecuaria Brasileira, v.14, n.3, p.202-228, jul. 1979.

KOUTIKA, L. S.; CHONE, T.; ANDREUX, F.; BURTIN, G.; CERRI, C. C. Factors influencing carbon decomposition of topsoils from the brazilian Amazon basin. Biology and Fertility of Soils, v.28, n.4, p.436-438, Feb. 1999.

KRONBERG, B. I.; BENCHIMOL, R. Aridez no Acre. A história climática de uma região. Ciência Hoje, v.16, n.93, p.44-47, 1993.

KRONBERG, B. I.; NESBITT, H. W. Quantification of weathering, soil geochemistry and soil fertility. Journal of Soil Science, v.32, n.3, p.453-459, 1981.

KRONBERG, B. I.; BENCHIMOL, R. E.; BIRD, M. I. Geochemistry of Acre subbasin sediments. Window on ice age Amazonia. Interciencia, v.16, n.3, p.138-141, May./June. 1991.

KRONBERG, K. I.; FYFE, W. S. Geochemical controls in Amazonia on weathering rates. Mitteilungen aus dem Geologisch-palaontologischen Institut der Universitat Hamburg, v.55, p.215-222, Dec. 1983.

LATRUBESSE, E. M. El cuaternario fluvial de la cuenca del Purus en el estado de Acre, Brasil. San Luis, 1992. 213 p. Tese (Doctorado) - Universidad Nacional de San Luis.

LATRUBESSE, E. M.; BOCQUENTIN, J.; SANTOS, C. R.; RAMONELL, C. G. Paleoenviromental model for the late cenozoic of southwestern Amazonia: Paleontolgy and geology. Acta Amazonica, v.27, n.2, p.103-118, 1997. 
MARTINELLI, L. A.; PESSENDA, L. C. R.; ESPINOZA, E.; CAMARGO, P. B.; TELLES, E. C.; CERRI, C. C.; VICTORIA, R. L.; ARAVENA, R.; RICHEY, J.; TRUMBORE, S. Carbon-13 variation with depth in soils of Brazil and climate change during the quaternary. Oecologia, v.106, n.3, p.376-381, May. 1996.

MARTINS, J. S. Pedogênese de Podzólicos vermelho-amarelos do Estado do Acre. Belém, 1993. 101 p. Dissertação (Mestrado) - Faculdade de Ciências Agrárias do Pará, Universidade Federal do Pará.

MELO, A. W. F.; AMARAL, E. F. Levantamento de reconhecimento de baixa intensidade dos solos da Reserva Extrativista do Alto Juruá, Marechal Thaumaturgo, Acre. Rio Branco: Embrapa Acre, 2000. 77 p. (Documentos, 53).

MORAES, J. F. L. D. Propriedades do solo e dinâmica da matéria orgânica associadas as mudanças do uso da terra em Rondônia (ro) / Brasil. Piracicaba, 1995. 69 p. Tese (Doutorado) - Centro de Energia Nuclear na Agricultura, Universidade de São Paulo.

MORAES, J. F. L. Conteúdo de carbono e nitrogênio e tipologia de horizontes nos solos da bacia amazônica. Piracicaba, 1991. 84 p. Dissertação (Mestrado) Centro de Energia Nuclear na Agricultura, Universidade de São Paulo.

MORAES, J. F. L.; VOLKOFF, B.; CERRI, C. C.; BERNOUX, M. Soil properties under Amazon forest and changes due to pasture installation in Rondônia, Brazil. Geoderma, v.70, n.1, p.63-81, Mar. 1996.

MORAES, J. L.; CERRI, C. C.; MELILLO, J. M.; KICKLIGHTER, D.; NEILL, C.; SKOLE, D. L.; STEUDLER, P. A. Soil carbon stocks of the brazilian Amazon basin. Soil Science Society of America Journal, v.59, n.1, p.244-247, Jan./Feb. 1995. 
MOTAVAlLI, P. P.; PALM, C. A.; PARTON, W. J.; ELLIOTT, E. T.; FREY, S. D. Soil ph and organic C dynamics in tropical forest soils: Evidence from laboratory and simulation studies. Soil Biology \& Biochemistry, v.27, n.12, p.1589-1599, Dec. 1995.

MULLINS, C. E.; HUTCHISON, B. J. The variability introduced by various subsampling techniques. Journal of Soil Science, v.33, n.3, p.547-561, 1982. NEILL, C.; FRY, B.; MELILLO, J. M.; STEUDLER, P. A.; MORAES, J. F. L.; CERRI, C. C. Forest and pasture derived carbon contributions to carbon stocks and microbial respiration of tropical pasture soils. Oecologia, v.107, n.1, p.113119, July. 1996.

POST, W. M.; EMANUEL, W. R.; ZINKE, P. J.; STANGENBERGER, A. G. Soil carbon pools and world life zones. Nature, v.298, n.5870, p.156-159, 1982.

POWERS, J. S.; SCHLESINGER, W. H. Relationships among soil carbon distributions and biophysical factors at nested spatial scales in rain forests of northeastern Costa Rica. Geoderma, v.109, n.3/4, p.165-190, Oct. 2002.

POWLSON, D. S.; JENKINSON, D. S. Effects of biocidal treatments on metabolism in soil II. Gamma irradiation, autoclaving, air-drying and fumigation. Soil Biology \& Biochemistry, v.8, n.3, p.179-188, 1976.

PRENTICE, I. C.; FARQUHAR, G. D.; FASHAM, M. J. R.; GOULDEN, M. L.; HEIMANN, M.; JARAMILLO, V. J.; KHESHGI, H. S.; LE QUÉRÉ, C.; SCHOLES, R. J.; WALLACE, D. W. R. The carbon cycle and atmospheric carbon dioxide. In: HOUGHTON, J. T.; DING, Y.; GRIGGS, D. J.; NOGUER, M.; VAN DER LINDEN, P. J.; DAI, X.; MASKELL, K.; JOHNSON, C. A. (Ed.). Climate change 2001: the scientific basis. contribution of working group I to the third assessment report of the Intergovernmental Panel on Climate Change. Cambridge, United Kingdom and New York: Cambridge University Press, 2001. cap. 3, p. 183-237. 
RAIJ, B. Van; QUAGGIO, J. A.; CANTARELLA, H.; FERREIRA, M. E.; LOPES, A. S.; BATAGLIA, O. A. Análise química do solo para fins de fertilidade. Campinas: Fundação Cargill, 1987. 165 p.

RODRIGUES, T. E.; SILVA, J. M. L.; CORDEIRO, D. G.; GOMES, T. C.; CARDOSO JÚNIOR, E. Q. C. Caracterização e classificação dos solos do campo experimental da Embrapa Acre, Rio Branco, Estado do Acre. Belém: Embrapa Amazônia Oriental, 2001. (Documentos, 122).

SALIMON, C. I. Respiração do solo sob floresta e pastagens na Amazônia sulocidental, Acre. Piracicaba, 2003. 97 p. Tese (Doutorado) - Centro de Energia Nuclear na Agricultura, Universidade de São Paulo.

SCHIMEL, D. S. Terrestrial ecosystems and the carbon cycle. Global Change Biology, v.1, n.1, p.77-91, Feb. 1995.

SCHJONNING, P.; THOMSEN, I. K.; MOBERG, J. P.; de JONGE, H.; KRISTENSEN, K.; CHRISTENSEN, B. T. Turnover of organic matter in differently textured soils. I. Physical characteristics of structurally disturbed and intact soils. Geoderma, v.89, n.3/4, p.177-198, May. 1999.

SCHLESINGER, W. H. Carbon balance in terrestrial detritus. Annual Review of Ecology and Systematics, v.8, p.51-81, 1977.

SCHOENHOLTZ, S. H.; VAN MIEGROET, H.; BURGER, J. A. A review of chemical and physical properties as indicators of forest soil quality: Challenges and opportunities. Forest Ecology and Management, v.138, n.1/3, p.335356, Nov. 2000.

SCHUMACHER, B. A.; SHINES, K. C.; BURTON, J. V.; PAPP, M. L. Comparison of three methods for soil homogenization. Soil Science Society of America Journal, v.54, n.4, p.1187-1190, July/Aug. 1990.

SCOTT, N. A.; COLE, C. V.; ELLIOTT, E. T.; HUFFMAN, S. A. Soil textural control on decomposition and soil organic matter dynamics. Soil Science Society of America Journal, v.60, n.4, p.1102-1109, July/Aug. 1996. 
SENEVIRATNE, R.; WILD, A. Effect of mild drying on the mineralization of soilnitrogen. Plant and Soil, v.84, n.2, p.175-179, 1985.

SILVA, J. R. T. Solos do Acre: Caracterização, física, química, mineralógica e adsorção de fosfato. Viçosa, 1999. 117 p. Tese (Doutorado) - Universidade Federal de Viçosa.

SINGH, B.; GILKES, R. J. Nature and properties of iron rich glaebules and mottles from some south-west australian soils. Geoderma, v.71, n.1/2, p.95-120, May. 1996.

SMITH, B. N.; EPSTEIN, S. 2 categories of $\mathrm{G}-13 / \mathrm{C}-12$ ratios for higher plants. Plant Physiology, v.47, n.3, p.380-384, 1971.

SMITH, N. J. H.; SERRAO, E. A. S.; ALVIM, P.; FALESI, I. C. Amazonia: resiliency and dynamism to the people. New York: United Nations University, 1995. 253 p.

SMITH, R. B.; PRATT, D. N. The variability in soil particle size test results by various subsampling techniques. Journal of Soil Science, v.35, n.1, p.23-26, 1984.

SOMBROEK, W. G. Soils of the Amazon region. In: SIOLI, H. (Ed.). The Amazon: limnology and landscape ecology of a mighty tropical river and its basin. Dordrecht: Dr. W. Junk Publishers, 1984. cap. 20, v.56, p. 521-535.

SOMBROEK, W. G.; NACHTERGAELE, F. O.; HEBEL, A. Amounts, dynamics and sequestering of carbon in tropical and subtropical soils. Ambio, v.22, n.7, p.417-426, Nov. 1993.

SORENSEN, L. H. Rate of decomposition of organic matter in soil as influenced by repeated air drying-rewetting and repeated additions of organic material. Soil Biology \& Biochemistry, v.6, n.5, p.287-292, 1974.

STATSOFT, I. Statistica for Windows [computer program manual]. 5.ed. Tulsa: StatSoft, 1999. 
TELLES, E. C. C.; CAMARGO, P. B.; MARTINELLI, L. A.; TRUMBORE, S. E.; COSTA, E. S.; SANTOS, J.; HIGUCHI, N.; OLIVEIRA JUNIOR., R. C. Influence of soil texture on carbon dynamics and storage potential in tropical forest soils of Amazonia. Global Biogeochemical Cycles, v.17, n.2, p.9.1-9.12, June. 2003.

TRUMBORE, S. E.; DAVIDSON, E. A.; CAMARGO, P. B.; NEPSTAD, D. C.; MARTINELLI, L. A. Belowground cycling of carbon in forests and pastures of eastern Amazonia. Global Biogeochemical Cycles, v.9, n.4, p.515-528, Dec. 1995.

VALENTIM, J. F. Agronegócio: É preciso tirar o pé da crise. Jornal O Rio Branco, Rio Branco, 18 ago. 2002. p.C1-1.

VALENTIM, J. F. Recuperação ecológica de pastagens. Jornal A Gazeta, Rio Branco, 28 mar. 2003. p.2.

VALEMTIM, J. F.; CARNEIRO, J. C. Redução dos impactos ambientais da pecuária de corte no Acre. Rio Branco: Embrapa Acre, 1999. 2 p. (Série Impactos).

VALENTIM, J. F.; AMARAL, E. F.; MELO, A. W. F. Zoneamento de risco edáfico atual e potencial de morte de pastagem de Brachiaria brizantha no Acre. Rio Branco: Embrapa Acre, 2000. 26 p. (Boletim de Pesquisa, 29).

VALENTIM, J. F.; SÁ, C. P.; GOMES, F. C. R.; SANTOS, J. C. Tendências da pecuária bovina no Acre entre 1970 e 2000. Rio Branco: Embrapa Acre, 2002a. (Boletim de Pesquisa e Desenvolvimento, 38).

VALENTIM, J. F.; ANDRADE, C. M. S.; FEITOZA, J. E.; SALES, M. G.; VAZ, F. A. Métodos de introdução do amendoim forrageiro em pastagens já estabelecidas no Acre. Rio Branco: Embrapa Acre, 2002b. 6 p. (Comunicado Técnico, 152).

VALVERDE, O. A organização do espaço na faixa da transacreana. Rio de Janeiro: IBGE, 1989. 224 p. 
VAN GESTEL, M.; LADD, J. N.; AMATO, M. Carbon and nitrogen mineralization from 2 soils of contrasting texture and microaggregate stability: Influence of sequential fumigation, drying and storage. Soil Biology \& Biochemistry, v.23, n.4, p.313-322, 1991.

VELDKAMP, E. Organic carbon turnover in three tropical soils under pasture after deforestation. Soil Science Society of America Journal, v.58, n.1, p.175180, Jane/Feb. 1994.

VOLKOFF, B.; MELFI, A. J.; CERRI, C. C. Solos Podzólicos e Cambissolos eutróficos do alto Purus (Estado do Acre). Revista Brasileira de Ciência do Solo, v.13, n.3, p.363-372, 1989.

VOSTI, S. A.; CARPENTIER, C. L.; WITCOVER, J.; VALENTIM, J. F. Intensified small-scale livestock systems in the western brasilian Amazon. In: ANGELSEN, A.; KAIMOWITZ, D. (Ed.). Agricultural technologies and tropical deforestation. Wallingford: CAB International, 2000. cap. 7, p. 45-60.

WALKLEY, A.; BLACK, I. A. An examination of the degtjareff method for determinig soil organic matter and a proposed modification of the chromic acid tritation method. Soil Science, v.37, p.29-38, 1934.

WEINER, J. Os próximos cem anos: em nossas mãos o destino da terra. Rio de Janeiro: Campus, 1992. $278 \mathrm{p}$.

ZECH, W.; SENESI, N.; GUGGENBERGER, G.; KAISER, K.; LEHMANN, J.; MIANO, T. M.; MLTNER, A.; SCHROTH, G. Factors controlling humification and mineralization of soil organic matter in the tropics. Geoderma, v.79, n.1/4, p.117-161, Sept. 1997. 